\title{
High resolution magnetic resonance imaging of the anorectum
}

Citation for published version (APA):

Beets-Tan, R. G. H. (2000). High resolution magnetic resonance imaging of the anorectum. [Doctoral Thesis, Maastricht University]. UM. https://doi.org/10.26481/dis.20001208rb

Document status and date:

Published: 01/01/2000

DOI:

10.26481/dis.20001208rb

Document Version:

Publisher's PDF, also known as Version of record

\section{Please check the document version of this publication:}

- A submitted manuscript is the version of the article upon submission and before peer-review. There can be important differences between the submitted version and the official published version of record.

People interested in the research are advised to contact the author for the final version of the publication, or visit the DOI to the publisher's website.

- The final author version and the galley proof are versions of the publication after peer review.

- The final published version features the final layout of the paper including the volume, issue and page numbers.

Link to publication

\footnotetext{
General rights rights.

- You may freely distribute the URL identifying the publication in the public portal. please follow below link for the End User Agreement:

www.umlib.nl/taverne-license

Take down policy

If you believe that this document breaches copyright please contact us at:

repository@maastrichtuniversity.nl

providing details and we will investigate your claim.
}

Copyright and moral rights for the publications made accessible in the public portal are retained by the authors and/or other copyright owners and it is a condition of accessing publications that users recognise and abide by the legal requirements associated with these

- Users may download and print one copy of any publication from the public portal for the purpose of private study or research.

- You may not further distribute the material or use it for any profit-making activity or commercial gain

If the publication is distributed under the terms of Article $25 \mathrm{fa}$ of the Dutch Copyright Act, indicated by the "Taverne" license above, 
High Resolution Magnetic Resonance Imaging of the Anorectum 
(C) R.G.H. Beets-Tan, Eysden 2000

ISBN 90-9014213-4

Printed by Drukkerij Groenevelt BV, Landgraaf, The Netherlands 


\title{
High Resolution Magnetic Resonance Imaging of the Anorectum
}

\author{
PROEFSCHRIFT \\ ter verkrijging van de graad van doctor \\ aan de Universiteit Maastricht, \\ op gezag van de Rector Magnificus \\ Prof.Dr. A.C. Nieuwenhuijzen Kruseman, \\ volgens het besluit van het College van Decanen, \\ in het openbaar te verdedigen \\ op vrijdag 8 december 2000 om 14.00 uur
}

door

Regina Gien Hoa Beets - Tan

geboren te Makassar, Indonesiē 


\section{Promotores}

Prof. Dr. J.M.A. van Engelshoven

Prof. Dr. C.G.M.I. Baeten

Co-promotor

Dr. G.L. Beets

\section{Beoordelingscommissie}

Prof. Dr. J.L.H. Evers (voorzitter)

Prof. Dr. J.W. Arends

Prof. Dr. J.S. Laméris (Universiteit van Amsterdam)

Prof. Dr. M.F. von Meyenfeldt

Prof. Dr. T. Wiggers, (Rijksuniversiteit Groningen) 
in memory of my father 
Reading maketh a full man, conference a ready man and writing an exact man Francis Bacon 


\section{Contents}

\section{Chapter 1}

Introduction and Aim of the Thesis

\section{Chapter 2}

High Resolution Magnetic Resonance Imaging of the Anorectal Region without an Endocoil .

Abdominal Imaging 1999; 24: 576-581

\section{Chapter 3}

Measuring Anal Sphincter Muscles: Endoanal Ultrasound, Endoanal MRI or Phased Array MRI ?

Accepted for Publication in Radiology

\section{Chapter 4}

Preoperative Magnetic Resonance Imaging of Anal Fistulas: Does it Really Help the Surgeon?

Radiology 2000, in Press

Chapter 5

Can MRI Predict the Circumferential Resection Margin in Rectal Cancer Surgery? 65

Accepted for Publication in The Lancet

Chapter 6

Preoperative Assessment of Local Tumor Extent in Advanced Rectal Cancer: CT

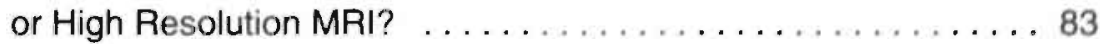
Abdominal Imaging 2000; 25: 533-541

\section{Chapter 7}

Summary, Conclusions and Recommendations .............. 101

Samenvatting, Conclusies en Aanbevelingen . . . . . . . . . . . . . . 111

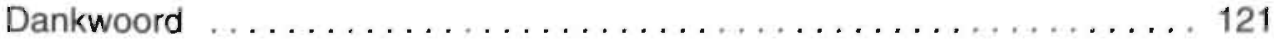

Curriculum Vitae .................................... 125 
Chapter 1

INTRODUCTION AND AIM OF THE THESIS 
Chapter 1

2 
Until the early nineteen eighties imaging in diseases of the anus and rectum was mainly restricted to barium enema studies and fistulography. These conventional studies only revealed abnormalities of the luminal contour, with little information on the surrounding structures. Although the first rectal ultrasonography was performed more than 40 years ago ', it was not until the eighties that reports on the clinical use of rectal sonography started to appear ${ }^{2.3}$. Presently endoluminal ultrasound (EUS) has gained widespread acceptance in the clinical practice of proctological diseases ${ }^{4-8}$ and its impact is nicely illustrated by the change in insights in the causes of fecal incontinence. The so-called neurogenic incontinence had long been thought to be caused by pudendal nerve damage due to stretching during chronic straining or childbirth ${ }^{9}$, until endoanal sonography revealed that damage to the anal sphincter muscles occurred more often than previously appreciated ${ }^{0,10}$. EUS has the advantage of a low cost and a wide availability. There are however some disadvantages. The main drawback is the limited soft tissue contrast resolution that impairs an accurate delineation of the external anal sphincter complex ${ }^{11.12}$ and a reliable differentiation between tumor tissue and inflammatory or fibrotic tissue ${ }^{13}$. Another disadvantage is the limited field of view, preventing an accurate evaluation of the extent of the disease in the surrounding organs ${ }^{14,15}$. As with any ultrasound method EUS is operator dependent with significant interobserver variability ${ }^{16.17}$.

Computed tomography (CT) has been used for more than 20 years in the management of patients with various pelvic tumors ${ }^{18-22}$, including rectal cancer ${ }^{23-25}$. CT has the advantage of imaging the whole pelvic region, permitting an assessment of the local extent of the disease. The initial studies on rectal cancer staging mainly focused on locally advanced rectal cancer, and reported good results ${ }^{24.25}$. However, more recent studies on less advanced rectal tumor have shown accuracy figures for CT that were not as high as anticipated ${ }^{26-33}$. This can be explained by the inherent low soft tissue contrast resolution of $C T$ that does not allow a detailed evaluation of the layers of the rectal wall. This limitation also hampers the visualization of the individual anal sphincter muscles, and for this reason CT has never gained much popularity in the diagnoștic work up of patients with anal sphincter lesions and anal fistulas ${ }^{34}$.

The introduction of magnetic resonance imaging (MRI) was a major advance in diagnostic imaging. MRI provides images in multiple planes and with a high soft tissue contrast resolution, without the need for ionizing radiation. Initial reports on magnetic resonance imaging of the pelvic region were promising, and MR was soon evaluated for rectal and anal diseases. The conventional MR techniques with a body or external surface coil showed a resolution that was still insufficient to differentiate the layers of the rectum and anus ${ }^{28,29: 35-37}$. Efforts were aimed at increasing the signal to noise ratio in order to obtain small voxel sizes. With the introduction of surface coils 
in the rectal lumen and anal canal, image resolution improved considerably and detailed evaluation of the layers of the rectal wall and anal sphincter was feasible ${ }^{38}$. 42. Endorectal and endoanal MRI however do suffer from some disadvantages. The sudden signal drop off at short distance from the coil limits the field of view, obscuring the pelvic structures around the anorectum ${ }^{39}$. In patients with stenosing or painful anorectal conditions, the positioning of an endoluminal device can be difficult or impossible, and failure rates for the insertion as high as $40 \%$ have been reported in patients with rectal cancer ${ }^{43}$. An additional practical disadvantage is that the use of endoanal MRI has mainly been restricted to specialized centers as the endoanal coil is not yet available with every MR machine.

Since the current MR techniques in anorectal dișeases are not entirely satisfactory, improvement is desirable ${ }^{44}$. The ideal would be a MR technique without an endoluminal coil that results in images with a spatial resolution as high as obtained with an endoluminal coil and with a larger field of view. A body coil has an insufficient signal to noise ratio to obtain such images. An external surface coil provides a higher signal to noise ratio, but the limited depth range of the surface coil prevents detailed imaging of the pelvic structures that lay beyond the range of the coil. A phased array coil consists of an arrangement of multiple surface coils that result in a considerable increase of the signal to noise ratio. With this high signal to noise ratio images can be obtained with small voxel sizes and therefore a high spatial resolution. The specific coil used in our study was a quadrature phased array spine coil. Unlike the linear arrangement of the coil components in a standard torso or pelvic phased array coil, the coil components in a quadrature phased array coil are arranged in quadrature. This further improves the signal to noise ratio (up to 50\%) and even smaller voxel sizes can be generated. Theoretically a MR technique with this quadrature phased array coil could produce images with a very high spatial resolution and a large field of view.

\section{The Aim of this Thesis is :}

1. To evaluate whether high spatial resolution images of the entire anorectal region can be obtained with a noninvasive MR technique using a quadrature phased array coil.

2. To assess whether the application of high resolution phased array MRI is of clinical benefit in the management of patients with anorectal diseases. 


\section{The Outline of this Thesis:}

Chapter 2 evaluates the feasibility of a high resolution MR technique with a quadrature phased array spine coil in a pilot study with 22 normal volunteers and 12 patients.

Chapter 3 compares the high resolution phased array MR technique with endoanal ultrasound and endoanal MRI for the measurements of anal sphincter muscles in 60 normal volunteers. The study investigates the intra- and interobserver reliability of the measurements and the correlations between the different techniques.

In Chapter 4 the results of a preoperative MR study in 56 patients with anal fistulas are reported. The study evaluates the accuracy and the additional clinical value of a preoperative high resolution phased array MRI as compared to surgery alone.

Chapter $\mathbf{5}$ evaluates the accuracy of high resolution MRI with a phased array coil for staging rectal cancer and the accuracy for predicting the circumferential resection margin after a total mesorectal excision in a study of 76 patients with primary rectal cancer.

Chapter 6 describes the results of a comparative study between phased array MRI and $\mathrm{CT}$ in the assessment of tumor infiltration in surrounding structures for locally advanced primary and recurrent rectal cancer.

Chapter 7 consists of the summary of the thesis, the conclusions and recommendations.

\section{References}

1. Wild JJ. Reid. JM. Diagnostic use of ultrasound. British Journal of Physical Medicine 1956;19:248-57.

2. Dragsted J, Gammelgaard J. Endoluminal ultrasonic scanning in the evaluation of rectal cancer: a preliminary report of 13 cases. Gastrointest Radiol 1983;8(4):367-9.

3. Hildebrandt U, Feifel G, Zimmerman F, Koch B, Alzin H. Significant improvement in clinical staging of rectal carcinoma with a new intrarectal ultrasound scanner. Journal of experimental and clinical research 1983:2:53-6.

4. Banerjee AK, Jehie EC, Shorthouse AJ, Buess G. Local excision of rectal tumours. Br J Surg 1995;82(9):1165-73.

5. Law PJ, Kamm MA, Bartram Cl. A comparison between electromyography and anal endosonography in mapping external anal sphincter defects. Dis Colon Rectum 1990;33(5):370-3.

6. Law PJ, Kamm MA, Bartram Cl. Anal endosonography in the investigation of faecal incontinence. $\mathrm{Br} J$ Surg 1991:78:312-314:

7. Meyenberger $C$, Bertschinger $P$, Zala. GF, Buchmann P. Anal sphincter defects in fecal incontinence: correlation between endosonography and surgery. Endoscopy 1996;28(2):217-24.

8. Sultan AH, Kamm MA, Talbot IC, Nicholls RJ, Bartram Cl. Anal endosonography for identifying external sphincter defects confirmed histologically. Br J Surg 1994;81(3):463-5.

9. Parks AG. Swash M. Urich H. Sphincter denervation in anorectal incontinence and rectal prolapse. Gut 1977:18(8):656-65. 
10. Burnett SJ, Spence-Jones C. Speakman CT, Kamm MA, Hudson CN, Bartram CI. Unsuspected sphincter damage following childbirth revealed by anal endosonography. $\mathrm{Br} J$ Radiol 1991;64(759):225-7.

11. Briel JW, Stoker J, Rociu E, Lameris JS, Hop WC, Schouten WR. External anal sphincter atrophy on endoanal magnetic resonance imaging adversely affects continence after sphincteroplasty. Br J Surg $1999 ; 86(10): 1322-7$.

12. Burnett SJ, Speakman CT, Kamm MA, Bartram Cl. Confirmation of endosonographic detection of external anal sphincter defects by simultaneous electromyographic mapping. $\mathrm{Br} J \mathrm{Surg}$ 1991:78(4):448-50.

13. Hulsmans FJ, Tio TL, Fockens P, Bosma A, Tytgat GN. Assessment of tumor infiltration depth in rectal cancer with transrectal sonography: caution is necessary. Radiology 1994:190(3):715-20.

14. Hawes RH. New staging techniques. Endoscopic ultrasound. Cancer 1993;71(12 Suppl):4207-13.

15. Choen S, Bumett S, Bartram Cl, Nicholls RJ. Comparison between anal endosonography and digital examination in the evaluation of anal fistulae. Br J Surg 1991;78(4):445-7.

16. Gold DM, Halligan S, Kmiot WA, Bartram Cl. Intraobserver and interobserver agreement in anal endosonography. Br J Surg 1999;86(3):371-5.

17. Enck P. Heyer T, Gantke B, et al. How reproducible are measures of the anal sphincter muscle diameter by endoanal ultrasound? Am J Gastroenterol 1997:92(2):293-6.

18. Walsh JW. Amendola MA, Konerding KF, Tisnado J, Hazra TA. Computed tomographic detection of pelvic and inguinal lymph-node metastases from primary and recurrent pelvic mafignant disease. Radiology 1980:137(1 Pt 1):157-66.

19. Chen SS, Kumari S, Lee L. Contribution of abdominal computer tomography (CT) in the management of gynecologic cancer: correlated study of CT image and gross surgical pathology. Gynecol Oncol 1980;10(2):162-72.

20. Waish JW, Amendola MA, Hall DJ, Tisnado J, Goplerud DR. Recurrent carcinoma of the cervix: CT diagnosis. AJR Am J Roentgenol 1981;136(1):117-22.

21. Walsh JW, Goplerud DR. Prospective comparison between clinical and CT staging in primary cervical carcinoma. A.JR Am J Roentgenol 1981:137(5):997-1003.

22. van Engelșhoven JM, Versteege $\mathrm{CW}$. Ruys $\mathrm{JH}$, de Haan J, Sanches $\mathrm{H}$. Computed tomography in staging untreated patients with cervical cancer. Gyneco! Obstet Invest 1984:18(6):289-95.

23. van Waes PF, Koehler PR, Feldberg MA. Management of rectal carcinoma: impact of computed tomography. AJR Am J Roentgenol 1983;140(6):1137-42.

24. Thoeni RF, Moss AA, Schnyder P. Margulis AR. Detection and staging of primary rectal and rectosigmoid cancer by computed tomography. Radiology 1981:141(1):135-8.

25. Zaunbauer W, Hạertel M. Fuchs WA. Computẹd tomography in carcinoma of the rectum. Gastrointest Radiol 1981:6(1):79-84.

26. Moss AA. Imaging of colorectal carcinoma. Radiology 1989:170(2):308-10.

27. Thoeni RF. Colorectal cancer. Radiologic staging, Radiol Clin North Am 1997;35(2):457-85.

28. Butch RJ, Stark DD, Wittenberg J, et al. Staging rectal cancer by MR and CT. AJR Amt J Roentgenol 1986;146(6): :1155-60.

29. Hodgman CG, MacCarty RL, Wolft BG, et al. Preoperative staging of rectal carcinoma by computed tomography and $0.15 \mathrm{~T}$ magnetic resonance imaging. Preliminary report. Dis Colon Rectum 1986:29(7):446-50

30. Rifkin MD. Ehrlich SM, Marks G. Staging of rectal carcinoma: prospective comparison of endorectal US and CT. Radiology 1989:170(2):319-22.

31. Balthazar EJ. Megibow AJ. Hulnick D. Naidich DP. Carcinoma of the colon: detection and preoperative staging by CT. A.JR Am J Roentgenol 1988;150(2):301-6. 
32. Holdsworth PJ, Johnston D, Chalmers AG, et al. Endoluminal ultrasound and computed tomography in the staging of rectal cancer. Br J Surg 1988;75(10):1019-22.

33. Guinet C, Buy JN, Ghossain MA, et al. Comparison of magnetic resonance imaging and computed tomography in the preoperative staging of rectal cancer. Arch Surg 1990;125(3):385-8.

34. Halligan S. Imaging fistula-in-ano. Clin Radiol 1998;53(2):85-95.

35. Aronson MP, Lee RA, Berquist TH. Anatomy of anal sphincters and related structures in continent women studied with magnetic resonance imaging. Obstet Gynaecol 1990;76:846-851.

36. Lunniss PJ, Armstrong P. Barker PG, Reznek RH, Phillips RK. Magnetic resonance imaging of anal fistulae. Lancet 1992;340(8816):394-6.

37. Schafer A, Enck P. Furst G, Kahn T, Frieling T, Lubke HJ. Anatomy of the anal sphincters.Comparison of anal endosonography to magnetic resonance imaging. Dis Colon Rectum 1994:37:777-781.

38. Hussain SM, Stoker J, Lameris JS. Anal sphincter complex: endoanal MR imaging of normal anatomy. Radiology 1995;197(3):671-7.

39. deSouza NM, Hall AS, Puni R, Gilderdale DJ, Young IR, Kmiot WA. High resolution magnetic resonance imaging of the anal sphincter using a dedicated endoanal coil. Comparison of magnetic resonance imaging with surgical findings. Dis Colon Rectum 1996;39:926-934.

40. Chan TW, Kressel HY, Milestone B, et al. Rectal carcinoma: staging at MR imaging with endorectal surface coil. Work in progress. Radiology 1991;181(2):461-7.

41. Imai Y, Kressel HY, Saul SH, et al. Colorectal tumors: an in vitro study of high-resolution MR imaging. Radiology 1990;177(3):695-701.

42. Schnall MD, Furth EE, Rosato EF, Kressel HY. Rectal tumor stage: correlation of endorectal MA imaging and pathologic findings [see comments]. Radiology 1994;190(3):709-14.

43. Hunerbein $M_{n}$ Pegios W, Vogl TJ, Felix R, Schlag PM. Endorectal MRI for staging rectal carcinoma. Preliminary experience. Br J Cancer 1995;72 (Suppl XXV):11.

44. Read TE, Fleshman JW. Outcornes: assessing the effectiveness of fecal incontinence therapy. Seminars in Colon and rectal surgery 1997;8:121-125. 


\section{Chapter 2}

\section{HIGH RESOLUTION MAGNETIC RESONANCE IMAGING OF THE} ANORECTAL REGION WITHOUT AN ENDOCOIL

Beets-Tan RGH, Beets GL, Gerritsen van der Hoop A, Borstlap ACW, van Boven H, Rongen MJGM, Baeten CGMI, van Engelshoven JMA

Abdominal Imaging 1999; 24: 576-581 


\section{Abstract}

Background: To evaluate the feasibility of a high resolution MRI technique in detailed imaging of the anal sphincter and lower pelvic region without the use of an endoluminal coil.

Methods: MR scans with an external phased array coil (T1W and T2W TSE) were performed in 22 volunteers and 12 patients with an anal fistula, an anal sphincter defect or a rectal tumor. The normal scans were evaluated by three independent observers. The scans of the patients were compared with surgical and/or histological findings.

Results: The anal sphincter was visualized with detail. In the anal canal hemorrhoidal tissue could be seen, as well as the submucosae ani muscle. The MAI technique also allowed detailed imaging of anatomical structures above the pelvic floor. The MR findings in the 12 patients showed exact correlation with surgery and/or histology.

Conclusion: High resolution MR imaging of the anorectal region without an endoluminal coil is feasible. The MR technique with an external phased array coil allows detailed imaging of the anal sphincter at rest, the rectum and the surrounding peivic structures with one single investigation. The results are promising and suggest useful applications in the management of anorectal diseases. 


\section{Introduction}

Detailed and accurate anatomical imaging of the anorectal region including the sphincter complex is essential for the management of many defecation disorders, anorectal sepsis and rectal tumors. The presently available imaging methods are not satisfactory and in a recent consensus statement on fecal incontinence colorectal surgeons expressed the need for an objective and physiological imaging method of the anal sphincter [1].

Although computed tomography has been used for imaging of the anorectal region, it does not provide enough soft tissue contrast to allow a detailed evaluation of the region. Endoluminal ultrasound provides, better resolution of the anal sphincter, but the visualization of the external sphincter layer is poor [2-9]. The technique is operator dependent and interpretation of sonography images requires considerable skill [10].

Initial reports on magnetic resonance imaging of the anorectal region were promising, but resolution of the various muscle layers remains poor when using a surface or body coil [11-15]. With the introduction of an endoanal surface coil image resolution improved and detailed evaluation of the anorectai sphincter was possible [16-21]. However, with the endoanal coil only a limited area, the anal canal and the immediate surroundings, can be visualized with anatomical detail due to the signal to noise drop off with distance from the coil [19]. A practical disadvantage is that the endoanal coil is not widely available. The purpose of this study was to evaluate the feasibility of a high resolution MRI technique that provides a detailed imaging of the anal sphincter and lower pelvic region without the use of an endoluminal coil.

\section{Materials and Methods}

MR imaging was performed at 1.5 Tesla (Gyroscan, NT, Philips Medical Systems, Best, The Netherlands) using a surface phased array coil (synergy spine coii). All subjects were positioned supine with their pelvis centered on the proximal end of the synergy spine coil and in feet first position. Sequences used were a T1 weighted, 2D, turbo spin echo (T1W TSE: TR/TE $612 / 15 \mathrm{msec}, 5$ turbo factor, $3 \mathrm{~mm}$ slice thickness, $0.3 \mathrm{~mm}$ gap, 8 signal averages, $383 \times 512$ matrix, $20 \mathrm{~cm}$ field of view (FOOV), $0.6 \mathrm{~mm}^{3}$ voxel size, $9.0 \mathrm{~min}$. acquisition time) and a T2 weighted, 2D, turbo spin echo (T2W TSE: TR/TE $3427 / 150 \mathrm{msec}, 25$ turbo factor, $3 \mathrm{~mm}$ slice thickness, $0.3 \mathrm{~mm}$ gap, 8 signal averages, $175 \times 256$ matrix, $20 \mathrm{~cm}$ FOV, $2.64 \mathrm{~mm}^{3}$ voxel size, $6.5 \mathrm{~min}$ acquisition time).

Coronal T1W and coronal, sagittal and axial T2W TSE. images were obtained from 22 healthy volunteers and 12 patients. Additionally coronal and axial 
Gadolinium-DTPA contrast enhanced T1W TSE images were obtained from 6 volunteers and 8 patients, while 2 volunteers and 6 patients were scanned with and without a probe in the anal canal. The probe consisted of a cylindrical coil holder with a length of $80 \mathrm{~mm}$ and a diameter of $19 \mathrm{~mm}$, in dimensions comparable to a standard ultrasound probe and an endoanal coil. This probe was used to assess the influence of the probe on the normal anatomy. Twelve patients with a variety of anorectal pathology (anorectal sepsis: 4, fecal incontinence: 3, and primary or recurrent rectal cancer: 5) were scanned.

Three observers (two radiologists and one surgeon) systematically evaluated the scans of the normal volunteers, scoring various anatomical structures below and above the pelvic floor using a subjective quality scoring scale from 1 to 5 . A score of 5 represented excellent visualization and delineation of the anatomical structure and a score of 1 represented no detection of the structure at all.

The anal sphincter dimensions were measured on T2W TSE images of the normal volunteers. Anal sphincter length was measured from the lower end of the external sphincter to the upper end of the puborectalis muscle in the mid-coronal plane (the oblique coronal plane centered on the longitudinal axis of the anal canal). The sphincter thickness was measured at a mid-anal section of the axial images.

All scans of the patients were interpreted by two radiologists in conference. Surgery was performed without prior knowledge of the MRI results except for the patients with cancer. MRI, surgical and histological findings were compared.

Table 1: Subjective quality score of the anatomical structures of the anal canal of 22 volunteers, scored by three independent observers on a scale from 1 (no detectability) to 5 (excellent visualization). Values given are median scores (range) of the three observers.

\begin{tabular}{lcccccc}
\hline & $\begin{array}{l}\text { coronal } \\
\text { T1W }\end{array}$ & $\begin{array}{l}\text { coronal TIW } \\
\text { +Gadolinium }\end{array}$ & $\begin{array}{l}\text { corona! } \\
\text { T2W }\end{array}$ & $\begin{array}{l}\text { axial } \\
\text { T2W }\end{array}$ & $\begin{array}{l}\text { axial T1W + } \\
\text { Gadolinium }\end{array}$ & $\begin{array}{l}\text { sag } \\
\text { T2W }\end{array}$ \\
\hline internal șphincter & $4(3-5)$ & $5(4-5)$ & $5(4-5)$ & $5(4-5)$ & $5(5-5)$ & $3(2-3)$ \\
Iongitudinal muscle & $3(2-4)$ & $4(1-5)$ & $4(2-5)$ & $3(1-4)$ & $4(3-5)$ & $3(2-3)$ \\
external sphincter & $5(4-5)$ & $5(5-5)$ & $5(5-5)$ & $5(4-5)$ & $5(5-5)$ & $3(2-3)$ \\
m. puborectalis & $5(4-5)$ & $5(1-5)$ & $5(3-5)$ & $5(4-5)$ & $5(5-5)$ & $3(1-5)$ \\
intersphincteric space & $5(5-5)$ & $5(4-5)$ & $5(5-5)$ & $5(3-5)$ & $5(5-5)$ & $5(4-5)$ \\
ischioanal space & $5(5-5)$ & $5(5-5)$ & $5(5-5)$ & $5(5-5)$ & $5(5-5)$ & $5(5-5)$ \\
m. submucosae ani & $4(1-5)$ & $5(4-5)$ & $4(1-5)$ & $4(1-5)$ & $5(3-5)$ & $1(1-1)$ \\
m. levator ani & $5(5-5)$ & $5(5-5)$ & $5(5-5)$ & $3(2-4)$ & $3(2-4)$ & $5(5-5)$ \\
anal cushions & $2(1-3)$ & $3(2-4)$ & $3(1-4)$ & $5(5-5)$ & $5(5-5)$ & $1(1-1)$ \\
\hline
\end{tabular}


The median subjective quality score (range) of the three observers for structures of the anal sphincter and above the pelvic floor were calculated. The clinically relevant differences between scores were tested statistically with the Wilcoxon signed rank test, using the SPSS 8.0 for windows computer program.

\section{Results}

High resolution MRI was well tolerated by all volunteers and patients. Within the study of 22 volunteers a basic anatomical pattern of the anorectal region was recognized (fig. 1). The lower part of the anal canal was surrounded by the internal sphincter, the longitudinal muscle layer and the external sphincter, the upper part by the internal sphincter, the longitudinal muscle layer and the puborectalis muscle. The average length of the anal canal was $3.9 \mathrm{~cm}$ in women (range $3.0-4.5 \mathrm{~cm}$ ) and 4.5 $\mathrm{cm}$ in men (range $4.0-5.5 \mathrm{~cm}$ ). The internal sphincter was a direct continuation of the circular smooth muscle of the rectum and the average thickness was $3.4 \mathrm{~mm}$ in women (range 2.4-4.3 mm) and 3.9 mm in men (range 3.3-4.7 mm). On Gadolinium enhanced images it showed strong enhancement. The longitudinal muscle was seen as a thin layer running caudally in the intersphincteric space. The average thickness was $1 \mathrm{~mm}$ in both women and men (range 0.9-1.4 mm). The external sphincter showed inwards and upwards folding at the lower end. At its thinnest point the average thickness of the external sphincter was $1.4 \mathrm{~mm}$ in women (range 1.2-2 mm) and $1.8 \mathrm{~mm}$ in men (range $1.0-2.5 \mathrm{~mm}$ ). There was a clear distinction between the external sphincter group and the puborectalis muscle on the coronal plane. The internal sphincter did not completely close the anal canal. On contrast enhanced MR images the anal canal was filled with strongly enhancing structures, corresponding to hemorrhoidal vascular tissue or anal cushions, that provide complete closure of the anal canal. The anal cushions could not be seen when a probe was inserted (fig. 2). Another remarkable finding was the detection of a muscle layer, which proved to be the musculus submucosae ani at the histological section of the resection specimen (fig. 1).

The median subjective quality score of the three observers for structures above the pelvic floor ( $m$. levator ani, supralevator and retrorectal space, presacral and Denonvilliers fascia, anorectal angle, rectum, prostate, cervix, vagina, bladder, sacrum and coccyx) on axial and sagittal T2W images were excellent: 5 (range: 4-5). The median subjective quality scores for structures below the pelvic floor were more 

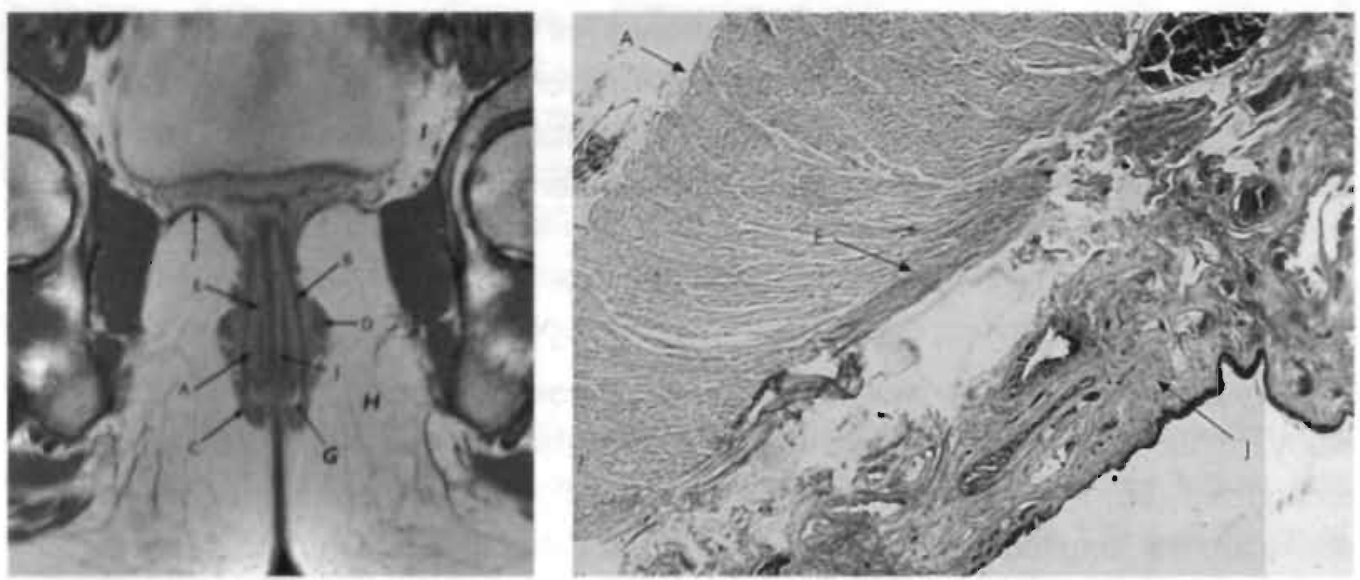

Figure 1. The anal sphincter complex: Coronal Gadolinium-contrast-enhanced T1W SE MR image and corresponding detailed coronal histological section. Note the muscles of the anal canal: the internal sphincter $r^{A}$, the longitudinal muscle layer ${ }^{B}$, the external sphincter ${ }^{C}$ and the puborectalis muscle ${ }^{D}$. The internal sphincter shows strong contrast enhancement. Note a thin muscle layer located within the submucosa ${ }^{J}$, the $\mathrm{m}$. submucosae ani ${ }^{E}$. Levator ani muscle ${ }^{F}$. Inter-sphincteric space ${ }^{6}$. Ischioanal space ${ }^{H}$. Supralevator space'.

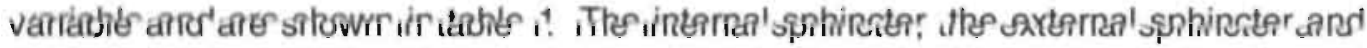
the puborectalis muscle were better visualized on coronal and axial sequences than on the sagittal sequence $(p<=0.001)$. The levator ani muscle was better visualized on coronal and sagittal sequences than on the axial sequences $(p<=0.001)$. The anal cushions were better visualized on the axial sequences than on the coronal and sagittal sequences $(\rho<0.05)$.

In the 4 patients with anorectal sepsis there was an exact correlation between operative and MR findings concerning the presence of abscesses and the course of the tracks. The internal opening site and level were a!ways correctiy identified (fig. 3). In the 3 patients with incontinence, a localized internal sphincter defect was seen (fig. 4). One patient with a primary rectal cancer had a locally advanced T4 tumor with invasion of the prostate and the anal sphincter. Another patient had a T2 tumor limited to the muscular rectal wall. The findings in both patients were confirmed at surgery and histology (fig. 5). Three patients with a rectal cancer recurrence after an abdominoperineal or anterior resection of the rectum were shown to have a resectable tumor recurrence by MRI. MRI correctly described the extent of the tumor invasion in the surrounding pelvic structures (fig. 6). 

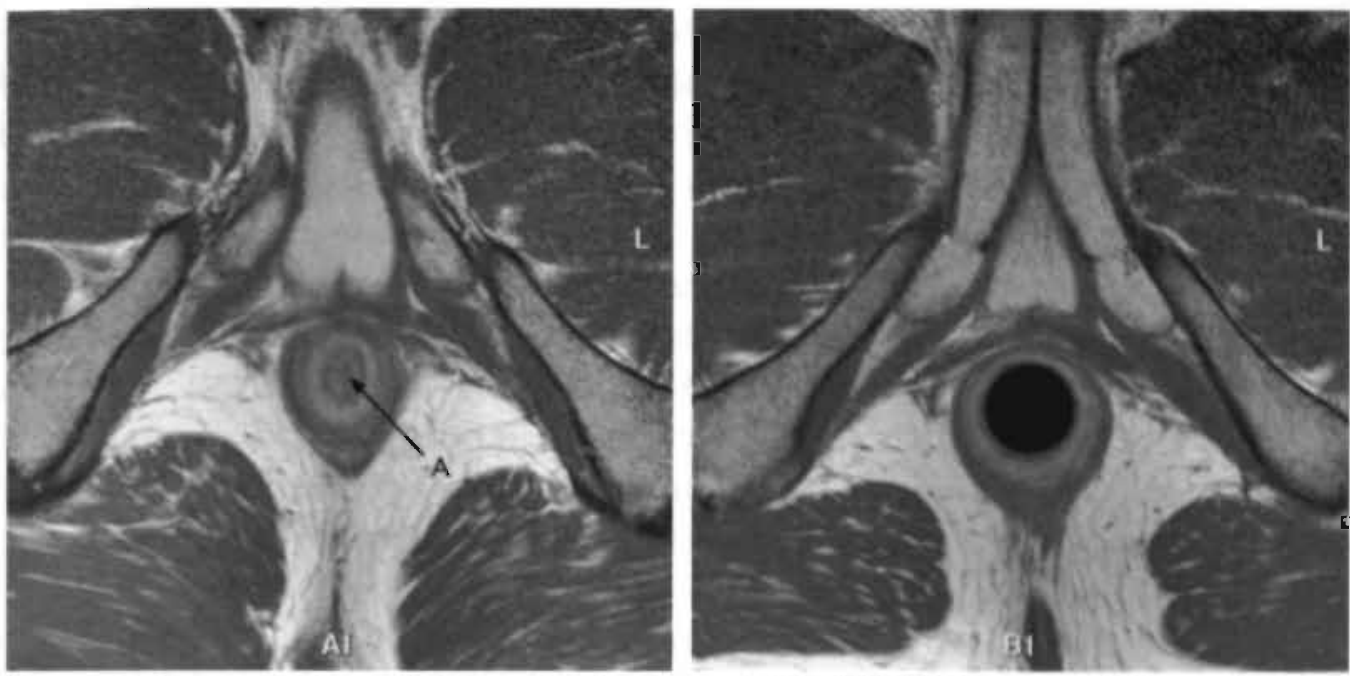

Figure 2. Anal cushions: Axial contrast enhanced T1W SE MR images of the anal canal, without and with an endoluminal probe. The internal sphincter does not completely close the anal canal. Strongly enhancing haemorrhoidal vascular tissue, also called the anal cushions ${ }^{\wedge}$, is seen within the anal canal, providing complete closure of the canal. When an endoluminal probe is used the anal cushions can not be visualized.

\section{Discussion}

The main goal of our study was to evaluate the feasibility of an MRI technique with the use of an external coil to obtain a detailed image of the anal sphincter at rest and surrounding pelvic structures. This study with 22 volunteers and the pilot study with 12 patients show that high resolution MR imaging of the anorectal region could be achieved without the use of an endoluminal coil. The essential part of our technique is the use of a surface phased array coil. MRI with a body coil generates images with insufficient resolution for imaging the various sphincter muscles and an external surface coil gives a limited superficial field of view. The use of a phased array coil significantly increases signal to noise ratio and allows us to obtain high resclution images with relatively small voxel size. We used a synergy spine phased array coil because a body phased array coil was not available with our MRI system. We searched for T1W and T2W sequences that could serve as optimal sequences both for detailed imaging of pathology of the anal canal (fistulas, sphincter defects and tumors) and of the lower pelvis (rectal cancer). Initially we experimented with TiW and T2W TSE sequences using a 512 matrix but soon abandoned the T2W sequence with high matrix because it was time consuming. In our opinion a T2W TSE sequence with 256 matrix provides the best balance between highlighting fistula tracks and supplying adequate anatomic information of the sphincter complex within an acceptable acquisition time. Although the T1W and T2W TSE sequences differ in 
voxel size, both can be considered "high resolution" as compared with the larger voxel size used in standard pelvic imaging with a body coil. Indeed the three observers generally judged the T2W TSE images to give equally good to excellent visualization of the anatomical structures as compared with the T1W TSE images (table 1).

The high resolution technique provides detailed visualization of the various muscles of the sphincter complex. In many aspects the anatomy correlates with the anatomy presented with endoanal MRI [17-21] and with the in vitro MR findings of dissected anal canals [22]. Different from the endoanal anatomy is the visualization of the anal sphincter in the undisturbed resting state. This is reflected in the higher measured thickness of the internal sphincter, as compared with measurements with endoluminal techniques [15].

Our MRI technique shows anatomical structures in the anal canal that so far have not been described with endoanal ultrasound or endoanal MRI. The musculus submucosae ani is a tiny muscle layer in the submucosa (fig. 1) [23,24]. Endoanal MRI has not been able to show this thin muscular layer because the endoluminal coil causes signal overload near the coil and obscures detailed imaging of the submucosal and subepithelial tissue layer [25]. We were also able to visualize the internal hemorrhoidal vascular plexuses, the anal cushions (fig. 2). Anal cushions play an important role in completely closing off the anal canal [26-28], and information on the aspect of anal cushions may play at role in the treatment of incontinence in some patients.

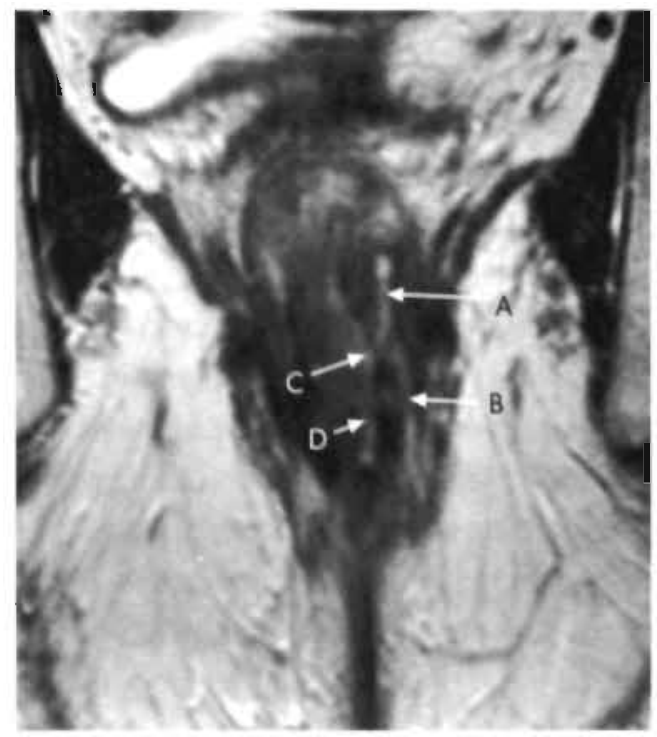

Figure 3. Anal sepsis: Coronal T2W TSE MR image of the anal region in a patient with purulent anal discharge and no abnormality on clinical examination. A complex fistulous track is seen within the left sphincter complex with secondary intersphincteric upward extension ${ }^{\wedge}$ to a supralevatoric abscess collection (not visualized on this image, as it was located ventral to this plane) and a blind ending track terminating in the intersphincteric space ${ }^{\mathrm{B}}$. No external opening was found. The internal opening $^{c}$ is identified at the level of the linea dentata. Purulent secretion is visible in the anal canal $^{D}$. The MR findings correlated well with the surgical findings. 
A major advantage of this imaging technique with an external phased array coil is that one single examination provides detailed imaging not only of the anal sphincter but also of the entire lower pelvic region: rectum, prostate. Denonvilliers fascia, vagina and cervix, the presacral and the rectosacral fascia, the sacral bone, the retrorectal and supralevator space.

After testing the high resolution MR technique in 22 volunteers we performed a pilot study on 12 patients with various anorectal diseases. The preliminary results were promising, and suggest useful applications in the treatment of anorectal fistulas, fecal incontinence and anorectal tumors.

For most fistulas the extent of the fistulous tracks can be adequately assessed during operation. However, complex fistulas such as recurrent fistulas, fistulas associated with Crohn's disease and postoperative anastomotic fistulas are more difficult to assess during surgery. Reports have shown higher sensitivity rates for the detection and classification of fistulas with endoanal MRI than with endosonography [29-31]. Recent publications have reported even better accuracy rates with a body coil than with an endoanal coil $[32,33]$. The main limitations of the endoanal MRI were insertion failure of the coil especially with complex fistulas, and difficulty to detect fistula tracks several $\mathrm{cm}$ away from the anal canal due to the signal to noise drop off with distance from the coil $[19,32,33]$. High resolution MRI with a phased array coil can overcome these problems (fig. 3 ).
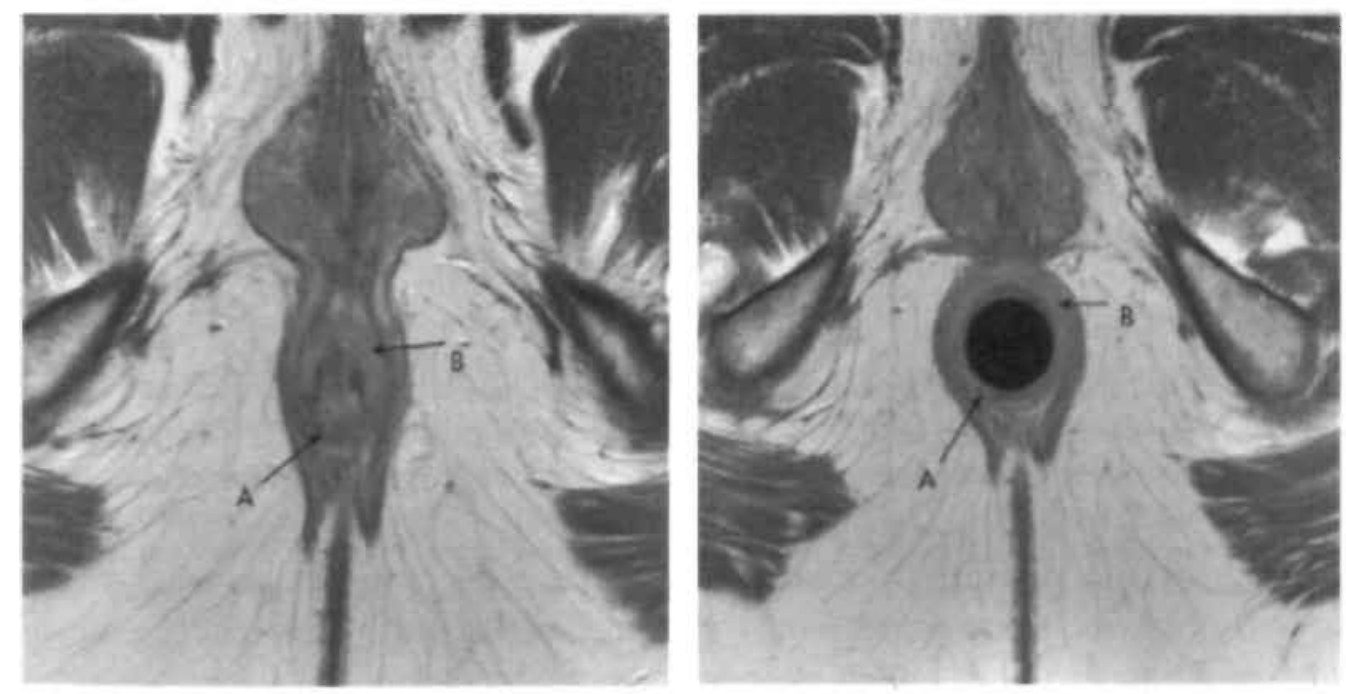

Figure 4. Localized sphincter defect: Axial T2W TSE MR image of the anal sphincter, without and with an endoluminal probe, in a female patient with fecal incontinence and suspected sphincter trauma. A localized sphincter defect ${ }^{A}$ is seen posteriorly in the internal sphincter muscle ${ }^{B}$, between 4 and 8 o'clock. Note how the sphincter is stretched when an endoluminal probe is inserted. 
Some patients with rectal cancer (i.e., advanced primary or recurrent) require extensive diagnostic work-up to plan optimal treatment. Detailed anatomical information is essential in determining the optimal surgical approach: anterior and/or posterior approach, sphincter saving or sphincter resecting procedures, and for the planning of additional radiotherapy. Detailed anatomical information can also be useful in the follow up of patients after surgery and/or radiotherapy, allowing early detection of local recurrence. Endoanal MRI has been used in evaluating the extent of anorectal tumors, but the limited length of the coil and the limited field of view have made it difficult to assess the full upward extent of the tumor, unless a receiver coil is inserted in the rectum [19]. Our preliminary results show that with our MR technique we were able to accurately assess the full upward, downward and lateral extent in the patients with primary and recurrent rectal cancer. The combination of a wide field of view and a high resolution of pre and post contrast T1W images produces excellent images of structures outside the scope of the endoanal coil, allowing an accurate and detailed assessment of the extent of the tumor.
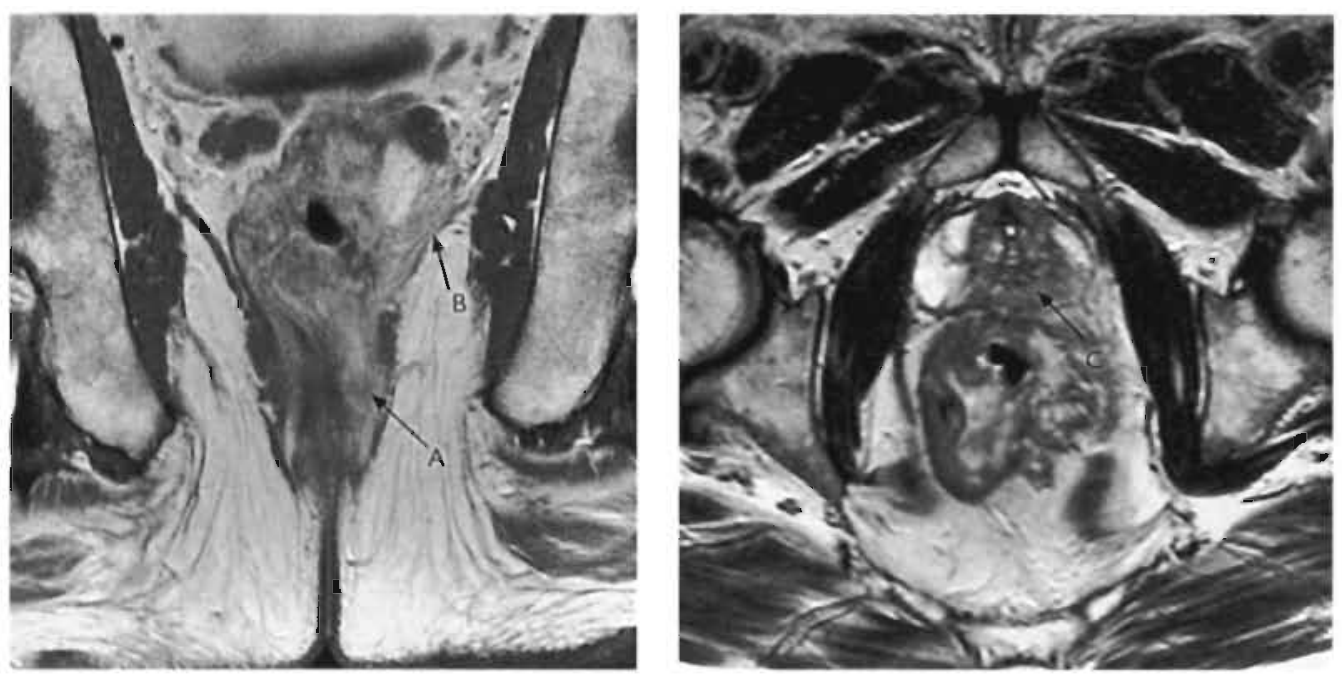

Figure 5. Primary rectal cancer: Coronal contrast enhanced T1W SE MR and axial T2W TSE MR images. A locally advanced distal rectal tumour is shown with invasion of the left sphincter complex $^{A}$ and the left pelvic floor ${ }^{B}$ (levator ani muscle). Prostate invasion ${ }^{C}$ is also clearly visible on the axial T2W image as a region of hypointense signal intensity within the normal hyperintense peripheral zone. MR findings showed exact correlation with surgery and histology.

For the diagnosis of sphincter defects endoluminal ultrasound is shown to be accurate $[3,9,17]$. One considerable disadvantage is that the technique is operator dependent. Endoluminal MRI has been reported to have a high accuracy in defining the site and extent of sphincter tears [25,30]. In both endoluminal ultrasound and MRI 
the endoanal probe disturbs the normal anatomy of the anal sphincter and pelvic floor. Whether or not this disturbance of anatomy is relevant for making a precise diagnosis is not yet clear. The potential of our MR technique without an endoluminal coil for assessing sphincter defects was demonstrated (fig. 4).

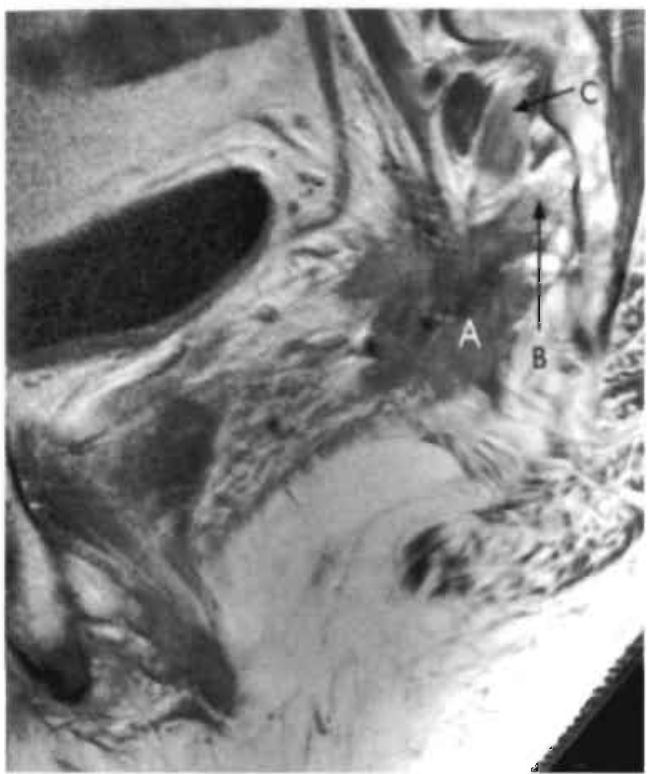

Figure 6. Recurrent rectal cancer: Sagittal contrast enhanced T1W SE image of the presacral region. This patient was referred with perineal pain, 2 years after an anterior resection of the rectum for rectal cancer. CT had shown a recurrent tumour mass, but failed to define the extent of the tumour. MRI accurately shows the tumour $^{\wedge}$ with invasion in the presacral space ${ }^{B}$ and the piriformis muscle ${ }^{C}$. Due to the ultra detailed preoperative information the optimal surgical approach was planned, combining an anterior approach with a posterior approach including partial resection of the sacrum.

MRI imaging with an external phased array coil gives a minimum of discomfort to patients. Introduction of an anal probe, as used with endoanal MRI, can be painful. Patient comfort is further enhanced in our technique by using the feet first, supine position, resulting in fewer problems with claustrophobia.

In conclusion, detailed MR imaging of the anorectal region with the use of an external phased array coil is feasible. This technique offers a wide field of view and allows a physiological and high resolution image not only of the anal sphincter complex but also of the surrounding pelvic organs. Although the technique is tested in only a limited number of patients, the preliminary results demonstrate the potential of this technique for the diagnosis of anal sepsis, rectal tumors and anal sphincter defects. Further studies are needed to evaluate the impact of this MRI technique in the management of these diseases and to compare this technique with other imaging methods. We are currently performing such studies for the anorectal region, and we encourage other MR radiologists and surgeons to do the same, as we believe that high resolution MRI with a phased array coil will become invaluable in the management of diseases of the anorectal region. 


\section{References}

1. Read TE, Fleshman JW. Outcomes: assessing the effectiveness of fecal incontinence therapy. Seminars in Colon and rectal surgery 1997; 8: 121-125.

2. Law PJ, Bartram Cl. Anal endosonography: technique and normal anatomy. Gastrointestinal Padiology 1989; 14: 349-353.

3. Law PJ, Kamm MA, Bartram Cl. A comparison between electromyography and anal endosonography in mapping external anal sphincter defects. Dis Colon Rectum 1990; 33: 370-373.

4. Pittman JS, Benson TB, Sumners JE. Physiologic evaluation of the anorectum - a new ultrasound technique. Dis Colon Rectum 1990; 33: 476-478.

5. Burnett SJD, Bartram Cl. Endosonographic variations in the normal internal anal sphincter. Int J Colorectal Dis 1991; 6: 2-4.

6. Nielsen MB, Pedersen JF, Hauge C, Rasmussen OO, Christiansen J. Endosonography of the anal sphincter: findings in healthy volunteers. AJR 1991; 157: 1199-1202.

7. Gantke B, Enck P, Schafer A, Lubke H. Morphology and function: sonographic, manometric and myographic evaluation of the anal sphincters. Dis Colon Rectum 1993; 36: 1037-1041.

8. Sultan AH, Nicholls RJ, Kamm MA, Hudson CN. Beynon J, Bartram Cl. Anal endosonography and correlation with in vitro and in vivo anatomy. Br J Surg 1993; 80: 508-511.

9. Solomon MJ, McLeod RS, Cohen EK, Simons ME, Wilson S. Reliability and validity studies of endoluminal ultrasonography for anorectal disorders. Dis Colon Rectum 1994; 37: 546-551.

10 Choen S, Burnett S, Bartram Cl, Nicholls RJ. Comparison between anal endosonography and digital examination in the evaluation of anal fistulae. Br $J$ Surg 1991; 78: 445-447.

11. Aronson MP, Lee RA, Berquist TH. Anatomy of anal sphincters and related structures in continent women studied with magnetic resonance imaging. Obstet Gynaecol 1990; 76: 846-851.

12 Myhr GE, Myrvold HE, Nilsen G, Thorensen JE, Rinck PA. Perianal fistulas: use of magnetic resonance imaging for diagnosis. Radiology 1994; 191: 545-549.

13. Tjandra JJ. Sissons GR. Magnetic resonance imaging facilitates assessment of perianal Crohns disease. Aust N Z J Surg 1994; 64: 470-474.

14 Lunniss PJ, Armstrong P. Barker PG. Reznek RH. Phillips RKS. Magnetic resonance imaging of anal fistulae. The Lancet 1992; 340: 394-396.

15. Schäfer A, Enck P. Furst G, Kahn T, Frieling T, Lubke HJ. Anatomy of the anat sphincters.Comparison of anal endosonography to magnetic resonance imaging. Dis Colon Rectum 1994; 37: 777-781.

16 Puni R. Hall AS, Coutts GA, deSouza NM. Development of an insertable surface coil for MRI of the anal sphincter [abstract]. Br J Radiology 1994: 68: 679

17. Hussain SM, Stoker J, Zwamborn AW, et al. Endoanal MRI of the anal sphincter complex: correlation with cross-sectional anatomy and histology. J Anat 1996; 189: 677-682.

18 Hussain SM, Stoker J. Lameris JS. Anal sphincter complex: endoanal MR imaging of normal anatomy. Radiology 1995; 197: 671-677.

19 deSouza NM, Hall AS, Puni R, Gilderdale. DJ, Young IR, Kmiot WA. High resolution magnetic, resonance imaging of the anal sphincter using a dedicated endoanal coil. Comparison of magnetic resonance imaging with surgical findings. Dis Colon Rectum 1996; 39: 926-934.

20. deSouza NM, Kmiot WA, Puni R, El AL. Anatomy of the anal sphincters: comparison of endosonography to magnetic resonance imaging. Gut 1995; 37: 284-287.

21 deSouza NM, Puni R, Kmiot WA, Bartram Cl, Hall AS, Bydder GM. MRI of the anal spincter. J Comput Assist Tomogr 1995; 19: 745-751. 
22. Van Beers BE, Kartheuser A, Delos MA, et al. MAl of the anal canal: correlation with histologic examination. Magnetic Res Imaging 1996; 14: 151-156.

23 Marcio J, Jorge N, Wexner D. Anatomy and physiology of the rectum and anus. Eur J Surg 1997; 163: 723-731.

24. Fenger C. Anal Canal. In: Stemberg SS, ed. Histology for Pathologists. New York: Raven Press, 1992: 607-623.

25 deSouza NM, Puni R, Zbar A, Gilderdale DJ, Coutts GA, Krausz T. MR imaging of the anal sphincter in multiparous women using an endoanal coil : correlation with in vitro anatomy and appearances in fecal incontinence. AJR 1996; 167: 1465-1471.

26. Thompson WHF. The nature of hemorrhoids. Br J Surg 1975; 62: $542-552$.

27. Gibbons CP. Trowbridge EA, Bannister JJ, Read NW. Role of anal cushions in maintaining continence. The Lancet 1986; 1 (8486): 886-888.

28. Lestar B, Penninckx F, Rigauts H, Kerremans R. The internal sphincter can not close the canal completely. Int J Colorectal Dis 1992; 7: 159-161.

29. Hussain SM, Stoker J, Schouten WR, Hop WC, Lameris JS. Fistula in ano: endoanal sonography versus endoanal MR imaging in classification. Radiology 1996; 200: 475-481.

30. Stoker J, Hussain SM, Lameris JS. Endoanal magnetic resonance imaging versus endosonography. Radiol Med 1996; 189: 738-741.

31. Zbar AP, deSouza NM, Puni R, Kmiot WA. Comparison of endoanal magnetic resonance imaging with surgical findings in perirectal sepsis. Br J Surg 1998; 85: 111-114.

32. Beckingham IJ, Spencer JA, Ward J, Dyke GW, Adams C, Ambrose NS. Prospective evaluation of dynamic contrast-enhanced magnetic resonance imaging in the evaluation of fistula-in-ano. $\mathrm{Br} \mathrm{J}$ Surg 1996;83:1396-1398.

33. Halligan S, Bartram Cl. MR imaging of fistula in ano: are endoanal coils the gold standard? AJR 1998; 171: $407-412$. 
Chapter 2 


\section{Chapter 3}

MEASURING ANAL SPHINCTER MUSCLES: ENDOANAL ULTRASOUND, ENDOANAL MRI OR PHASED ARRAY MRI?

\section{A STUDY IN NORMAL VOLUNTEERS}

Beets-Tan RGH, Morren GL, Beets GL, Kessels AGH, el Naggar K, Lemaire E, Baeten CGMI, van Engelshoven JMA

Accepted for publication in Radiology 


\section{Abstract}

Purpose: To compare endoanal ultrasound (EUS), endoanal MRI and phased array MRI for the measurement of anal sphincter muscles.

Materials and Methods: Sixty healthy volunteers (21 nulliparous and 25 multiparous women and 14 men) underwent a MRI with a quadrature phased array spine coil, a MRI with an endoanal coil (both at $1.5 \mathrm{~T}$ ) and an endoanal sonography. The thickness of the sphincter muscles and the perineal body was measured. The reliability of the measurements was analyzed and correlations between the imaging methods were calculated. A multivariate analysis was performed to assess the influence of age, weight, length, gender, parity and obstetric trauma on sphincter dimensions.

Results: The mean (SD) thickness in $\mathrm{mm}$ of the internal sphincter measured with EUS in women and men was 3.8 (1.2) and 3.4 (1.4), with endoanal MRI $2.0(0.4)$ and $1.8(0.3)$, and with phased array MRI $3.2(0.7)$ and $2.9(0.4)$. For the external sphincter these figures for women and men were: EUS: 7.2 (2.3) and 6.1 (1.7), endoanal MRI: $1.2(0.3)$ and $1.3(0.4)$, and phased array MRI: $1.3(0.2)$ and $1.4(0.5)$. Both MR methods showed a good reliability for the measurements of all sphincter components, whereas endosonography was only reliable for the internal sphincter measurement. Overall there was little correlation between the techniques, except for the fwo MRI techniques, which showed a strong correlation for total sphincter and perineal body thickness. The internal sphincter significantly thickened with age on EUS and endoanal MRI, but not on phased array MRI. Small gender differences for the sphincter muscles existed only for phased array MIRI.

Conclusion: EUS can only reliably measure internal sphincter thickness, whereas both MRI methods are reliable for all sphincter components. Sphincter measurement with a phased array MRI is as reliable as endoanal MRI. 


\section{Introduction}

In many patients with fecal incontinence the anal sphincter muscles show localized defects that are most often related to trauma during childbirth or surgery $(1,2)$. Endoanal sonography (EUS) is widely accepted as a reliable imaging tool to detect these sphincter lesions, and to select patients for anal sphincter repair (3-8). There are a number of reports describing more subtle diffuse changes in the anal sphincter. Denervation of the external sphincter in idiopathic fecal incontinence is reported to lead to thinning of the external and thickening of the internal sphincter muscle $(9,10)$. Passive fecal incontinence (soiling) is associated with primary degeneration of the internal sphincter resulting in thinning of this muscle (11). In other defecation disorders, like obstructed defecation the internal sphincter has been reporteci to be thickened $(12,13)$. It has been suggested by these authors that in patients with defecation problems it is not only important to evaluate the sphincter integrity but also to perform accurate measurements of sphincter muscle thickness $(9,11-13)$.

Several imaging modalities can be used to evaluate the anal sphincter muscles. The advantage of EUS is that it is inexpensive and widely available. A major disadvantage is that it is difficult to visualize the externall sphincter muscles due to the inherent low soft tissue contrasit resolution $(14,15)$. As with any ultrasound method it is operator dependent with significant interobserver variability $(16,17)$. MRI with an endoanal coil has been introduced as a complementary imaging modality to EUS (10, 18, 19), especially for the evaluation of the external sphincter complex (20-22). A disadvantage is that its use has been restricted to specialized centers as the endoanal coil is not yet available with every MR machine. MRI with a body coil is more widely available but shows insufficient spatial resolution for distinguishing the individual small muscles of the anal sphincter (23-25). Recently a high spatial resolution MR technique with a quadrature phased array spine coil has been described, with promising results for the evaluation of the anal sphincter (26).

At present it is unclear which imaging method is best suited for anal sphincter measurements. Anal sphincter components are small and are measured in millimeters. To detect subtle changes in thickness an imaging technique is required with an accurate discriminatory power and an accurate reproducibility. The available data on sphincter measurements give conflicting results. For example some studies have found a correlation between internal sphincter thickness and age (9, 27-30), whereas other studies could not confirm these findings (24, 31, 32). Some investigators found a correlation between sphincter morphology and manometry (5, 27), whereas others did not $(6,28,31,33)$. These conflicting results may reflect the inherent inaccuracies of the imaging techniques. So far only one study in 8 volunteers compared the measurements of the anal sphincter dimensions with different imaging 
modalities (25). The authors concluded that EUS was superior to conventional MRI with a body coil, but the MR technique that was used is no longer considered up to date.

The aim of this study is to compare EUS, endoanal MRI and phased array MRI for the measurement of anal sphincter muscles in normal volunteers.

\section{Materials and Methods}

The study was approved by the institutional review board. Sixty healthy volunteers with no history of anorectal disease (fecal incontinence, constipation, gastrointestinal disease or anorectal surgery) were recruited through advertising. The participating volunteers were: twenty-one nulliparous women (mean age 39 yrs, range $19-68$ yrs), 25 women with a history of one or more deliveries (mean age 52 yrs, range 31 . 72 yrs), and 14 men (mean age 46 years, range $19-72$ years). Fourteen of the women who had given childbirth reported an obstetric trauma (perineal rupture or episiotomy). After informed consent the volunteers underwent an MRI with a quadrature phased array spine coil, an endoanal MRI and an endoanal sonography. The three examinations were always performed in this order and the whole procedure was completed within one hour. After the three investigations each volunteer was asked to give their subjective score of discomfort for each of the investigations on a visual analogue scale (VAS). A score of 0 represents "not uncomfortable, excellently tolerated" and a score of 10 represents a "very uncomfortable, hardly tolerable".

\section{Phased array MA imaging}

MR imaging was pertormed at 1.5 Tesla (Gyroscan, Powertrak 6000. NT release 6.2.1, $23.0 \mathrm{mT} / \mathrm{m}$, rise time $0.2 \mathrm{~ms}$, slewrate $105 \mathrm{~T} / \mathrm{m} / \mathrm{s}$ Philips Medical Systerns, Best, The Netherlands). All subjects were positioned supine with their pelvis centered on the proximal end of a quadrature phased array spine coil in feet first position. Sequences used were a T1 weighted, 2D, turbo spin echo (T1W TSE: TR/TE 656/10 msec, 5 echo train length, $8 \mathrm{~mm}$ slice thickness, $0.8 \mathrm{~mm}$ gap, 4 signal averages, 166x256 matrix, $25 \mathrm{~cm}$ FOV, $1.4 \mathrm{~min}$. acquisition time) and a T2 weighted, 2D, turbo spin echo (T2W TSE: TR/TE $3427 / 150 \mathrm{msec}, 25$ echo train length, $3 \mathrm{~mm}$ slice. thickness, $0.3 \mathrm{~mm}$ gap, 8 signal averages, $175 \times 256$ matrix, $20 \mathrm{~cm}$ FOV, $2.64 \mathrm{~mm}^{3}$ voxel size, $6.5 \mathrm{~min}$ acquisition time). The T1W TSE sequence was obtained in the axial plane and the T2W sequences were obtained in the sagittal, coronal and axial planes. The T1W and the sagittal and coronal T2W sequences served for accurate planning of the axial T2W sequences as it was important to angle these planes exactly perpendicular to the long axis of the anal canal. Subjects did not receive 
bowel preparation and no catheters were inserted in the anal canal during the procedure. The total scan time of the phased array MR imaging was 20 minutes.

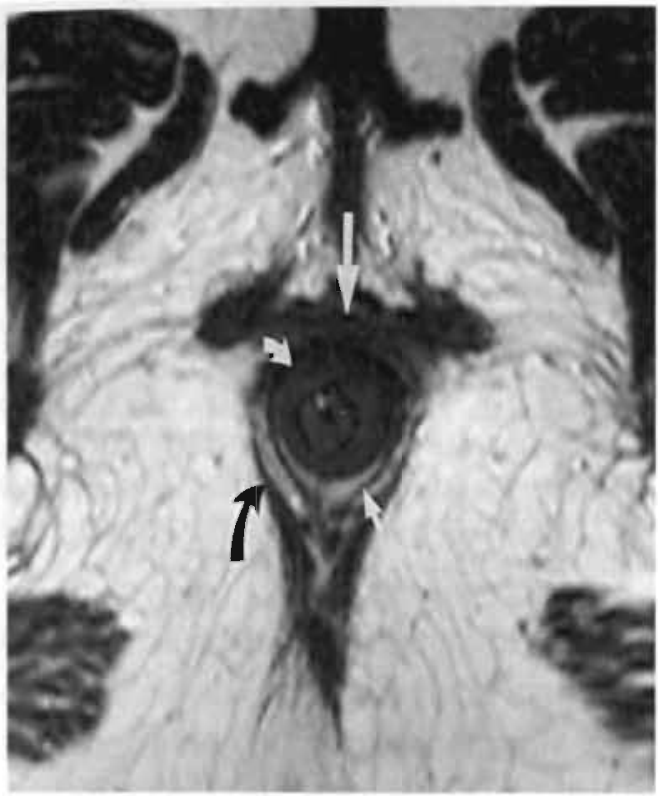

Figure 1. Phased array MRI of the anal sphincter complex in a 44-year-old healthy female volunteer.

Axial T2W TSE (TR/TE 3427/150) MR images at midanal level show the internal sphincter muscle as a homogenous iso- to hypointense circular band (small white curved arrow) surrounding the anal canal. The external sphincter is the outer most hypointense sphincter muscle (black curved arrow) and presents with a typical teardrop appearance. The hypointense longitudinal muscle (small white arrow) can be found coursing in the hyperintense fat tissue of the intersphincteric space between the internal and external sphincter muscles. The hypointense perineal body (large white arrow) is at the level of the central perineal tendon and is formed by the fibers of the external sphincter and transverse perineal muscle.

\section{Endoanal MR imaging}

Endoanal MR imaging was performed on the same MR unit. All subjects were repositioned in head first position after removing the phased array spine coil. The endoanal coil is a coil designed for imaging the anal canal. It is a rigid coil with a length of $10 \mathrm{~cm}$ and a diameter of $19 \mathrm{~mm}$. The device was covered with a condom and after application of lubricant it was positioned in the anal canal in a left lateral decubitus position, after which the volunteers were carefully turned in the supine position. On the coronal and sagittal survey scans, an axial plane perpendicular to the long axis of the anal canal was identified and T2 weighted, 2D, turbo spin echo sequences were obtained (T2W TSE: TR/TE $3427 / 150 \mathrm{msec}, 25$ echo train length, 3 $\mathrm{mm}$ slice thickness, $0.3 \mathrm{~mm}$ gap, 8 signal averages, $175 \times 256$ matrix, $12 \mathrm{~cm}$ FOV, $0.96 \mathrm{~mm}^{3}$ voxel size, $6 \mathrm{~min}$ acquisition time). The total scan time of the endoanal MR imaging was 7 minutes.

\section{Endoanal Sonography}

Anal endosonography was performed by a colorectal surgeon experienced in performing endoanal sonography, using a SSD-2000 MultiView ultrasound scanner (Aloka, Japan) with a radial endoscopic probe and 7.5 $\mathrm{MHZ}$ transducer. A plastic cone with a diameter of $17 \mathrm{~mm}$ covered the transducer head which was then covered by a latex balloon filled with degassed water. Over the balloon a lubricated condom was applied. Subjects were investigated in the supine left lateral position with the 


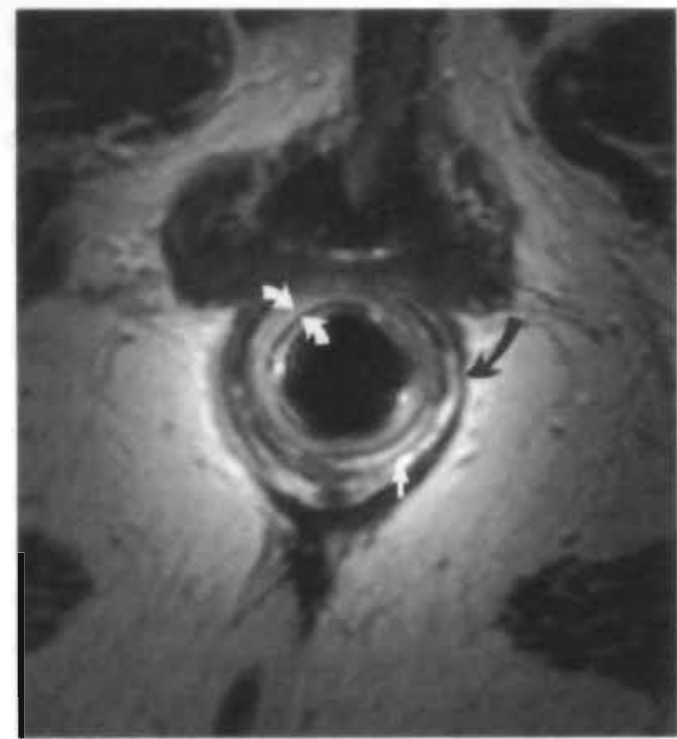

Figure 2. Endoanal MRI of the anal sphincter complex obtained in the same volunteer as in figure 1.

Axial T2W TSE (TR/TE 3427/150) MR images at midanal level show the internal sphincter muscle as a homogenous hyperintense circular band surrounding the anal canal. Note that the internal sphincter muscle is more stretched and much thinner (white curved arrows) when an endoanal coil is inserted. The hypointense longitudinal muscle (small white arrow) courses in the intersphincteric space between the internal and hypointense external (black curved arrow) sphincter muscle.

knees bent at 90 degrees. The probe was introduced into the anal canal, positioned at the upper aspect of the puborectalis sling, and rotated so that 12 o'clock was anterior as in a normal orientation for cross-sectional imaging (three o'clock represents the patient's left side and nine o'clock is the patient's right side). A personal computer with a video frame grabber was used to capture the series of the sonographic images taken from the video output of the scanner. When a frozen image was acquired, the probe was withdrawn one increment and the new position scanned and acquired. This process was repeated until all levels perpendicular to the anal canal were scanned and each examination saved for subsequent review. The total examination time for endoanal sonography was 10 minutes.

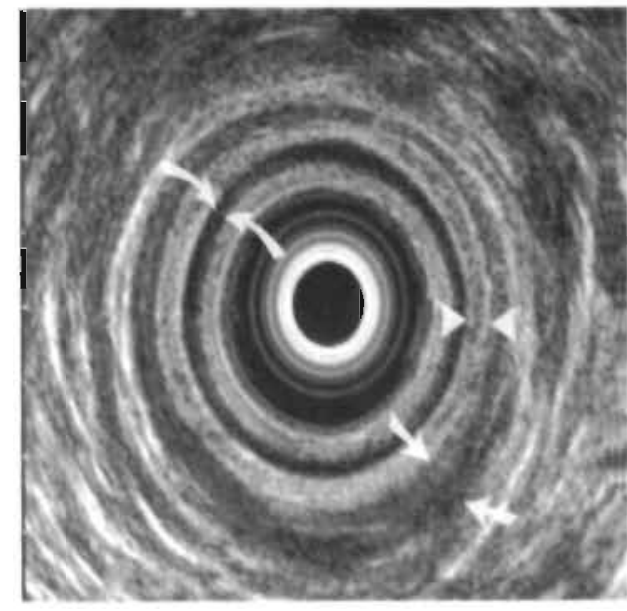

Figure 3. Endoanal sonography of the anal sphincter complex in the same volunteer as in figure 1 and 2.

The internal sphincter muscle is visualized as a homogenous hypoechoic circular band (white curved arrows). The external sphincter is shown with mixed echogeneicity (white arrows). Note that the borders of the external sphincter are more difficult to define on endosonography. Between the internal and the external sphincter the intersphincteric space is visualized as a hyperechoic band (white arrow heads). Within this band the hypoechoic longitudinal muscle can be identified. 
Image Evaluation

\section{MR images}

All MR scans were evaluated independently by a radiologist and a colorectal surgeon, both experienced in reading pelvic MRI. The presence of motion artifacts was evaluated only by the radiologist. The MR measurements were performed using an Easy Vision Workstation (Philips Medical Systems) at least two months after data acquisition in order to avoid bias of the other imaging techniques. Each observer was unaware of the other's findings at all times. To assess intraobserver agreement of the MR measurements, the radiologist performed two separate assessments of each MR study, separated by at least two weeks and blinded to previous measurements.

Measurements of the internal sphincter, the longitudinal muscle, the external sphincter and the total sphincter thickness were performed on the axial images. All measurements were taken at the 4 o'clock left lateral aspect at the midanal level of the anal canal, using software callipers accurate to $0.1 \mathrm{~mm}$. The 4 o'clock site was chosen somewhat arbitrarily on the posterior aspect to avoid interference with occult sphincter lesions that are often located anteriorly. On phased array MRI the internal anal sphincter is visualized as an iso- to hypointense circular band, whereas on endoanal MRI it appears as a hyperintense circular band. At midanal level the external sphincter appears as a typical teardrop with the tip of the drop pointing to the coccyx. The hypointense longitudinal muscle can be found in the hyperintense fat tissue of the intersphincteric space between the internal and external sphincter muscle (fig.1 and 2). The total sphincter thickness was defined as the distance between the inner border of the internal sphincter and the outer border of the external sphincter. The perineal body is formed by the fibers of the external sphincter and transverse perineal muscle (fig. 1 ). It is much more developed in women and provides anterior support of the anal canal. The thickness of the perineal body was measured in the midline and was defined as the distance between the inner surface of the internal sphincter and the outer surface of the anterior muscle complex. It was measured only in women, and the internal sphincter was included in the measurement, because of the practical difficulty on phased array MRI to define the border between the hypointense internal sphincter and the hypointense perineal body.

\section{Endoanal u/trasound images}

The ultrasound measurements were performed independently by the colorectal surgeon and the radiologist, using a personal computer and image analysis software that allowed the captured images to be viewed and measured sequentially. Again each observer was unaware of the other's findings at all times. To assess intraobserver agreement the colorectal surgeon performed two measurements on the 
images of each study, separated by at least two weeks and blinded to previous measurements. At the 4 o'clock left lateral site at midanal level the internal, longitudinal, external and total sphincter thickness was measured. The internal sphincter is seen as a homogenous hypoechoic circular band and the external sphincter is identified as a muscle with mixed echogeneicity. Between the internal and the external sphincter the intersphincteric space is visualized as a hyperechoic band. Within this band the hypoechoic longitudinal muscle is located (fig.3). The perineal body thickness was defined as the distance in the midline between the inner surface of the internal sphincter and the outer surface of the hypoechoic anterior muscle complex.

\section{Analysis and statistics}

Differences in proportions between dichotomous variables were compared with the chi $\mathrm{X}$. test, and the Fischer's exact test when appropriate. Differences between the VAS scores of patient discomfort were analyzed with the paired students $t$ test when comparing different imaging modalities and with the unpaired students $t$ test when comparing men with women. The difference in motion artifacts between the two MR methods was analyzed with the Mc Nemar test (binomial distribution). The reliability of the measurements was analyzed with a one way ANOVA, and intraclass correlation coefficients were calculated to quantify both the intra- and the interobserver reliability (34). The results of the different imaging modalities were compared with the Pearson's correlation method, and orthogonal regression curves were constructed for the significant correlations. For every imaging modality a multivariate analysis was performed to assess the influence of age, weight, height, gender, parity and obstetric trauma on those sphincter dimensions that can be measured with reasonable reliability. The statistical analyses were performed using the software package SPSS ${ }^{\oplus}$ for windows release 8.0 (SPSS, Chicago, IL, USA). P values less than 0.05 were considered significant.

\section{Results}

\section{Motion artifacts - Patient Comfort}

All volunteers tolerated the EUS and both MR examinations. Seven out of 60 endoanal MR scans showed motion artifacts, whereas none of the phased array MR scans showed motion artifacts. This difference was statistically significant ( $p=0.02$, two tailed). One of the seven volunteers with motion artifacts on the endoanal MR scan experienced feelings of claustrophobia.

The volunteers considered the examination with the phased array MRI as the least uncomfortable investigation, and the endoanal MRI as the most uncomfortable. 
The scores with the visual analogue scale for discomfort of the investigation were: a mean (SD) of $1.4(1.8)$ for endoanal ultrasound, 2.6 (2.3) for endoanal MRI, and 0.6 (0.9) for phased array MRI. The differences between the three methods were significant (three times $p<0.001$ ). Men found the insertion of an endoanal probe, both with ultrasound and MRI, more unpleasant than women (mean difference on the VAS score of 1), but the difference was not statistically significant.

\section{Normal values}

The values of the sphincter measurements with the three imaging methods in our normal population are given in table 1. The values of both MR techniques were within the same range, except for the internal sphincter and the perineal body. The internal sphincter and perineal body measured with phased array were thicker than measured with endoanal MRI. There was a marked difference in external sphincter thickness between EUS (7.2 $\mathrm{mm}$ for women and $6.1 \mathrm{~mm}$ for men) and both MA techniques (endoanal MRI: 1.2 and $1.3 \mathrm{~mm}$, phased array MRI: 1.3 and $1.4 \mathrm{~mm}$ ).

\section{Reliability of measurements by a single observer and by two different observers}

The intraclass correlation coefficients of the sphincter thickness measurements performed by a single observer and by two different observers are shown in table 2 . When the variability of the repeated measurement comes close to or exceeds the vallability in the population, the intraclass correlation coefficient is close to zero or will become zero. meaning that the measurement is completely unreliable. When there is no variability at all in the measurements within one observer or between two observers, the intraclass correlation coefficient becomes 1 , meaning that the measurement is completely reliable. The intraobserver reliability was higher than the interobserver reliability for all muscie components for the three imaging techniques. For the internal sphincter the coefficient was high for all three techniques. Endosonography showed a low correlation coefficient for all the other sphincter components, especially when comparing different observers, indicating a poor reliability of the measurements. On the other hand, both MRI methods showed a reasonable to good reliability for the measurements of all sphincter components. For the external sphincter the correlation coefficient with the phased array MFI was higher with the endoanal MRI, both for the intra- and interobserver analysis. 
Table 1: Normal values of sphincter muscle thickness in mm(standard deviation) for endosonography, endoanal MRI and phased array MRI.

\begin{tabular}{lcccccc}
\hline & \multicolumn{2}{c}{ Endosonography } & \multicolumn{2}{c}{ Endoanal MRI } & \multicolumn{2}{c}{ Phased Array MRI } \\
\hline & $\mathrm{F}$ & $\mathrm{M}$ & $\mathrm{F}$ & $\mathrm{M}$ & $\mathrm{F}$ & $\mathrm{M}$ \\
\hline internal sphincter & $3.8(1.2)$ & $3.4(1.4)$ & $2.0(0.4)$ & $1.8(0.3)$ & $3.2(0.7)$ & $2.9(0.4)$ \\
longitudinal $\mathrm{m}$. & $2.9(1.0)$ & $2.3(1.0)$ & $0.8(0.2)$ & $0.8(0.2)$ & $1.0(0.2)$ & $0.9(0.2)$ \\
external sphincter & $7.2(2.3)$ & $6.1(1.7)$ & $1.2(0.3)$ & $1.3(0.4)$ & $1.3(0.2)$ & $1.4(0.5)$ \\
total sphincter thickness & $18.7(4.1)$ & $18.7(5.2)$ & $7.2(1.5)$ & $6.1(0.7)$ & $8.3(1.7)$ & $7.8(1.7)$ \\
perineal body & $22.9(5.4)$ & - & $13.9(4.3)$ & - & $19.0(4.3)$ & - \\
\hline
\end{tabular}

( $F=46$ women, $M=14$ men)

Table 2a: Intraclass correlation coefficients of the sphincter thickness measurements performed by the same observer with endosonography (colorectal surgeon), endoanal and phased array MRI (radiologist).

\begin{tabular}{lccc}
\hline & Endosonography & Endoanal MRI & Phased Array MRI \\
\hline internal sphincter & 0.79 & 0.78 & 0.92 \\
longitudinal muscle & 0.44 & 0.48 & 0.83 \\
external sphincter & 0.29 & 0.52 & 0.9 \\
total sphincter & 0.26 & 0.89 & 0.96 \\
perineal body & 0.18 & 0.91 & 0.95 \\
\hline
\end{tabular}

Table 2b: Intraclass correlation coefficients of the sphincter thickness measurements performed by the 2 different observers with endosonography, endoanal MRI and phased array MRI.

\begin{tabular}{lccc}
\hline & Endosonography & Endoanal MRI & Phased Array MRI \\
\hline internal sphincter & 0.67 & 0.65 & 0.75 \\
longitudinal muscle & 0 & 0.42 & 0.42 \\
external sphincter & 0.21 & 0.45 & 0.53 \\
total sphincter & 0.02 & 0.75 & 0.81 \\
perineal body & 0 & 0.8 & 0.71 \\
\hline
\end{tabular}


Table 3. Correlations (Pearson correlations: $\eta$ ) and significance levels ( $p$-values) between the 3 different imaging techniques for the measurements of thicknesses of the sphincter muscles and perineal body.

\begin{tabular}{lcccccc}
\hline & \multicolumn{2}{c}{$\begin{array}{l}\text { Endosography vs } \\
\text { Endoanal MRI }\end{array}$} & \multicolumn{2}{c}{$\begin{array}{l}\text { Endosonography vs } \\
\text { Phased Array MRI }\end{array}$} & \multicolumn{2}{c}{$\begin{array}{l}\text { Phased Array MRI vs } \\
\text { Endoanal MRI }\end{array}$} \\
\hline & $r$ & $p$ & $r$ & $p$ & $r$ & $p$ \\
\hline internal sphincter & 0.33 & 0.01 & 0.22 & 0.094 & 0.25 & 0.059 \\
longitudinal muscle & 0.12 & 0.379 & 0.11 & 0.386 & 0.16 & 0.21 \\
external sphincter & 0.16 & 0.232 & -0.09 & 0.483 & 0.12 & 0.357 \\
total sphincter & 0.38 & 0.003 & 0.2 & 0.122 & 0.61 & 0.000 \\
perineal body & 0.26 & 0.085 & 0.1 & 0.5 & 0.82 & 0.000 \\
\hline
\end{tabular}

\section{Correlations between imaging techniques - regression curve}

The correlations between the three different imaging techniques are shown in table 3. There was a moderate but significant correlation between EUS and endoanal MRI for the measurements of the internal sphincter $(r=0.33)$ and total sphincter $(r=0.38)$. The orthogonal regression formulas (curves not shown) are: EUS $=-13.3+8.8 \times$ endoMRI for the internal sphincter, and EUS $=-17.4+5.1 \times$ endoMRI for the total sphincter thickness. There is no correlation between EUS and phased array MRI for any of the sphincter components. Phased array MRI and endoanal MRI show a strong correlation for the measurement of total sphincter thickness ( $r=0.61)$ and perineal body ( $r=0.82$ ). The orthogonal regression curves and coefficients are shown in fig 4 . Although there is a strong correlation, the regression curve in fig. $4 \mathrm{~b}$ shows that the measured thickness varies with the MRI technique, suggesting that both MR techniques measure in a different way. When the correlations were recalculated for the observations of the other obsenver, only the correlation between the two MR techniques for the total sphincter thickness and the perineall body remained significant $(p<0.01)$. 


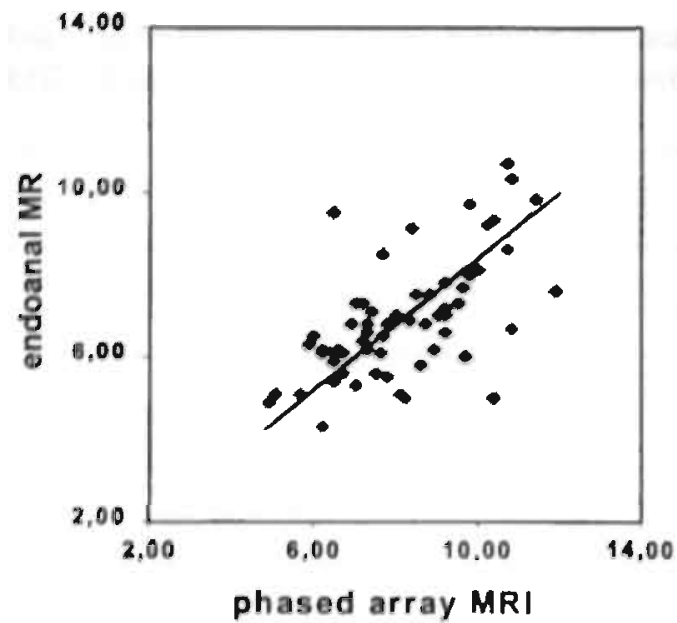

Figure 4a. Orthogonal regression for the total sphincter thickness $(\mathrm{mm})$ measured with endoanal MRI vs phased array MRI $(\alpha=0.4, \beta=0.8)$

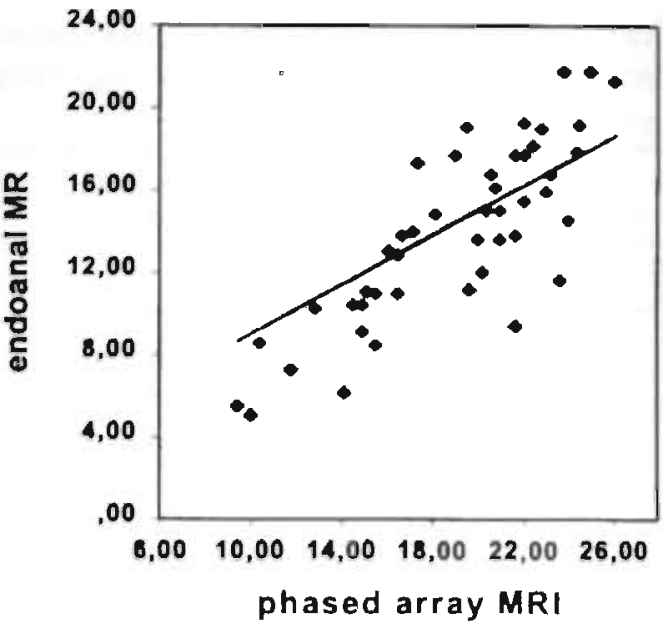

Figure $\mathbf{4 b}$. Orthogonal regression for the perineal body thickness $(\mathrm{mm})$ measured with endoanal MRI vs phased array MRI $(\alpha=3, \beta=0.6)$

Influence of age, weight, height, gender, parity and obstetric trauma on sphincter dimensions

The results of the multivariate analysis are shown in table 4 . The analysis was not performed for measurements that were completely unreliable i.e., the longitudinal muscie, the total sphincter thickness and the perineal body thickness with EUS. A significant increase of the internal sphincter thickness with age was found when measured with EUS and endoanal MRI, but not with phased array MRI. The internal sphincter was thinner in men with the three imaging methods, the difference being significant with phased array MR and almost significant with endoanal MRI $(p=0.051)$. When measured with the phased array MRI, men showed significantly thicker external sphincters than women. This was not observed with the two other imaging techniques. With the phased array MRI men had significantly thinner longitudinal muscles than women. The total sphincter thickness was positively correlated with the parital status, but this was significant only when measured with the endoanal MRI. For perineal body thickness there was a significant positive correlation with the number of obstetric traumas only when measured with the phased array MRI. Body weight had no significant influence on any of the sphincter components, whereas with increasing height there was a significant increase in internal sphincter and perineal body thickness when measured with both MRI methods. 
Table 4. Multivariate analysis: regression coefficients (B) and significance levels (p). Influence of age (per year), parital status (per partus), obstetric trauma (per event), gender (women:1 \& men: 2), body weight (per $\mathrm{kg}$ ) and height (per $\mathrm{cm}$ ) on sphincter thicknesses in $\mathrm{mm}$.

\begin{tabular}{|c|c|c|c|c|c|c|}
\hline \multirow[b]{2}{*}{ internal sphincter } & \multicolumn{2}{|c|}{ Endosonography } & \multicolumn{2}{|c|}{ Endoanal MRI } & \multicolumn{2}{|c|}{ Phased Array MRI } \\
\hline & B & $p$ & B & $p$ & B & $p$ \\
\hline age & 0.04 & 0.002 & 0.01 & 0.002 & 0 & 0.755 \\
\hline parital status & -0.04 & 0.742 & -0.04 & 0.437 & 0.1 & 0.234 \\
\hline obstetric trauma & 0.46 & 0.104 & -0.08 & 0.388 & 0.2 & 0.263 \\
\hline gender & -0.58 & 0.178 & -0.29 & 0.051 & -0.59 & 0.039 \\
\hline weight & 0.03 & 0.141 & 0 & 0.511 & -0.01 & 0.403 \\
\hline height & 0.03 & 0.24 & 0.02 & 0.035 & 0.04 & 0.032 \\
\hline \multicolumn{7}{|l|}{ longitudinal musc } \\
\hline age & $\cdot$ & . & 0 & 0.714 & 0 & 0.709 \\
\hline parital status & $\cdot$ & - & 0 & 0.905 & 0.01 & 0.762 \\
\hline obstetric trauma & - & - & -0.03 & 0.584 & 0.04 & 0.513 \\
\hline gender & - & $=$ & 0.08 & 0.303 & -0.22 & 0.014 \\
\hline weight & - & $\cdot$ & 0 & 0.175 & 0.01 & 0.85 \\
\hline height & - & $\cdot$ & 0 & 0.377 & 0 & 0.488 \\
\hline \multicolumn{7}{|l|}{ external sphincter } \\
\hline age & -0.03 & 0.336 & 0 & 0.203 & 0 & 0.852 \\
\hline parital status & -0.14 & 0.614 & -0.01 & 0.87 & 0.01 & 0.783 \\
\hline obstetric trauma & 0.66 & 0.277 & -0.16 & 0.056 & 0.08 & 0.427 \\
\hline gender & -0.74 & 0.434 & 0.11 & 0.379 & 0.29 & 0.024 \\
\hline weight & 0.02 & 0.563 & 0.01 & 0.121 & 0 & 0.761 \\
\hline height & -0.06 & 0.313 & 0 & 0.821 & -0.01 & 0.381 \\
\hline \multicolumn{7}{|l|}{ total sphincter } \\
\hline age: & - & $\cdot$ & 0.03 & 0.072 & 0.02 & 0.328 \\
\hline parital status & - & $=$ & 0.39 & 0.014 & 0.29 & 0.152 \\
\hline obstetric trauma & - & $\cdot$ & -0.08 & 0.817 & 0.23 & 0.6 \\
\hline gender & $\cdot$ & $\cdot$ & -0.78 & 0.144 & 0.56 & 0.41 \\
\hline weight & - & - & 0.03 & 0.18 & 0.01 & 0.631 \\
\hline height & $\cdot$ & - & 0.03 & 0.357 & -0.03 & 0.504 \\
\hline \multicolumn{7}{|l|}{ perineal body } \\
\hline age & $\cdot$ & - & 0.12 & 0.025 & 0.09 & 0.095 \\
\hline parital status & * & - & 0.61 & 0.253 & 0.82 & 0.109 \\
\hline obstetric trauma & $\cdot$ & $\cdot$ & 0.99 & 0.438 & 2.52 & 0.041 \\
\hline weight & - & - & -0.06 & 0.404 & 0 & 0.988 \\
\hline height & - & - & 0.32 & 0.024 & 0.27 & 0.044 \\
\hline
\end{tabular}




\section{Discussion}

\section{Reliability}

There are many reports on anal sphincter dimensions measured with EUS (11, 17, $25,28,29,32,35,36)$ and $\operatorname{MRI}(20,23,26,30)$. Generally it has not been appreciated that inconsistent findings may be caused by measurement error. Measurement error results from two phenomena: the inherent discriminatory power of the imaging method and the ability of the observer to perform consistent reading. The intra- and interobserver variability of repeated measurements in a given population can be used to calculate a reliability index (34). When the intra-observer variability of a method comes close to or exceeds the variability in the population, the method is clearly not able to perform reliable measurements. The better this profile for a given technique, the more reliable the measurements will be. Likewise, a good profile is needed for the interobserver reliability, in order to be able to communicate and to compare results.

Our results show that with endosonography (EUS) only the internal anal sphincter thickness can be reliably measured, whereas with MRI, and especially with phased array MRI, reliable measurements can be made of all the sphincter components. It is important to realize that this restriction for EUS only applies to subtle variations in sphincter thickness, in the same order of the variation between a normal population. The reliability is likely to improve when the pathologic: changes would be more obvious i.e., tripling of thickness. Even more so, it is obvious tha? this restriction for EUS does not apply for the detection of localized sphincter defects, where its benefit has been proved $(5,7,8)$.

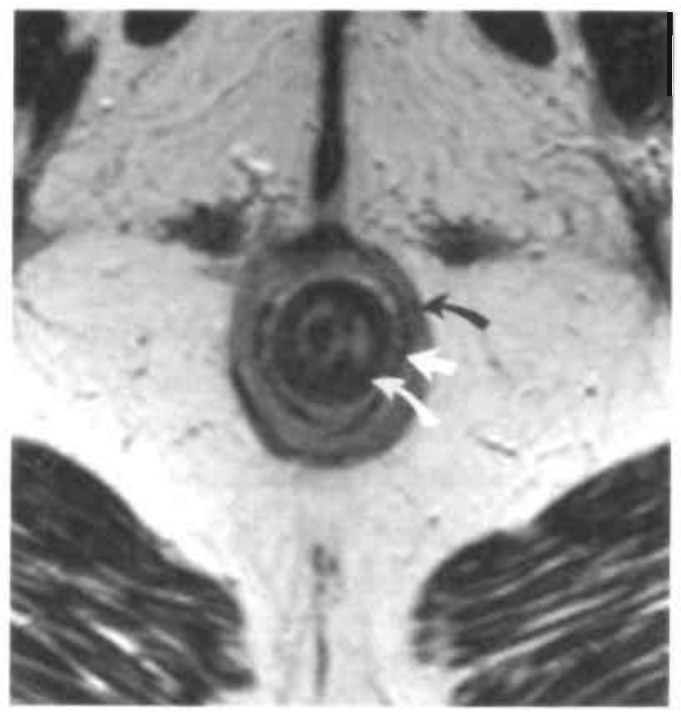

Figure 5a. Phased array MRI of the ana! sphincter complex in a 57-year-old healthy female volunteer. Axial T2W TSE (TR/TE. 3427/150) MR images.

On phased array MRI the hypointense internal sphincter (white curved arrow). the hypointense longitudinal sphincter (white straight, arrow) and the hypointense external sphincter (black. curved arrow) can be distinguished. 


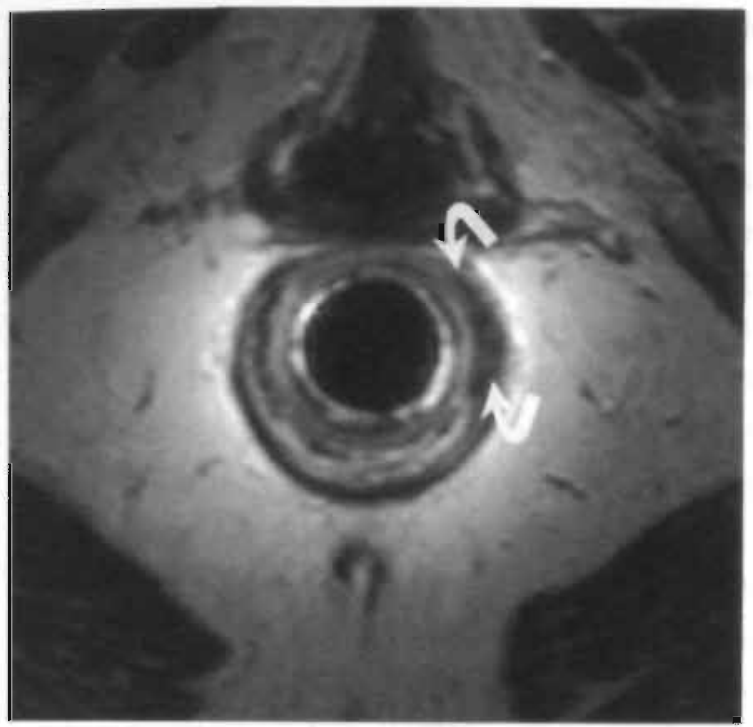

Figure 5b. The endoanal MRI of the same volunteer as in fig. 5 a shows that reliable differentiation between the hypointense longitudinal and hypointense external sphincter muscle can sometimes be difficult (white angled arrows), because the interfaces of these muscles with the hyperintense fat tissue of the intersphincteric space are more likely to fade when the sphincter is stretched by a coil.

Two studies have specifically addressed the problems of reproducibility in EUS in sphincter measurements $(16,17)$. Enck et al studied a small group of healthy volunteers and concluded that EUS did not provide a reliable measurement on internal and external sphincter thickness (16). Gold et al studied fifty-one patients and found that measurements of the internal sphincter was more reproducible than the external sphincter (17). These findings are consistent with our results. On EUS the internal sphincter is easy to define because it is a hypoechoic structure that is highlighted against hyperechoic adjacent tissues. In contrast to the internal sphincter, the more hyperechoic longitudinal and external sphincter muscle show less contrast with the surrounding hyperechoic fatty tissue. Both the inner and outer border of the external sphincter are more difficult to define, leading to less reliable measurements (fig 3). The high inherent soft tissue contrast resolution makes MRI a more reliable imaging method to measure anal sphincter components. Previous studies by Rociu et al. have shown that endoanal MRI is superior to EUS in assessing localized and diffuse sphincter lesions, especially for the external sphincter $(14,22)$. Our results support this finding.

\section{MR techniques}

MRI with a body coil has insufficient spatial resolution for accurate delineation of individual small muscle components of the anal sphincter (23-25). MRI with an endoanal coil however generates high spatial resolution images of the anal sphincter because of a very high signal to noise ratio nearby the coil $(10,18,20,37)$. Recent reports have shown that detailedimages of the anal sphincter can also be generated with a phased array coil $(26,38)$. The present study confirms that with this external coil results can be obtained that are at least as reliable as with an endoluminal coil. 
The multiple coil arrangement in a phased array coil increases the signal to noise ratio and images with small voxel sizes and a high spatial resolution can be obtained. The specific coil in our study was a quadrature phased array spine coil. Unlike the linear arrangement of the coil components in a standard torso or pelvic phased array coil, the coil components in a phased array spine coil are arranged in quadrature. This further improves the signal to noise ratio and even smaller voxel sizes can be generated.

\section{Correlation}

There were no strong correlations between the measurements with the endoanal ultrasound and with the two different MR techniques. This is no surprise when considering the low reliability of most of the sonographical measurements. As the measurements with the two MR techniques are more reliable for all muscle components, one would expect a high correlation. However, there was only a consistent and strong correlation between the two MR techniques for the total sphincter and the perineal body thickness. The absence of correlation for the internal and external sphincter muscles, with a strong correlation for the total sphincter thickness suggests a difference in distinguishing the individual muscle components between the two MR techniques. In our experience it was not always easy to distinguish the longitudinal muscle from the external sphincter on endoanal MRI. This is also reflected in the lower reliability of endoanal MRI as compared with phased array MRI for the measurements of the external sphincter and longitudinal muscle. These two muscles often lay close to each other and the interface of these muscles with the hyperintense fat tissue of the intersphincteric space is more likely to fade when the sphincter complex is stretched by an endoluminal coil (fig.5). The outer border of the total sphincter complex is less influenced by the strecthing effect of the coil, explaining the strong correlation between the MR techniques for the measurements of total sphincter thickness.

\section{Normal values}

The effect of sphincter muscle stretch by the insertion of an endoanal coil is reflected in the difference in internal sphincter thickness between our two MR techniques. The internal sphincter measured with phased array MRI was thicker than measured with endoanal MRI.

In the literature the same effect can be observed. Reported normal values for internal sphincter thickness with endoanal MRI vary from $2.9 \mathrm{~mm}$ (SD 0.1) to $5.1 \mathrm{~mm}$ (SD 1.4) measured with a 19 and $12 \mathrm{~mm}$ coil respectively $(20,30)$. Reported normal values for internal sphincter thickness with endoanal sonography in healthy volunteers range from $1.5 \mathrm{~mm}$ (SD 0.6), measured with a $23 \mathrm{~mm}$ probe to $2.6 \mathrm{~mm}$ (SD 0.9), measured with a $17 \mathrm{~mm}$ probe $(17,25,28,32,35,36)$. 
A. striking observation was the large difference in external sphincter thickness between endosonography and both MR techniques with a much thicker external sphincter and larger variability for EUS than for MRI. Although our ultrasound values are within the range of values given in literature, this large difference between the two imaging modalities again illustrates the inherent inaccuracy of endosonography to define and measure the external sphincter muscle.

Normal values for sphincter dimensions differ between techniques and the lack of strong correlations between the different imaging modalities suggests that values of anal sphincter muscle thickness performed with different techniques are not interchangeable. The question can be asked which of these imaging techniques reveals the true values of sphincter muscle thickness in healthy individuals, and it may even be that none of the methods is correct. This question however is not very relevant, as the purpose of measuring anal sphincters is to distinguish with consistency normal from abnormal, regardless of the absolute values. The practical consequence therefore is that one needs to refer to normal sphincter values for each technique, in order to decide whether a measured thickness is normal or abnormal. Even then there can be differences. Our values for internal sphincter thickness with endosonography were slightly higher than those of other authors who used a probe with the same diameter, and our values for the individual sphincter muscle thickness with endoanal MRI were slightly lower than in other reports (30). This can be explained by the differences between the equipment that is used, differences in sequences, differences in performing the measurements and differences in definitions and subjective interpretations. In order to minimize the effect of these confounding variables the imaging techniques should be standardized. At present, the most practical advice is when one wants to compare sphincter dimensions to a set of normal values from the literature, the imaging technique that is used should be as close to the referenced technique as possible.

\section{Multivariate analysis}

Our study shows that with increasing age the internal sphincter becomes slightly thicker, at least when measured with EUS and endoanal MRI. With EUS the muscle thickness increases $0.38 \mathrm{~mm}$ every 10 years, and with endoana! MRI $0.13 \mathrm{~mm}$. This confirms the findings of many other reports $(9,27-30,39,40)$. The age related increase in internal sphincter size is most likely the result of connective tissue. infiltration, rather than true hypertrophy $(29,41-43)$. Surprisingly this increase in. thickness could not be demonstrated with phased array MRI.

There are small gender differences for the internal, external and longitudinal muscle, but only when measured by the phased array MRI. In men the external sphincter was found to be thicker. Other authors report conflicting results on gender differences, some authors reporting a thicker external sphincter in men $(32,44)$, and 
others reporting no difference $(29,35)$. In an endoanal MR study with 50 female and 50 male healthy volunteers Rociu et al. generally did not find any gender difference except in the younger age group, where men had a thicker external sphincter than women (30).

Parital status had little effect on anal sphincter dimensions. This seems to be in contrast with the results of a study by Zetterstrom et al. who found thinner perineal bodies in multiparous women than in their nulliparous control groups (36). In their study however the multiparous women had symptomatic sphincter defects and no other variables were taken into account such as obstetric trauma. An interesting finding in our study is that in women who had an episiotomy or a perineal laceration during childbirth the perineal body was thicker when measured with phased array MRI. This can be explained by the fibrotic scar tissue after healing of the episiotomy wound or the perineal laceration.

It remains difficult to interpret the fact that some differences and correlations are apparent with one imaging method and not with the other, and that many reports show divergent findings. Some of the apparent differences may be caused by a type I error, especially when performing multiple analyses. Other inconsistencies may be caused by the poor reliability of the imaging method and by the difficulties in comparing different imaging techniques and different investigators, as discussed above.

At present endoanal ultrasound is the imaging method of choice in the workup of patients with fecal incontinence. The majority of younger patients will be found to have an underlying structural sphincter damage. Endoanal sonography is used to select those patients with sphincter damage who may benefit from surgical repair $(5,7,8)$. However a small group of patients will exist in whom EUS can not identify any sphincter damage. In this group of patients it has been suggested that measuring sphincter thickness may be important to exclude diffuse structural sphincter changes associated with idiopathic fecal incontinence, passive fecal incontinence or obstructive defecation disorders $(9,11-13)$.

The present study shows that with endosonography only the internal anal sphincter thickness can be reliably measured, whereas with MRI reliable measurements can be made of all the sphincter components. MRI with a phased array spine coil is as reliable as the more established endoanal MRI. A disadvantage is that normal values for sphincter dimensions not only differ between imaging techniques, but also between authors apparently using the same technique. When sphincter measurements are going to be used for clinical decision making or for further research the imaging techniques should be standardized as much as possible. 


\section{References}

1. Sultan $\mathrm{AH}$, Kamm MA, Hudson $\mathrm{CN}$, Thomas JM, Bartram $\mathrm{Cl}$. Anal-sphincter disruption during vaginal delivery. N Engl J Med 1993; 329:1905-1911.

2. Deen KI, Kumar D, Williams JG, Olliff J, Keighley MR. The prevalence of anal sphincter defects in faecal incontinence: a prospective endosonic study. Gut 1993; 34:685-688.

3. Abou-Zeid AA. Preliminary experience in management of fecal incontinence caused by internal anal sphincter injury. Dis Colon Rectum 2000; 43:198-202.

4. Meyenberger $C$, Bertschinger P. Zala GF, Buchmann P. Anal sphincter defects in fecal incontinence: correlation between endosonography and surgery. Endoscopy 1996: 28:217-224.

5. Law PJ, Kamm MA, Bartram Cl. Anal endosonography in the investigation of faecal incontinence. $\mathrm{Br} J$ Surg 1991; 78:312-314.

6. Sultan AH, Kamm MA, Talbot IC, Nicholls RJ, Bartram Cl. Anal endosonography for identifying external sphincter defects confirmed histologically. Br J Surg 1994; 81:463-465.

7. Romano G, Rotondano G. Esposito P. Pellecchia L, Novi A. External ana! sphincter defects: correlation between pre-operative anal endosonography and intraoperative findings. $\mathrm{Br} J \mathrm{~J}$ Radiol 1996: 69:6-9.

8. Law PJ, Kamm MA, Bartram Cl. A comparison between electromyography and anal endosonography in mapping external anal sphincter defects. Dis Colon Rectum 1990; 33:370-373.

9. Emblem R, Dhaenens G. Stien R, Morkrid L, Aasen AO, Bergan A. The importance of anal endosonography in the evaluation of idiopathic fecal incontinence. Dis Colon Rectum 1994; 37:42-48.

10. deSouza NM, Puni R, Kmiot WA, Bartram CI. Hall AS, Bydder GM. MAI of the anal sphincter. J Comput Assist Tomogr 1995; 19:745-751.

11. Vaizey CJ, Kamm MA, Bartram Cl. Primary degeneration of the internal anal sphincter as a cause of passive faecal incontinence. Lancet 1997; 349:612-615.

12. Kamm MA, Hoyle $\mathrm{CH}$, Burleigh $\mathrm{DE}$, et al. Hereditary internal anal sphincter myopathy causing proctalgia fugax and constipation. A newly identified condition. Gastroenterology 1991; 100:805-810.

13. Nieisen MB, Rasmussen $O O$, Pedersen JF, Christiansen J. Anal endosonographic findings in patients with obstructed defecation. Acta Radiol 1993; 34:35-38.

14. Briel JW, Stoker J, Rociu E, Lameris JS, Hop WC, Schouten WR. External anal sphincter atrophy on endoanal magnetic resonance imaging adversely affects continence after sphincteroplasty. Br J Surg 1999; 86:1322-1327.

15. Burnett SJ, Speakman CT, Kamm MA, Bartram Cl. Confirmation of endosonographic detection of external anal sphincter defects by simultaneous electromyographic mapping. Br J Surg 1991; 78:448450.

16. Enck P. Heyer T. Gantke B, et al. How reproducible are measures of the anal sphincter muscle diameter by endoanal ultrasound? Am J Gastroenterol 1997: 92:293-296.

17. Gold DM, Halligan S, Kmiot WA, Bartram Cl. Intraobserver and interobserver agreement in anal endosonography. Br J Surg 1999; 86:371-375.

18. Hussain: SM, Stoker J, Lameris JS. Anal sphincter complex: endoanal MA imaging of normal anatomy. Radiology 1995; 197:671-677.

19. Hussain SM, Stoker J, Zwamborn AW, et al. Endoanal MRI of the anal sphincter complex: correlation with cross-sectional anatomy and histology. J Anat 1996: 189:677-682.

20. deSouza NM, Puni R, Zbar A, Gilderdale DJ, Coutts GA, Krausz T. MR imaging of the anal sphincter in multiparous women using an endoanal coil : correlation with in vitro anatomy and appearances in fecal incontinence. AJR 1996; 167:1465-1471. 
21. Stoker J, Hussain SM, Lameris JS. Endoanal magnetic resonance imaging versus endosonography. Radiol Med (Torino) 1996; 92:738-741.

22. Rociu E, Stoker J, Eijkemans MJ, Schouten WF, Lameris JS. Fecal incontinence; endoanal US versus endoanal MR imaging. Radiology 1999; 212:453-458.

23. Aronson MP, Lee RA, Berquist TH. Anatomy of anal sphincters and related structures in continent women studied with magnetic resonance imaging. Obstet Gynaecol 1990; 76:846-851.

24. Fenner DE, Kriegshauser JS, Lee HH, Beart RW, Weaver A, Comella JL. Anatomic and physiologic measurements of the internal and external anal sphincters in normal fernales. Obstet Gynecol 1998; 91:369-374

25. Schafer A, Enck P. Furst G, Kahn T. Frieling T, Lubke HJ. Anatomy of the anal sphincters. Comparison of anal endosonography to magnetic resonance imaging. Dis Colon Rectum 1994; 37:777-781.

26. Beets-Tan RG, Beets GL, van der Hoop AG, et al. High-resolution magnetic resonance imaging of the anorectal region without an endocoil. Abdom Imaging 1999; 24:576-581.

27. Schafer A, Heyer T, Gantke B, et al. Anal endosonography and manometry: comparison in patients with defecation problems. Dis Colon Rectum 1997; 40:293-297.

28. Gantke B, Enck P. Schafer A, Lubke H. Morphology and function: sonographic, manometric and myographic evaluation of the anal sphincters. Dis Colon Rectum 1993; 36:1037-1041.

29. Nielsen MB, Pedersen JF. Changes in the anal sphincter with age. An endosonographic study. Acta Radiol 1996; 37:357-361.

30. Rociu E, Stoker J, Eijkemans MJC, Lameris JS. High resolution endoanal MRI; age and sex related variations in normal sphincter anatomy. Radiology; in press.

31. Eckardt VF. Jung B. Fischer B, Lierse W. Anal endosonography in healthy subjects and patients with idiopathic fecal incontinence. Dis Colon Rectum 1994; 37:235-242.

32. Sultan AH, Kamm MA, Hudson CN, Nicholls JP, Bartram Cl. Endosonography of the anal sphincters: normal anatomy and comparison with manometry. Clin Radiol 1994; 49:368-374.

33. Nielsen MB, Hauge C. Pedersen JF, Christiansen J. Endosonographic evaluation of patients, with anal incontinence: findings and influence on surgical management. AJR 1992; 160:771-775.

34. Shrout PE. Fleiss JL. Intraclass correlations: Uses in assessing rater reliability. Psychological Bulletin 1979: 86:420-428.

35. Nielsen MB, Hauge C, Rasmussen OO, Sorensen M, Pedersen JF, Christiansen J. Anal sphincter size measured by endosonography in healthy volunteers. Effect of age, sex, and parity. Acta Radiol 1992; 33:453-456.

36. Zetterstrom JP, Mellgren A, Madoft RD, Kim DG, Wong WD. Perineal body measurement improves evaluation of anterior sphincter lesions during endoanal ultrasonography. Dis Colon Rectum 1998; 41:705-713.

37. Stoker J, Rociu E. Endoluminal MR imaging of anorectal diseases. J Magn Reson Imaging 1999; 9:631-634.

38. Beets-Tan RGH, Beets GL, Gerritsen v.d. Hoop A, et al. Preoperative Magnetic resonance imaging of anal fistulas: does it really help the surgeon? Radiology 2000; in press.

39. Papachrysostomou M. Pye SD, Wild SR. Smith AN. Significance of the thickness of the anal sphincters with age and its relevance in faecal incontinence. Scand J Gastroenterol 1994; $29: 710$ 714.

40. Bumett SJ, Bartram Cl. Endosonographic variations in the normal internal anal sphincter. Int $\mathrm{J}$ Colorectal Dis 1991; 6:2-4.

41. Swash M, Gray A, Lubowski DZ. Nicholls RJ. Ultrastructural changes in internal anal sphincter in neurogenic faecal incontinence. Gut 1988: 29:1692-1698. 
42. Bartolo DC, Read NW, Jarratt JA, Read MG, Donnelly TC, Johnson AG. Differences in anal sphincter function and clinical presentation in patients with pelvic floor descent. Gastroenterology 1983; 85:68. 75.

43. Speakman CT, Hoyle CH, Kamm MA, et al. Abnormal internal anal sphincter fibrosis and elasticity in fecal incontinence. Dis Colon Rectum 1995; 38:407-410.

44. Schafer A, Enck P. Heyer T, Gantke B, Frieling T, Lubke HJ. Endosonography of the anal sphincters: incontinent and continent patients and healthy controls. Z Gastroenterol 1994; 32:328-331. 
Chapter 4

PREOPERATIVE MAGNETIC RESONANCE IMAGING OF ANAL FISTULAS: DOES IT REALLY HELP THE SURGEON?

Beets-Tan RGH, Beets GL, Gerritsen van der Hoop A, Kessels AGH, Vliegen RFA, Baeten CGMI, van Engelshoven JMA

Radiology 2000, in press 


\section{Abstract}

Purpose: To evaluate the accuracy of MRI with a quadrature phased array coil for the detection of anal fistulas and to evaluate the additional clinical value of a preoperative MRI as compared with surgery alone.

Material and Methods: Fifty-six consecutive patients with anal fistulas were preoperatively evaluated with a high spatial resolution MRI (HR MRI) at $1.5 \mathrm{~T}$ using a phased array coil. Twenty-four patients had a primary fistula, 17 a recurrent fistula and 15 a fistula associated with Crohn's disease. The information of the MRI was withheld from the surgeon until the end of the operation. The MR findings were then verified, and the surgical treatment was extended when required.

Results: MRI showed important additional information in 12/56 patients (21\%). In patients with Crohn's disease the benefit was $40 \%$ in patients with recurrent fistulas $24 \%$ and in patients with primary fistulas $8 \%$. The difference in benefit between patients with and without Crohn's disease, and between patients with a simple fistula versus the rest was statistically significant $(p<0.05)$. The sensitivity and specificity for the detection of fistula tracks were $100 \%$ and $86 \%$, for abscesses $96 \%$ and $97 \%$, for horseshoe fistulas $100 \%$ and $100 \%$, and for internal openings $96 \%$ and $90 \%$.

Conclusion: HR MRI is accurate for the detection of anal fistulas. HR MRI provides important additional information in patients with Crohn's fistulas and recurrent anal fistulas and is recommended in the preoperative workup of theșe patients. 


\section{Introduction}

The majority of anal fistulas have a single simple fistula track that is easily identified during operation, and surgical treatment is generally successful (1). However, 5-15\% of anal fistula tracks have a more complicated course with secondary extensions outside the anal sphincter, often with horseshoe extensions and ischiorectal and supralevator abscesses. These so-called complex fistulas are often associated with recurrent fistulas and fistulas associated with underlying Crohn's disease. Failure in accurate assessment of the secondary extensions during surgery may be responsible for the high rate of recurrences (2). Diagnostic studies that allow accurate preoperative information on the course of the primary track and its secondary extensions may improve the surgical treatment of these complex fistulas. Contrast fistulography is correct in only $16 \%$ of patients (3) and computed tomography usually fails to detect subtle fistula tracks and abscesses due to the inherent low soft tissue contrast resolution $(4,5)$. Anal and transrectal endosonography show better resolution of fistulas and their relation to the anal sphincter muscles (6). The limited field of view however is a considerable disadvantage and endosonography is reported not to be more accurate than examination under anaesthesia (7). Generally the imaging of perianal fistulas has been disappointing until the introduction of MRI.

The first reports on the accuracy of MRI for the detection and classification of fistulas date from 1992 and $1994(8,9)$. In these publications Lunniss et al. report a concordance rate between MR and surgical findings of $86-88 \%$. Since then many' papers have reported high accuracy figures for MRl in the detection of fistula tracks and secondiary extensions (10-15). It is however unclear whether these high accuracy figures also !ead to better surgery. A preoperative MRI obviously has no clinical value. when it identifies only lesions that are easily found by a standard surgical exploration. Some authors have suggested that MRI can identify extensions that can be missed at surgery $(8,9,11,15)$, but none of these studies had been designed to evaluate the additional clinical value of MRI. To our knowledge only two studies specifically addressed this issue and the authors found little benefit of MRI in the management of patients with perianal fistulas $(16,17)$. In the study by Scholefield et al. most patients had primary simple fistulas and their conclusion may therefore not be valid for patients with more complex fistulas. Zbar et al. found important additional information in only one out of eleven patients with complex fistulas imaged with an endoanal MAI technique. This technique however has the inherent disadvantage of a limited field of view. It is still unclear what the clinical impact of MRI can be for the management of complex fistulas when using an MR technique that offers a wide field of view.

The aim of this prospective study is to evaluate the accuracy of a preoperative high spatial resolution MRI with a phased array coil for the detection of anal fistulas. 
and more importantly to evaluate its additional clinical value as compared with surgery alone in a group of patients with a high prevalence of complex fistulas.

\section{Materials and Methods}

The study was approved by the local institutional review board. Between Januan 1998 and August 1999 all patients with the clinical diagnosis of an anal fistula whe were scheduled for a surgical exploration were considered candidates for inclusion Fifty-six patients (32 male and 24 female) with a mean age of 42 years (range 13-7! years) entered the study. After obtaining informed consent the patients underwent 8 preoperative HR MRI. There was no other preoperative imaging. The stud! population represents the spectrum of patients treated by a specialized colorecta surgical unit in our referral center. Fifteen patients had a primary or recurrent periana fistula with associated Crohn's disease (mean age $34 \mathrm{yrs}$, range 13-61). Of tht remaining forty-one patients without Crohn's disease (mean age 45 yrs, range 19-79 fwenty-four presented with a primary fistula, nine of whom had a peri-anal abscesi drained previously. Seventeen patients hadi undergone previous fistula surgery ani

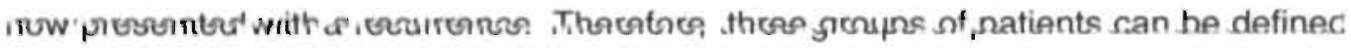
1) fifteen patients with Crohn's disease; 2) seventeen patients with a recurrent fistula; and 3) twenty-four patients with a primary fistula not associated with Crohn's disease. The first two groups will be referred to as patients with a "complex fistula", as opposed to the last group with a "simple fistula".

\section{Imaging Techniques}

MR imaging was performed at 1.5 Tesla (Gyroscan, Powertrak 6000, NT release 6.2.1. $23.0 \mathrm{mT} / \mathrm{m}$, rise time $0.2 \mathrm{~ms}$, slewrate $105 \mathrm{~T} / \mathrm{m} / \mathrm{s}$ Philips Medical Systems, Best, The Netherlands). A quadrature phased array spine coil was used. All subjects were positioned supine with their pelvis centered on the proximal end of the coil and in feet first position. Sequences used were a T1weighted, 2D, turbo spin echo (T1W TSE: TR/TE $656 / 10 \mathrm{msec}, 5$ echo train length, $8 \mathrm{~mm}$ slice thickness, $0.8 \mathrm{~mm}$ gap, 4 signal averages, 166x256 matrix, $25 \mathrm{~cm}$ FOV, $1.4 \mathrm{~min}$ acquisition time) and a T2 weighted, 2D, turbo spin echo (T2W TSE: TR/TE $3427 / 150 \mathrm{msec}, 25$ echo train length, $3 \mathrm{~mm}$ slice thickness, $0.3 \mathrm{~mm}$ gap, 8 signal averages, 175×256 matrix, $20 \mathrm{~cm}$ FOV, $2.64 \mathrm{~mm}^{3}$ voxel size, $6.5 \mathrm{~min}$ acquisition time). T2W sequences were obtained in sagittal, coronal and axial planes. The T1W TSE sequence was obtained in the axial plane and served for accurate planning of the coronal and axial T2W sequences as it was important to angle these planes exactly parallel and perpendicular to the long axis of the anal canal. Patients did not receive bowel preparation and no 
catheters were inserted in the anal canal during the procedure. The total scan time was 20 minutes.

\section{Image Evaluation}

The MR scans were prospectively evaluated by a radiologist experienced in reading pelvic MRI. The scans were evaluated for the presence and site of the primary fistula track, the presence and site of any external and internal opening, the presence and location of any abscess or horseshoe extension, for which a simple yes/no score was used. The fistula classification according to Parks was also given (18). Criteria for fistulas and fluid collections were based on shape and signal intensities as described in literature $(14,19)$. Mucin containing fistulas were recognized as tubular structures with a hyperintense signal surrounded by a hypointense rim on T2W TSE images. Non mucin containing fistulas were recognized as tubular structures with a hypointense signal on T2W images. Fluid filled cavities were hyperintense on T2W sequences surrounded by a border of hypointense signal. All findings were recorded on a standardized fistula operation sheet (fig 1) that was put in a sealed envelope without disclosing the information to the surgeon.

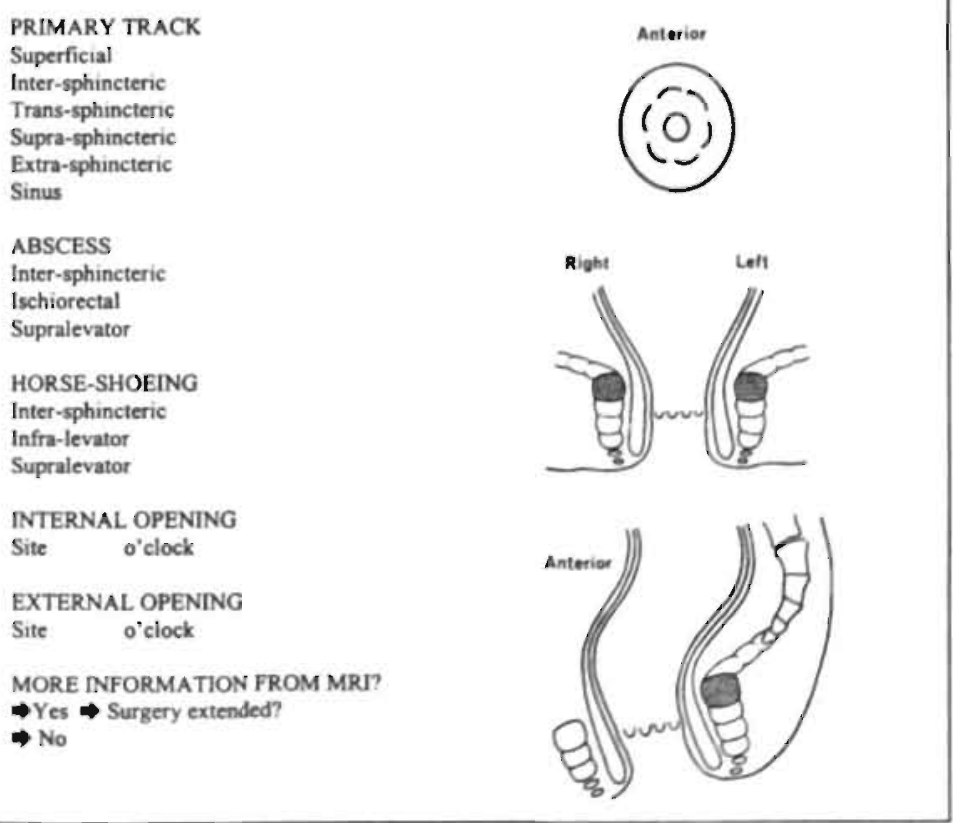

Figure 1. St Mark's hospital fistula operation sheet, based on the Park's classification. 


\section{Surgery}

The surgical procedure was performed by one of the three colorectal surgeons with experience in complicated fistula surgery. Surgical assessment was performed under general or locoregional anaesthesia with patients placed in lithotomy position. The extent of the disease was established by cannulating the fistulas with probes, and by laying open all primary tracks, extensions and abscesses. The presence and site of a primary fistula track, the site of any external and internal opening, the presence and location of any abscess or horseshoe extension and the Parks classification were recorded on a separate fistula operation sheet. With the patient still under anaesthesia and before performing the reconstructive surgery (i.e. mucosal advancement), the corresponding envelope with the MR findings was opened and the surgical results were compared with the MR results as recorded on the sheets. When MRI suggested more extensive disease, the surgeon went back to verify these additional MR findings. These findings were considered as true positive additional MR findings only when they were confirmed and led to additional surgical drainage.

\section{Interobserver and intraobserver variability}

To determine the inter- and intra-observer variability and to elucidate the sensitivity/ specificity profile of the MRI all the images were again evaluated, now retrospectively. This was done by three observers: the same radiologist who had evaluated the images prospectively (observer 1), a radiological resident (observer 2) and a surgeon experienced in reading pelvic MRI and not involved in the surgical treatment of any of the 56 patients (observer 3 ). The scans were evaluated for the same items as the prospective evaluation, but now a confidence level scoring system was used instead of a simple yes/no score. The following confidence levels were used: definitely absent, probably absent, possibly present, probably present and definitely present.

\section{Analysis and statistics}

The final surgical findings after correction by MRI were taken as the gold standard against which the MR findings were compared. A primary track, an abscess or horseshoe collection was considered as correctly identified by MRI when both the classification and location were in agreement with the findings at final surgery. An internal opening was considered as correctly identified when it was at the correct level in the anal canal and within the correct quadrant. The sensitivity, specificity, positive predictive value (PPV) and negative predictive value (NPV) were calculated for HR MRI in predicting the presence and exact location of primary tracks, abscesses, horseshoe fistulas and internal openings. The additional information of the preoperative MRI for each of the three groups of patients and for the three observers was compared with the Pearson Chi-Square test. 
Receiver operating characteristic (ROC) analyses for the detection of primary tracks, abscesses, horseshoe extensions and internal openings, were performed on the data generated by the confidence level scoring of the three observers. For each observer the accuracy of HR MRI for the detection of primary tracks, abscesses, horseshoe extensions and internal openings were measured by calculating the area under the ROC curve. Differences in accuracies between the three observers were evaluated by a pairwise comparison of the areas under the ROC curve $(20,21)$.

The interobserver agreement was measured with the linear weighted kappa statistic by pairwise comparison of the three observers for the detection of primary tracks, abscesses, horseshoe extensions and internal openings (22). For the intraobserver agreement the second reading with the confidence level score of observer 1 was dichotomized in order to compare it with the first reading using the yes/no score. The cut off point was between 'probably absent' and 'possibly present'. A non-weighted kappa statistic was used for this intraobserver agreement and the agreement on classification of fistulas. Kappa value can range from 0 (no agreement) to +1 (perfect agreement), and can be interpreted as poor (0), slight (0-.2), fair (.21$.40)$, moderate (.41-.60), substantial (.61-.80), and almost perfect (.81-1.00) (23).

Statistical analysis was performed using the software package SPSS ${ }^{\infty}$ for windows release 8.0 (SPSS, Chicago, IL, USA). P values less than 0.05 were considered significant.

\section{Results}

All patients tolerated the MRI examination and there were no motion artifacts. Overall MRI showed important additional information in 12 out of 56 patients $(21 \%)$. In the group of patients with Crohn's fistulas MRI showed additional information in 6/15 patients $(40 \%)$, in the group of patients with recurrent fistulas in $4 / 17$ patients $(24 \%)$, and in the group of patients with primary fistulas only $2 / 24$ patients $(8 \%)$. The difference in benefit from MRI between the group of the primary simple fistulas versus complex fistulas was statistically significant $(p<0.05)$, as was the difference in benefit between the group with Crohn's fistulas verșus non Crohn's fistulas $(p<0.05)$

The correlation of the MR findings, the findings at initial surgical exploration and the final surgical findings after correction by MRI are given in table 1 . The additional information from a preoperative MRI can be found in the column 'false negative for surgery'. MRI correctly detected all 56 primary tracks but misclassified 1 transsphincteric fistula as a sinus. MRI showed 8 false positive findings of a primary track. Two intersphincteric fistulas were missed at initial surgery but correctly predicted by MRI. MRI detected 25 out of 26 abscess collections. Seven supralevator abscess collections were missed at initial surgery but correctly predicted by MRI and 
Table 1: Correlation of MR findings with surgical findings for the detection and classification of primary tracks, abscesses and horseshoe extensions and for the detection of internal openings. The column "False Negative for Surgery" represents the additional information.

\begin{tabular}{|c|c|c|c|c|c|c|c|}
\hline \multicolumn{4}{|c|}{ MAI } & \multicolumn{3}{|c|}{ Surgery } & \multirow{2}{*}{$\begin{array}{l}\begin{array}{l}\text { Surgery (after } \\
\text { correction by } \\
\text { MRI) }\end{array} \\
\text { Gold Standard }\end{array}$} \\
\hline $\begin{array}{l}\text { Primary track } \\
\text { Classification }\end{array}$ & $\begin{array}{l}\text { True } \\
\text { Positive }\end{array}$ & $\begin{array}{l}\text { False } \\
\text { Positive }\end{array}$ & $\begin{array}{l}\text { False } \\
\text { Negative }\end{array}$ & $\begin{array}{l}\text { True } \\
\text { Negative }\end{array}$ & $\begin{array}{l}\text { True } \\
\text { Positive }\end{array}$ & $\begin{array}{l}\text { False } \\
\text { Negative }\end{array}$ & \\
\hline $\begin{array}{l}\text { superficial } \\
\text { submucosal }\end{array}$ & 3 & 0 & 0 & & 3 & 0 & 3 \\
\hline intersphincteric & 22 & 7 & 0 & & 20 & 2 & 22 \\
\hline transsphincteric & 20 & 0 & $1^{*}$ & & 21 & 0 & 21 \\
\hline suprasphincteric & 0 & 0 & 0 & & 0 & 0 & 0 \\
\hline extrasphincteric & 7 & 1 & 0 & & 7 & 0 & 7 \\
\hline sinus & 3 & $1^{\circ}$ & 0 & & 3 & 0 & 3 \\
\hline $\begin{array}{l}\text { Primary track } \\
\text { Detection }\end{array}$ & 56 & 8 & 0 & 48 & 54 & 2 & 56 \\
\hline
\end{tabular}

Abscess

Classification

\begin{tabular}{lcccccc}
\hline intersphincteric & 2 & 0 & 0 & 2 & 0 & 2 \\
ischiorectal & 3 & 1 & 1 & 4 & 0 & 4 \\
supralevator & 20 & 2 & 0 & 13 & 7 & 20 \\
\hline Abscess Detection & 25 & 3 & 1 & 83 & 19 & 7
\end{tabular}

Horse-shoeing

Classification

\begin{tabular}{|c|c|c|c|c|c|c|c|}
\hline $\begin{array}{l}\text { infralevator } \\
\text { (ischiorectal } \\
\text { fossa/intersphincteri } \\
\text { c) }\end{array}$ & 9 & 0 & 0 & & 6 & 3 & 9 \\
\hline supralevator & 5 & 0 & 0 & & 4 & 1 & 5 \\
\hline $\begin{array}{l}\text { Horse-shoeing } \\
\text { Detection }\end{array}$ & 14 & 0 & 0 & 98 & 10 & 4 & 14 \\
\hline $\begin{array}{l}\text { Internal Opening } \\
\text { Detection }\end{array}$ & 52 & 6 & 2 & 52 & 51 & 3 & 54 \\
\hline
\end{tabular}

" one transsphincteric fistula was misclassified as a sinus 
confirmed at extended surgery. MRI falsely predicted 3 abscesses. All 14 horseshoe collections were detected by MRI, including the four collections that the surgeons initially missed. MRI correctly identified 52 of the 54 internal openings. There were 6 false positive predictions of an enteric entry site. MRI correctly revealed an internal opening three times that was missed at initial surgical exploration. All three openings were in the lower rectum.

The sensitivity, specificity, PPV and NPV of HR MRI for the detection of the primary track, an abscess, a horseshoe collection and the internal opening are given in table 2.

Table 2: Accuracy of HR MRI for the detection of a primary track, abscess, horseshoe extension or internal opening.

\begin{tabular}{lcccc}
\hline & sensitivity & specificity & PPV & NPV \\
\hline primary track & $100 \%(56 / 56)$ & $86 \%(48 / 56)$ & $88 \%(56 / 64)$ & $100 \%(48 / 48)$ \\
abscess & $96 \%(25 / 26)$ & $97 \%(83 / 86)$ & $89 \%(25 / 28)$ & $99 \%(83 / 84)$ \\
horseshoe & $100 \%(14 / 14)$ & $100 \%(98 / 98)$ & $100 \%(14 / 14)$ & $100 \%(98 / 98)$ \\
Internal opening & $96 \%(52 / 54)$ & $90 \%(52 / 58)$ & $90 \%(52 / 58)$ & $96 \%(52 / 54)$ \\
\hline
\end{tabular}

The ROC curves and areas under the curves (AUC) for the detection and classification of anal fistulas, abscesses, horseshoe extensions and internal openings are shown in figure 2. The high areas under the ROC curves (all $>0.90$ ) indicate that the presence or absence of a fistula track, abscesses and horseshoe-extensions can be predicted with great accuracy. For the internai opening the area under the curve was somewhat lower, indicating that these are more difficult to predict. There was no statistically significant difference between the areas under the ROC curves for the three observers.

Table 3 shows the $\mathrm{x}$ analysis of interobserver and intraobserver agreement for the detection and classification of a fistula track, for the detection of an abscess, a horseshoe extension and an internal opening. Generally the interobserver agreement for the detection of fistula tracks, abscesses, horseshoes and internal openings were good to very good. There was more agreement for the detection of abscess and horseshoe extensions than for the detection of fistula tracks and internal openings. The intraobserver agreement of the experienced radiologist (observer 1) was very good with the best agreement achieved for the detection of horseshoe and abscess collections. For the classification of fistula tracks there was only moderate agreement between the observers but better intraobserver agreement for the radiologist. 


\section{Fistula}

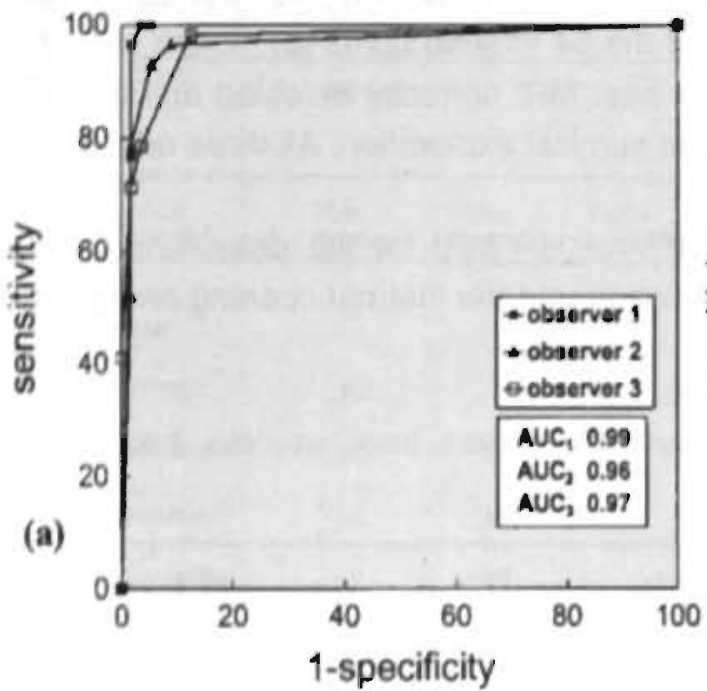

Horseshoe extension

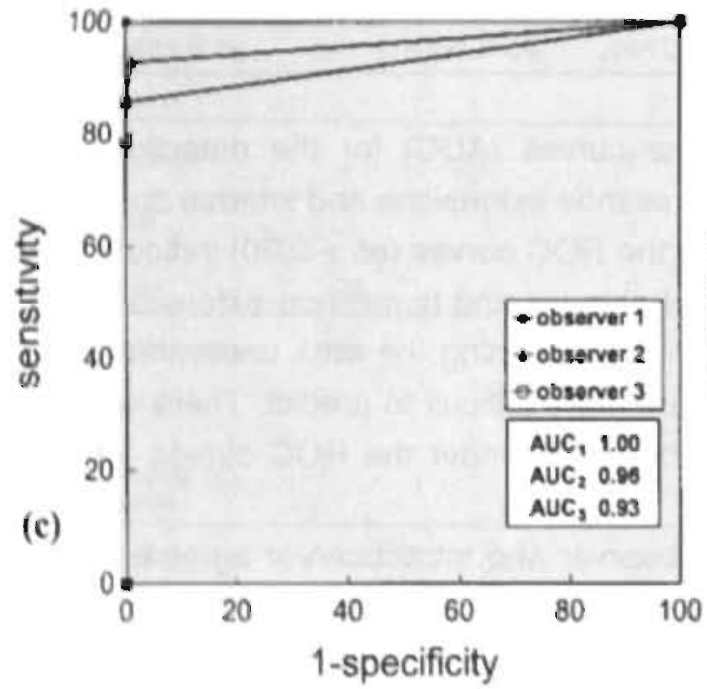

Abscess

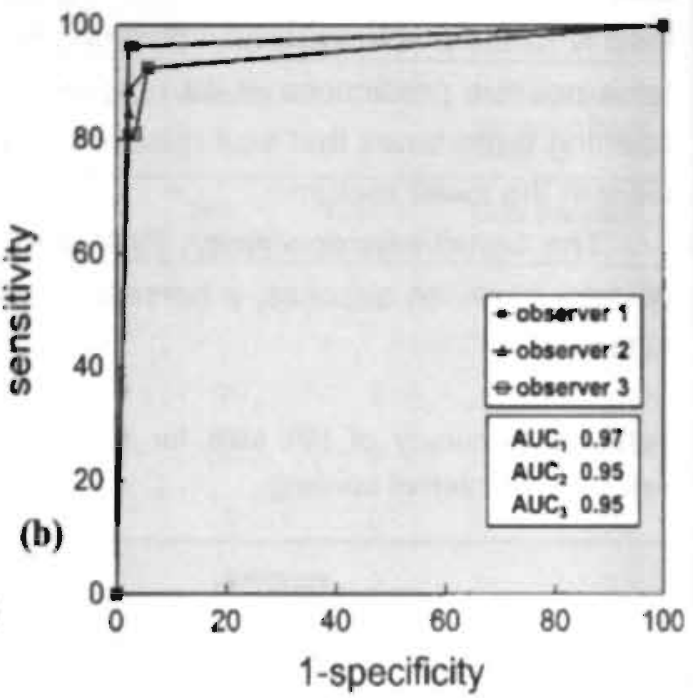

Internal opening

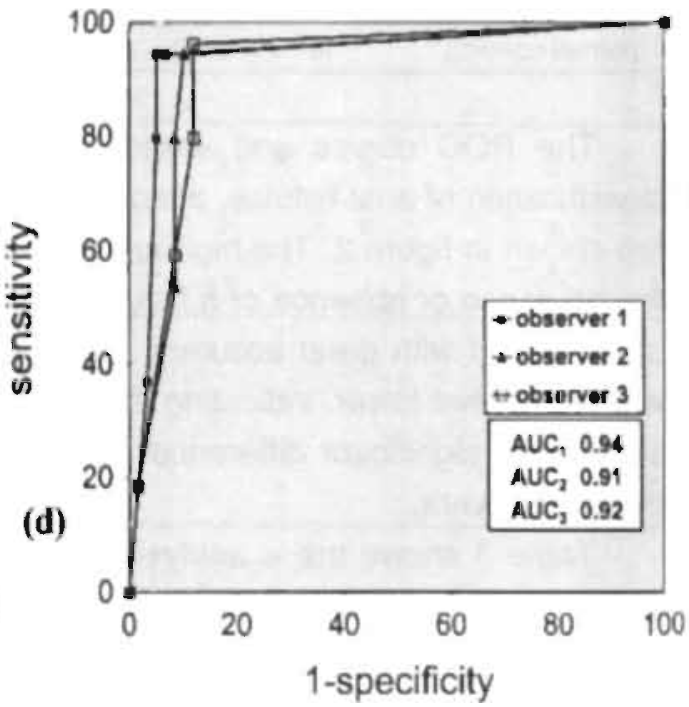

Figure 2. Receiver operating characteristic curves (ROC curves) and areas under the curves $\left(\mathrm{AUC}_{1,3}\right.$ ) of the 3 observers, for the detection of (a) fistula fracks, (b) abscesses, (c) horseshoe extensions and (d) internal openings.

The $95 \%$ confidence interval of the estimated areas under the curves (AUC) were: 0.97-1.00 for $\mathrm{AUC}_{1}, 0.92-1.00$ for $\mathrm{AUC}_{2}$ and 0.94-1.00 for $\mathrm{AUC}_{3}$ (fistula tracks) 0.92-1.00 for $A \cup C_{1}, 0.88-1.00$ for $A \cup C_{2}$ and 0.88-1.00 for $A \mathrm{CC}_{3}$ (abscesses) 1.00-1.00 for $A \cup C_{1}, 0.88-1.00$ for $\mathrm{AUC}_{2}$ and $0.82-1.00$ for $\mathrm{AUC}_{3}$ (horseshoe extensions) 0.89-0.99 for $A \cup C_{1}, 0.85-0.97$ for $\mathrm{AUC}_{2}$ and 0.86-0.97 for $\mathrm{AUC}_{3}$ (internal openings) 
Table 3a: Interobserver agreement for the detection and classification of fistula tracks, for the detection of abscesses, horseshoe extensions and internal openings with MRI.

\begin{tabular}{|c|c|c|c|}
\hline MRI & Observer & k & Confidence interval \\
\hline \multirow[t]{3}{*}{ Fistula detection } & 1 vs 2 & 0.85 & $0.79 * 0.91$ \\
\hline & 1 vs 3 & 0.75 & $0.67-0.83$ \\
\hline & 2 vs 3 & 0.80 & $0.73 \cdot 0.87$ \\
\hline \multirow[t]{3}{*}{ Fistula classification } & 1 vs 2 & 0.71 & $0.52 * 0.90$ \\
\hline & 1 vs 3 & 0.65 & $0.45 \cdot 0.85$ \\
\hline & 2 vs 3 & 0.60 & $0.38 \cdot 0.81$ \\
\hline \multirow[t]{3}{*}{ Internal opening } & 1 vs 2 & 0.76 & $0.67 \cdot 0.84$ \\
\hline & 1 vs 3 & 0.74 & $0.66 \cdot 0.82$ \\
\hline & 2 vs 3 & 0.76 & $0.69 \cdot 0.84$ \\
\hline \multirow[t]{3}{*}{ Abscess } & 1 vs 2 & 0.93 & $0.86-0.99$ \\
\hline & 1 vs 3 & 0.88 & $0.79 \cdot 0.97$ \\
\hline & 2 vs 3 & 0.93 & $0.86 * 1.00$ \\
\hline \multirow[t]{3}{*}{ Horseshoe } & 1 vs 2 & 0.90 & $0.80-1.00$ \\
\hline & 1 vs 3 & 0.88 & $0.74 \cdot 1.00$ \\
\hline & 2 vs 3 & 0.93 & $0.83-1.00$ \\
\hline
\end{tabular}

- confidence intervals have been truncated when the upper limit exceeds 1,0 .

Table 3b: Intraobserver agreement for observer 1 for the detection and classification of fistula tracks, for the detection of abscesses, horseshoe extensions and internal openings with MRI

\begin{tabular}{llc}
\hline MRI & $\kappa$ & Confidence interval \\
\hline Fistula detection & 0.87 & $0.69-1.00$ \\
Fistula classification & 0.75 & $0.59-0.91$ \\
Internal opening & 0.82 & $0.64-1.00$ \\
Abscess & 0.93 & $0.74 \cdot 1.00$ \\
Horseshoe & $\vdots$ & $0.82-1.00$ \\
\hline
\end{tabular}

"confidence intervals have been truncated whẹn the upper limit exceeds 1.0.

The radiologist's reading provided important additional information (not presented in table) in 12 out of 56 patients $(21 \%)$. The resident provided additional information in 10/56 (18\%) patients and the surgeon in $11 / 56(20 \%)$ patients. This difference was not statistically significant. 

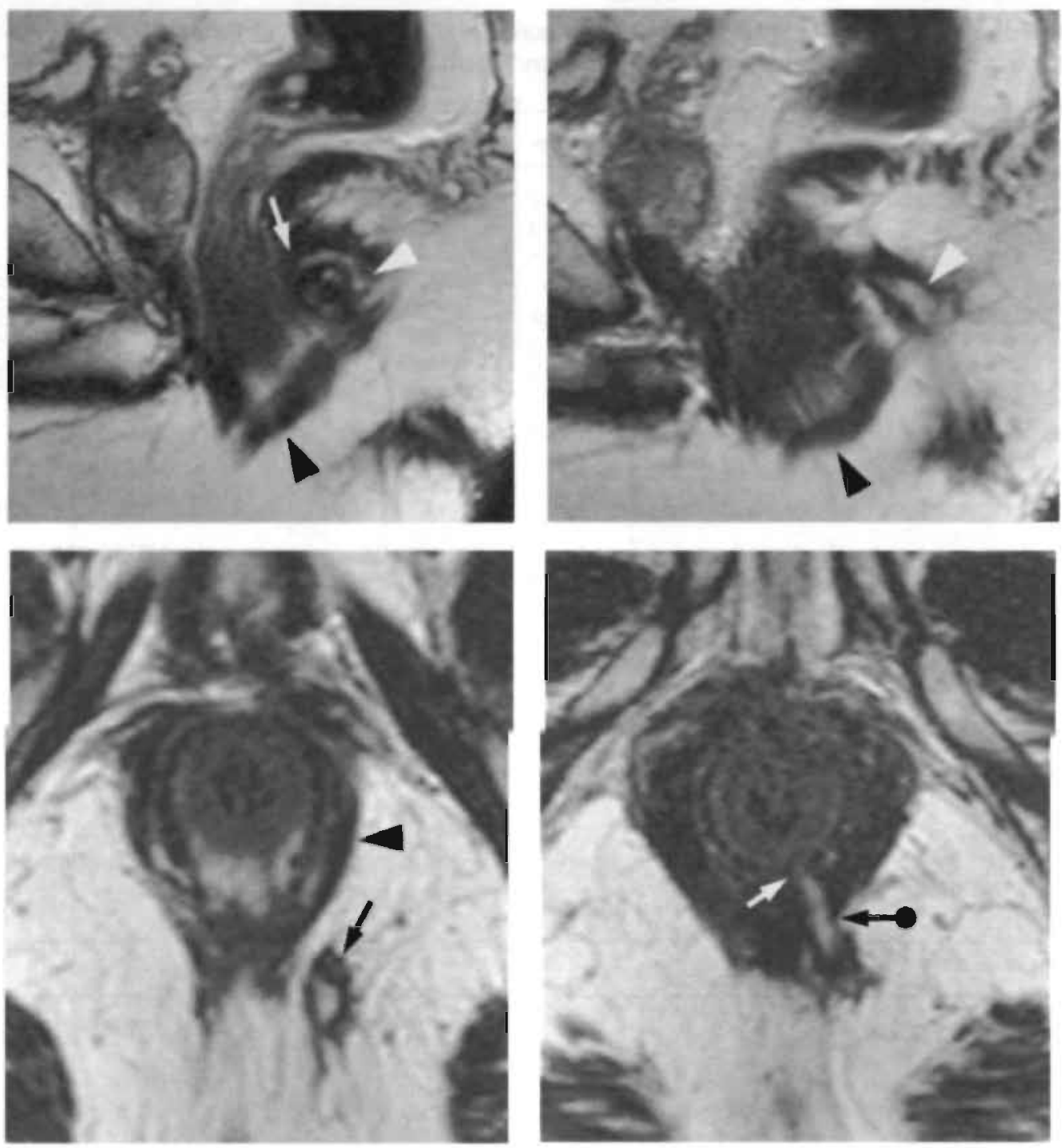

a

b

C

d

Figure 3. Transsphincteric fistula.(a,b) Sagittal T2W TSE. (TR/TE 3427/150) MR images show a hyperintense fistula track (white arrowhead) posterior to the anal canal (black arrowhead). The track crosses the sphincter muscles (white arrow) posteriorly.

(c,d) Axial T2W TSE (TR/TE 3427/150) MR images show the track (black arrow) first coursing laterodorsal from the left external sphincter muscles (black arrowhead), then crossing the external sphincter at a mid-anal level (bullet-arrow). A transsphincteric fistula track was diagnosed on MRI and confirmed at surgery. The internal opening was correctly predicted at 5 o'clock dorsally, at mid-anal level (white arrow). Note that the internal opening is not directly visualized but can only be inferred from the course and proximity of the fistula track in the sphincter muscle compartments. 


\section{Discussion}

This study evaluated the additional clinical value and the accuracy of a preoperative high spatial resolution MRI as compared with surgery alone in the treatment of anal fistula. Overall a preoperative MRI reveals important additional information in $21 \%$ (12/56) of patients. The benefit was most obvious for patients with Crohn's disease $(40 \%)$ and for patients with recurrent fistulas $(24 \%)$. In patients with a primary simple fistula the benefit was only $8 \%$.

The findings of our study seem to be in contrast with the results of a study with 27 patients by Scholefield et al., who found that a preoperative MRI was of little use in the surgical treatment of perianal fistula (16). This difference in outcome can be explained by the type of patients enrolled in both studies. The study of Scholefield et al. mainly consisted of patients with primary simple fistulas, whereas in the present study the percentage of complex fistulas was much higher $(57 \%)$. The $8 \%$ additional information from MRI in our group of patients with primary fistulas is in agreement with the $7.4 \%$ in their study, and the conclusion is therefore the same: preoperative diagnostic imaging is rarely needed in primary simple fistulas (fig. 3).

Fistulas associated with Crohn's disease and recurrent fistulas, the so-called complex fistulas, are often more difficult to evaluate during surgery because of the extensive secondary extensions and multiple perianal and perirectal abscess collections. When not identified and properly treated these extensions and abscesses may lead to recurrences (2). The recurrent nature of Crohn's perianal disease is well known, and a conservative treatment policy is often advocated (24). It is however debatable whether these recurrences are an inevitable consequence of the nature of Crohn's disease. It may be that many recurrences in Crohn's fistulas are simply due to overlooked abscesses and secondary extensions (25). The first study by Lunniss et al already suggested that MRI could detect more extensions than surgica! exploration (8). Our study convincingly shows that a preoperative MRI helps surgeons to identify all secondary extensions of a complex fistuia. The largest additional value was seen in the detection of supralevator abscesses and horseshoe collections (fig. 4,5). Secondary extensions are easily missed when located above the pelvic floor and in patients with multiple extensions. It is likely that the additional information obtained from MRI will improve the surgical results in patients with complex fistulas, although this can only be reliably established in a prospective randomized trial of surgery with and without a preoperative MRI.

\section{Accuracy}

Generally the sensitivity and specificity figures for the detection of fistula tracks, abscesses, horseshoe extensions and internal openings are in agreement with other reports $(9-12,14)$. Abscesses and horseshoe extensions were identified with a very high accuracy. Although the sensitivity for the detection of a primary track was high, the specificity is lower $(86 \%)$. Seven out of eight false positive predictions of fistula tracks were found to be healed fibrotic tracks at surgical exploration. In retrospect the 

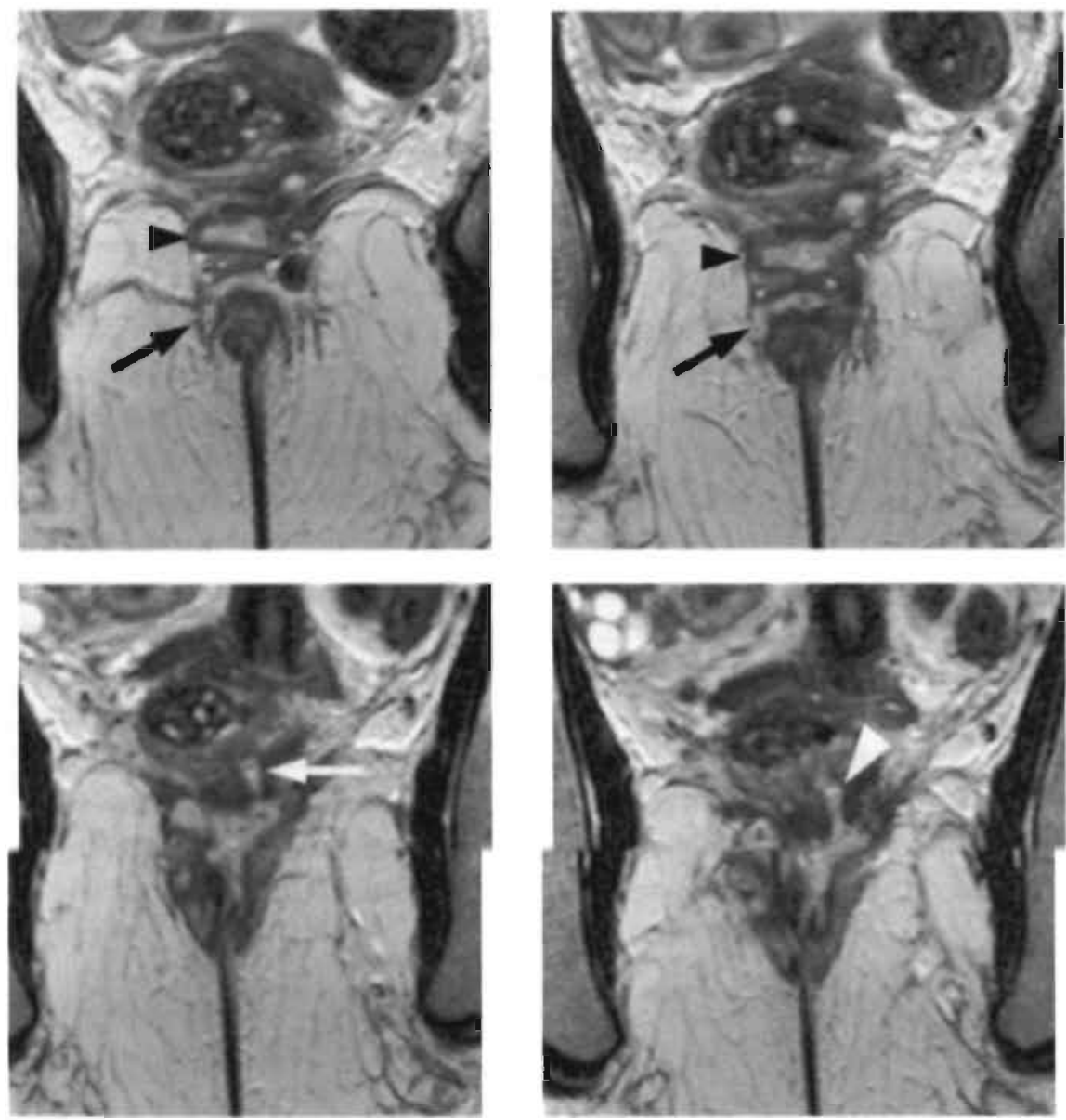

a

b

c

d

Figure 5. Horseshoe extension and rectal opening missed at surgery. (a,b,c,d) Coronal T2W TSE (TR/TE 3427/150) MR images from posterior(a) to anterior(d) show two hyperintense fluid collections crossing the midline, one located infralevator (black arrow) and the other at the level of the pelvic floor (black arrowhead). A secondary track (white arrow) ascends from the highest collection towards the rectal lumen. The rectal opening is clearly visualized (white arrow head). MRI suggested the presence of two horseshoe extensions at different levels with connection to the rectal lumen. The surgeons identified the lower horseshoe extension but missed the higher extensions, because the problem was thought to be solved by draining the lower extension. Due to the additional MR information surgical exploration was extended, the higher extensions found and properly treated.

the coil components in a synergy spine coil are arranged in quadrature. This, quadrature arrangement further improves the signal to noise ratio and even smaller voxel sizes can be generated. The $2.6 \mathrm{~mm}^{3}$ voxel size of the T2W TSE sequence in 


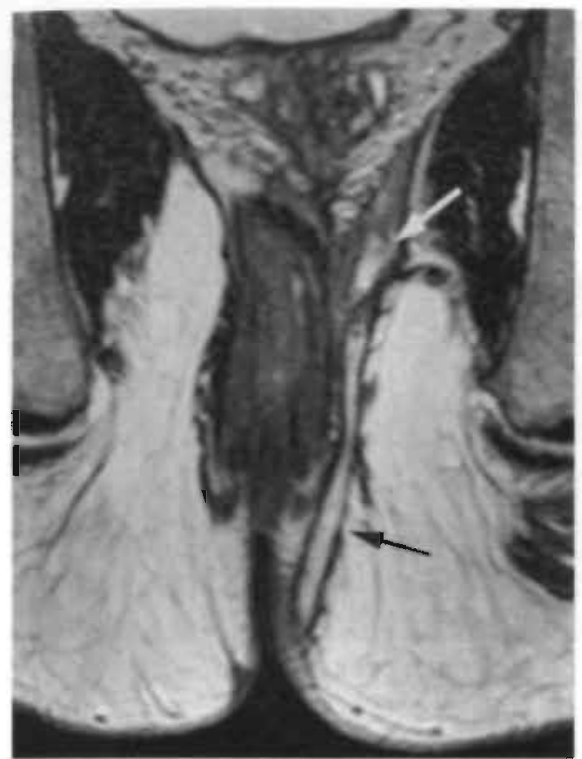

Figure 6a. True positive diagnosis of a fistula track. Coronal T2W TSE (TR/TE $3427 / 150)$ MR image shows a hyperintense tubular structure in the left ischiorectal fossa surrounded by a hypointense rim (black arrow), correctly diagnosed as an extrasphincteric fistula track. The track ends in a small abscess (white arrow) in the left pelvic floor.

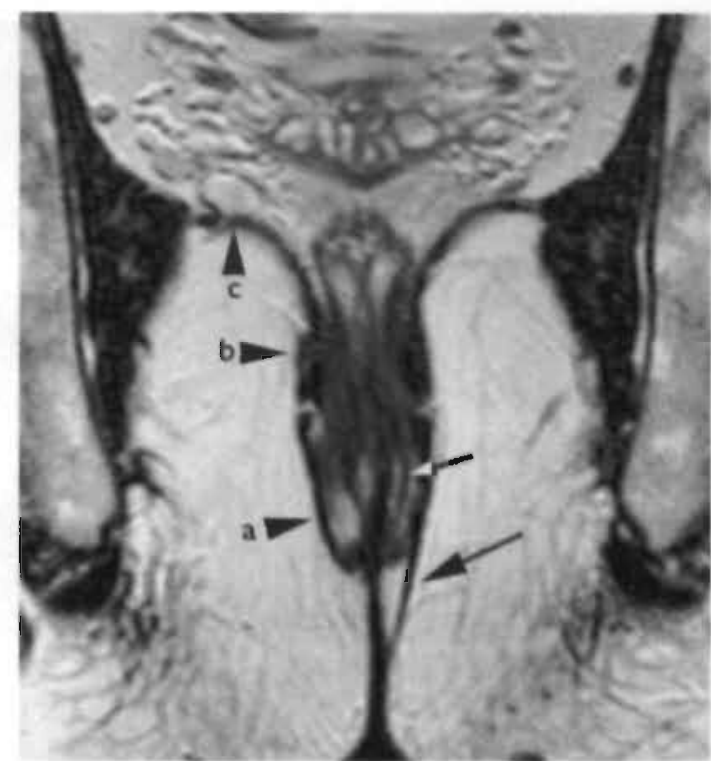

Figure 6b. False positive diagnosis of a fistula track. Coronal T2W TSE (TR/TE 3427/150) MR image shows a hypointense track (large arrow) coursing to the left sphincter muscle complex. This hypointense structure was mistaken for an inactive fistula track. At surgery only fibrosis was found. Note the detailed anatomy of the anal sphincter complex: the external sphincter muscle (arrowhead a), the puborectalis muscle (arrowhead b), the pelvic filoor muscles (arrowhead $c$ ) and the longitudinal muscle in the intersphincteric space (small arrow).

our study is substantially smaller than the 11 to $31 \mathrm{~mm}^{3}$ used in other techniques with a body coil $(9,14)$ or even a phased array coil $(12,32,33)$.

MRI with an endoanal coil can also generate images with a high spatial resolution because of the very high signal to noise ratio nearby the coil (34). However the results for fiștula imaging have been disappointing. A large study comparing endoanal MRI with body coil MRI found a surgical concordance rate of only $68 \%$ for the endoanal MRI compared with $96 \%$ for the body coil MRI (13). Another study showed a similar disappointing concordance rate of $64 \%$ (3.4). The main drawback of the endoanal MR technique is that it fails to show many secondary extensions that lie beyond the range of the coil $(12,13)$. De Souza et al. suggest that this problem can be overcome by combining the endoanal coil with a phased array coil(12). Our study shows that the combination of a high spatial resolution and a wide field of view can also be achieved with a quadrature phased array coil. The visualization of the perianal region and the entire pelvic region in one single investigation can be of particular value for patients with Crohn's anal fistulas who often present with simultaneous intrapelvic disease, as illustrated in figure 7. 

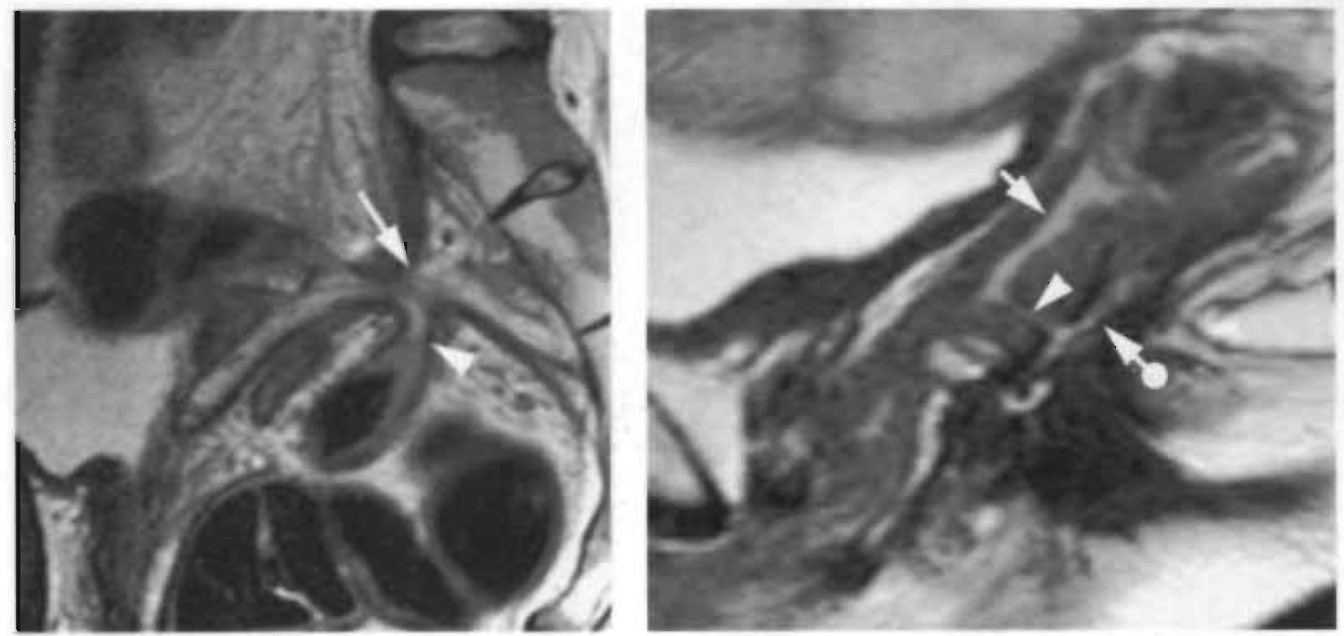

Figure 7. Intrapelvic disease in two patients with Crohn's perianal fistulas. (a) Sagittal T2W TSE (TR/TE 3427/150) MR image shows a presacral fluid collection (white arrow) with connection to the bladder (not shown on this slice) and to the sigmoid colon (white arrow head), correctly diagnosed as a presacral abscess which drains to the bladder and to the sigmoid.

(b) Sagittal T2W TSE (TR/TE 3427/150) MR image visualizes a fistula track (white arrowhead) connecting the rectal lumen (bullet arrow) with the vaginal lumen (white arrow) suggestive of a rectovaginal fistula and confirmed at surgery.

In conclusion high spatial resolution MRI with a quadrature phased array coil is accurate for the detection of perianal fistulas and provides important additional information on the secondary extensions in patients with complex fistulas. The largest additional value from a preoperative MRI was obtained in patients with complex fistulas associated with Crohn's disease and recurrences. HR MRi is therefore recommended in the preoperative work up of patients with Crohn's and recurrent anal fistulas. There is little place for MRI in the management of patients with primary simple fistulas.

\section{References}

1 Shouler PJ, Grimley RP. Keighley MR. Alexander-Williams J. Fistula-in-ano is usually simple to manage surgically. Int J Colorectal Dis 1986: 1:113- 115 .

2. Seow C. Phillips RK. Insights gained from the management of problematical anal fistulae at St. Mark's Hospital, 1984-88. Br J Surg 1991; 78:539-541.

3. Kuijpers HC. Schulpen T. Fistulography for fistula-in-ano. Is it useful? Dis Colon Rectum 1985: 28:103-104.

4. Yousem DM, Fishman EK, Jones B. Crohn disease: perirectal and perianal findings at CT. Radiology $1988 ; 167: 331-334$

5. Guillaumin E. Jeffrey RB, Jr., Shea WJ, Asling CW. Goldberg HI. Perirectal inflammatory disease: CT findings. Radiology 1986; 161:153-157. 
6. Van Outryve MJ, Pelckmans PA, Michielsen PP, Van Maercke YM. Value of transrectal ultrasonography in Crohn's disease. Gastroenterology 1991; 101:1171-1177.

7. Choen S, Burnett S, Bartram Cl, Nicholls RJ. Comparison between anal endosonography and digital examination in the evaluation of anal fistulae. Br J Surg 1991; 78:445-447.

8. Lunniss PJ, Armstrong P, Barker PG, Reznek RH, Phillips RK. Magnetic resonance imaging of anal fistulae. Lancet 1992; 340:394-396.

9. Lunniss PJ, Barker PG, Sultan AH, et al. Magnetic resonance imaging of fistula-in-ano, Dis Colon Rectum 1994; 37:708-718.

10. Barker PG, Lunniss PJ, Armstrong P, Reznek RH, Cottam K, Phillips RK. Magnetic resonance imaging of fistula-in-ano: technique, interpretation and accuracy. Clin Radiol 1994; 49:7-13.

11. Beckingham IJ, Spencer JA, Ward J, Dyke GW. Adams C, Ambrose NS. Prospective evaluation of dynamic contrast enhanced magnetic resonance imaging in the evaluation of fistula in ano. Br J Surg 1996; 83:1396-1398.

12. deSouza NM, Gilderdale DJ, Coutts GA, Puni R, Steiner RE. MRI of fistula-in-ano: a comparison of endoanal coil with external phased array coil techniques. J Comput Assist Tomogr 1998; 22:357-363.

13. Halligan S, Bartram Cl. MR imaging of fistula in ano: are endoanal coils the gold standard? A.JR Am J Roentgenol 1998; 171:407-412.

14. Spencer JA, Ward J. Beckingham IJ, Adams C, Ambrose NS. Dynamic contrast-enhanced MR imaging of perianal fistulas. A.JR Am J Roentgenol 1996; 167:735-741.

15. Spencer JA, Chapple K, Wilson D, Ward J, Windsor AC, Ambrose NS. Outcome after surgery for perianal fistula: predictive value of MR imaging. AJR Am J Roentgenol 1998; 171:403-406.

16. Scholefield JH, Berry DP, Armitage NC, Wastie ML. Magnetic resonance imaging in the management of fistula in ano. Int J Colorectal Dis 1997; 12;276-279.

17. Zbar AP, deSouza NM. Prospective comparison of endosonography, magnetic resonance imaging and surgical findings in anorectal fistula and abscess complicating Crohn's disease. Br J Surg 1999; 86:1093-1094.

18. Parks AG, Gordon PH, Hardcastle JD. A classification of fistula-in-ano. Br J Surg 1976; 63:1-12.

19. Hussain SM, Stoker J, Schouten WR. Hop WC, Lameris JS. Fistula in ano: endoanal sonography versus endoanal MR imaging in classification. Radiology 1996; 200:475-481.

20. Hanley JA, MCNeil BJ. A method of comparing the areas under receiver operating characteristic curves derived from the same cases. Radiology 1983; 148:839-843.

21. Hanley JA, MCNeil BJ. The meaning and use of the area under a receiver operating characteristic (ROC) curve. Radiology 1982; 143:29-36.

22. Cohen J. Weighted kappa: nominal scale agreement with provision for scaled disagreement or partial credit. Psycholl Buli 1968 1968; 70:213-230.

23. Landis JR, Koch GG. The measurement of observer agreement for categorical data. Biometrics 1977: 33:159-174.

24. Keighley MR, Allan RN. Current status and influence of operation on perianal Crohn's disease. Int J Colorectal Dis 1986; 1:104-107.

25. Gruwez JA, Christiaens; MR. Anat-perineal lesions in Crohn's disease. Ann Gastroenterol Hepatol (Paris) 1991: 27:251-255.

26. Van Beers B, Grandin C, Kartheuser A, et al. MAI of complicated anal fistulae: comparison with digital examination. J Comput Assist Tomogr 1994; 18:87-90. 
27. Orsoni P, Barthet M, Portier F, Panuel M, Desjeux A, Grimaud JC. Prospective comparison of endosonography, magnetic resonance imaging and surgical findings in anorectal fistula and abscess complicating Crohn's disease. Br J Surg 1999; 86:360-364.

28. Myhr GE, Myrvold HE, Nilsen G, Thoresen JE, Rinck PA. Perianal fistulas: use of MR imaging for diagnosis. Radiology 1994; 191:545-549.

29. Haggett PJ, Moore NR, Shearman JD, Travis SP, Jewell DP, Mortensen NJ. Pelvic and perineal complications of Crohn's disease: assessment using magnetic resonance imaging. Gut 1995; 36:407. 410.

30. Halligan S, Healy JC, Bartram CI. Magnetic resonance imaging of fistula-in-ano: STIR or SPIR? Br J Radiol 1998; 71:141-145.

31. Beets-Tan RG, Beets GL, van der Hoop AG, et al. High-resolution magnetic resonance imaging of the anorectal region without an endocoil. Abdom Imaging 1999; 24:576-581.

32. Laniado M, Makowiec F, Dammann F, Jehle EC, Claussen CD, Starlinger M. Perianal complications of Crohn disease: MR imaging findings. Eur Radiol 1997; 7:1035-1042.

33. Semelka RC, Hricak H, Kim B, et al. Pelvic fistulas: appearances on MR images. Abdom Imaging 1997; 22:91-95.

34. Hussain SM, Stoker J, Schutte HE, Lameris JS. Imaging of the anorectal region. Eur J Radiol 1996; 22:116-122. 


\section{Chapter 5}

\section{CAN MRI PREDICT THE CIRCUMFERENTIAL RESECTION MARGIN IN RECTAL CANCER SURGERY?}

Beets-Tan RGH, Beets GL, Vliegen RFA, Kessels AGH, Van Boven H, De Bruìne A, von Meyenfeldt MF, Baeten CGMI, van Engelshoven JMA

Accepted for publication in The Lancet 


\section{Abstract}

Background: To evaluate the accuracy of MRI with a phased array coil for preoperative staging of rectal cancer and to evaluate the accuracy for predicting the distance from the tumour to the circumferential resection plane in a total mesorectal excision (TME).

Methods: 76 patients with primary rectal cancer were preoperatively evaluated with MRI at $1.5 \mathrm{~T}$ (Philips, Gyroscan NT) using a phased array coil. Two observers independently scored the tumour for $T$ stage and measured the distance to the mesorectal fascia. MR findings were. compared with the final histology.

Findings: The MR T stage agreed with the histological stage in 63 of 76 patients ( $83 \%$ ) with a weighted $x$ of 0.77 for observer 1 , and in 51 of 76 patients $(67 \%)$ with a weighted $k$ of 0.52 for observer 2 . The intraobserver agreement on the $T$ stage was good $(x, 0.80)$ for observer 1 but moderate $(x, 0.49)$ for observer 2 . The interobserver agreement was only moderate $(x 0.53)$.

In 12 patients with an obvious. T4 tumour a margin of $0 \mathrm{~mm}$ to the mesorectal fascia was correctly predicted. Of the 29 patients in whom the pathologist reported a distance of at least $1 \mathrm{~cm}$ without specifying. observer 1 predicted a distance of at least $10 \mathrm{~mm}$ in 28 of the 29 patients, and observer 2 in 27 out of 29 patients. For the remaining 35 patients a regression curve with $95 \%$ prediction intervals was. constructed, and a histological distance of at least $1 \mathrm{~mm}$ can be predicted with high confidence when the measured distance on MRI is. at least $5 \mathrm{~mm}$. Both the intra- and interobserver reliability of the measurements were very high.

Conclusions: MRI with a phased array coil shows a moderate accuracy and reproducibility for predicting the $T$ stage of a rectal tumour. The clinically more important circumferential resection margin however can be predicted with high accuracy and consistency. This allows preoperative identification of patients at risk for a recurrence who will benefit from preoperative radiotherapy and/or more extensive surgery. 


\section{Introduction}

After a resection of the rectum for a rectal cancer local recurrences occur in 6 to $35 \%$ of patients ${ }^{1,2}$. Incomplete removal of the lateral spread of the tumour is now generally accepted as the cause of the majority of these recurrences ${ }^{3.4}$. Preoperative radiotherapy has proved to reduce the local recurrence rate from $27 \%$ to $11 \%$ in a large randomized trial ${ }^{5}$. At the same time attention has been directed at the surgical technique itself as a determinant for local recurrence rates ${ }^{6}$. Histological examination of resection specimens has shown that the incidence of local recurrence markedly decreases when a tumour free distance to the circumferential resection plane of more than $1 \mathrm{~mm}$ can be obtained ${ }^{6,7}$. Surgery by itself should therefore be able to achieve a local cure in virtually all T1 and T2 tumours, and in many T3 tumours. When the rectum and the surrounding mesorectal fat are removed by sharp dissection along the mesorectal fascia, a procedure called total mesorectal excision (TME), overall local recurrence rates are reported to be well below $10 \%$ without the help of radiotherapy ${ }^{6}$. Preoperative radiotherapy could then be limited to those patients in whom an involved or close resection margin is anticipated ". Paramount for this selection is a reliable preoperative imaging method that can predict the distance of the tumour to the circumferential resection plane of a TME specimen.

Many studies have reported the accuracy of imaging techniques in staging the local extension of rectal cancer. Endorectal ultrasound (EUS) is currently regarded as the most accurate imaging modality ${ }^{9}$ with accuracy rates for $T$ staging ranging from $64 \%$ to $94 \%^{9-13}$. The mesorectal fascia however is difficult to identify on ultrasound because of the limited soft tissue contrast resolution and limited field of view and it will therefore be difficult to predict the circumferential resection margin with EUS. The accuracy of conventional MR techniques for T staging has been disappointing due to insufficient spatial resolution ${ }^{14.15}$. With modern MR techniques, using endorectal and phased array coils, the spatial resolution is improved and with it the accuracy for predicting the $T$ stage ${ }^{16-25}$. The $T$ stage is an important prognostic factor, and can be used to select patients for adjuvant therapy. However, there is little benefit in the preoperative assessment of the $\mathrm{T}$ stage when the preoperative and operative management is not affected. Prediction of the circumferential resection margin on the other hand could be clinically useful to select patients for preoperative radiotherapy. In one MR study the mesorectal fascia was visualized but the authors did not attempt to predict the circumferential resection margin ${ }^{24}$. With a postoperative MRI of the resected specimen Blomqvist et al. were able to predict a tumour free lateral resection margin ${ }^{26}$. These two studies suggest that a preoperative MRI should be able to predict the circumferential resection margin. To our knowledge this has never been investigated.

The aim of this study is to evaluate the accuracy of a phased array MRI for preoperative staging of rectal carcinoma and to evaluate the accuracy for predicting the distance from the tumour to the circumferential resection plane in a total mesorectal excision. 


\section{Methods}

The study was approved by the local institutional review board. Between January 1998 and May 2000, 76 patients with a primary rectal cancer who were considered candidates for a curative or palliative resection entered the study. There were 58 men and 18 women, with a mean age of 65 years (range $30-85$ years). Sixty patients had a tumour that was clinically mobile in the pelvis while sixteen patients had a clinically fixed tumour. The relatively high number of patients with a fixed tumour is caused by the referral function of the surgical department. Of the sixty patients with a clinically mobile rectal cancer twelve participated in the Dutch randomized TME trial, seven of which were in the trial arm of a 5-day course of preoperative radiotherapy (25Gy) immediately followed by surgery. The five other patients that participated in the trial and the remaining 48 patients outside the trial did not receive preoperative radiotherapy. All sixty patients with a mobile rectal cancer had an MRI performed 1 to 3 weeks before surgery. Fifteen of the sixteen patients with a clinically fixed rectal cancer underwent a full 6-week course of radiotherapy and were operated on after a 4 - 6 week period in order to obtain a maximum tumour shrinkage effect of the irradiation. Eleven of the fifteen patients with a long course of radiotherapy had an MRI both before and after the irradiation. In the remaining five patients the radiotherapy had already been given without a baseline MRI and only a postradiotherapy MRI could be performed.

\section{imaging Techniques}

MR imaging was performed at 1.5 Tesla (Gyroscan, Powertrak 6000, NT release 6.2.1, $23.0 \mathrm{mT} / \mathrm{m}$, rise time $0.2 \mathrm{~ms}$, slewrate $105 \mathrm{~T} / \mathrm{m} / \mathrm{s}$ Philips Medical Systems, Best. The Nether!ands). The subjects were positioned supine and in feet first position with the pelvis ceritered on the proximal end of a quadrature phased array spine coil. Sequences used were a precontrast T1weighted, 2D, turbo spin echo (T1W TSE: TR/TE 656/10 msec, 5 echo train length, $8 \mathrm{~mm}$ slice thickness, $0.8 \mathrm{~mm}$ gap, 4 signal averages, 166x256 matrix, $25 \mathrm{~cm}$ FOV, 1.4 min acquisition time), a post Gadolinium contrast ( $0,2 \mathrm{ml} / \mathrm{kg}$. Magnevist, Schering. Berlin, Germany) enhanced T1 weighted, 2D, iurbo spin echo (T1W TSE: TR/TE $612 / 15 \mathrm{msec}, 5$ echo train length, $3 \mathrm{~mm}$ slice thickness, $0.3 \mathrm{~mm}$ gap, 8 signal averages, $383 \times 512$ matrix, $20 \mathrm{~cm}$ FOV, $0.6 \mathrm{~mm}^{3}$ voxel size, $9.0 \mathrm{~min}$ acquisition time) and a T2 weighted, 2D, turbo spin echo (T2W TSE: TR/TE $3427 / 150 \mathrm{msec}, 25$ echo train length, $3 \mathrm{~mm}$ slice thickness, $0.3 \mathrm{~mm}$ gap, 8 signal averages, $175 \times 256$ matrix, $20 \mathrm{~cm}$. FOV, $2.64 \mathrm{~mm}^{3}$ voxel size, $6.5 \mathrm{~min}$ acquisition time). The T1W precontrast sequence was obtained in axial plane and the first T2W TSE sequence in sagittal plane. These images were used to plan the T2W sequences in the axial and coronal planes. These axial and coronal planes were angled exactly perpendicular to the long axis of the rectal tumour. Post contrast. T1W sequences were performed in the axial and coronal planes. Patients did not receive bowel preparation, air insufflation or intravenous spasmolytic medication. The total scan time was approximately 45 minutes. 


\section{Image Evaluation}

The MR images were retrospectively evaluated by a radiologist experienced in reading pelvic MRI (observer 1: R.B.) and another radiologist experienced in reading MRI (observer 2: R.V.). Both observers performed a second reading for the T stage and the circumferential resection margin after at least a 10-week interval. At all times each observer was unaware of findings of the other observer and of the final histological diagnosis. In five patients the evaluation had to be carried out on a postradiotherapy MRI because there was no MRI performed before the start of the irradiation.

The T stage of the tumour was evaluated according to reported MR criteria ${ }^{21,24}$. The mesorectal fascia was defined as the fine linear structure enveloping the mesorectum, hypo intense on T2W and isointense on contrast enhanced T1W images (fig.1). For the prediction of the circumferential resection margin, the MR scans were evaluated for the shortest distance from the outermost part of the tumour to the adjacent mesorectal fascia at the level of the maximum depth of penetration of the tumour through the bowel wall (fig.2). This distance was measured on the axial images using an Easy Vision Workstation (Philips Medical Systems). If a tumour was staged T1 or T2 the shortest distance from the bowel wall at the level and site of the tumour to the adjacent mesorectal fascia was measured. When an extramural tumour

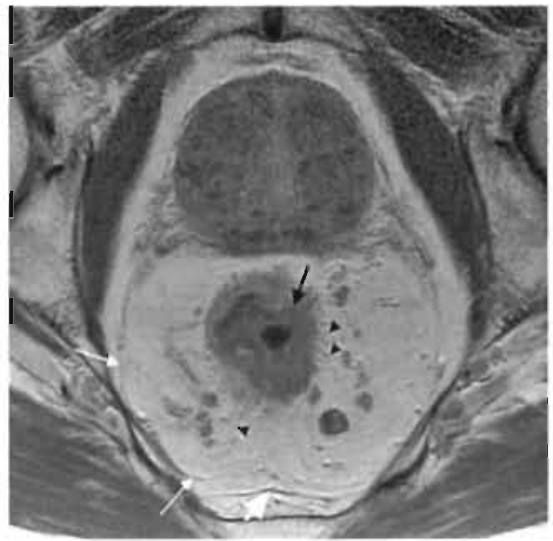

a

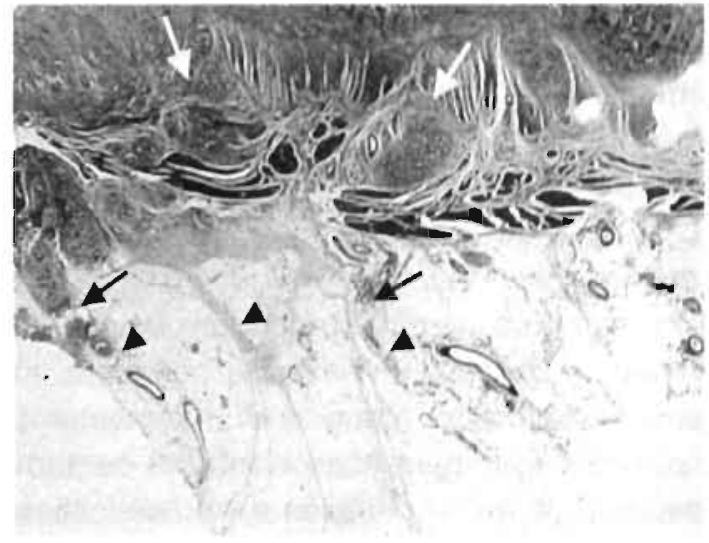

b

Figure 1. T3 rectal cancer in a 70-year-old male patient.

(a). Axial contrast enhanced T1W TSE (TR/TE 612/15 msec) MR image shows a tumour (black arrow) with extramural stranding (black arrowheads), suggesting a T3 rectal cancer. The mesorectal fascia (small white arrows) and the presacral fascia (white thick arrow) are well visualized. An enlarged lymph node is seen in the mesorectum posterolateral from the tumour. On these images a wide tumour free circumferential resection margin was predicted both when measured from the tumour as from the lymph node.

(b) Corresponding histology demonstrates that the spiculations consist of a desmoplastic reaction (black arrowheads). In contrast to the tumour shown in figure 6 these fibrotic strands contain tumour cells (black arrows). The tumour penetrates the muscular rectal wall (white arrows) and is therefore staged T3. The lymph node contained malignant cells and the distance to the fascia was more than $10 \mathrm{~mm}$. Figure 1 and 6 illustrate that it can be difficult with MRI to distinguish between desmoplastic reaction with and without tumour cells. 


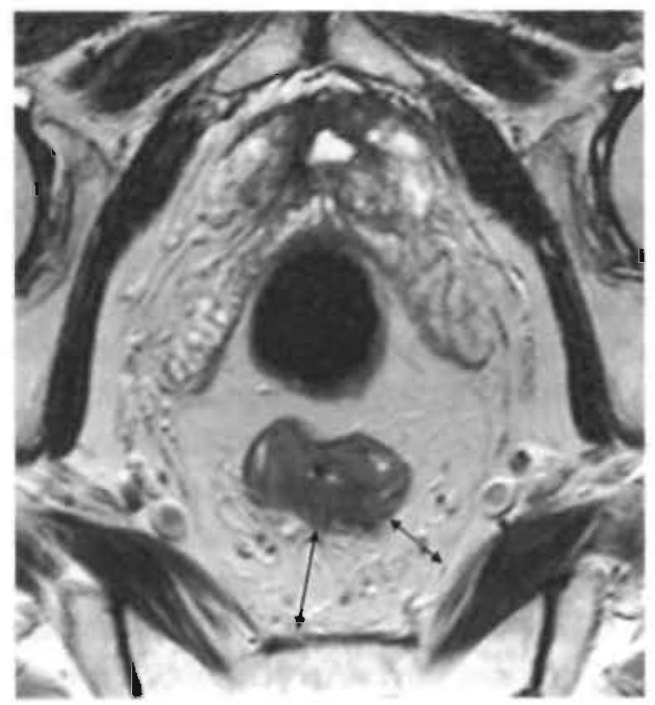

Figure 2. T3 rectal cancer with a wide margin in a 75 year-old-male patient.

Axial T2W TSE (TR/TE $3427 / 150 \mathrm{msec}$ ) MR image shows a tumour in the rectal wall, slightly hyperintense to the normal hypointense rectal muscular layer. Posteriorly the tumour penetrates the muscular wall and minimally invades the mesorectal fat. The distance (calipers) predicted by the 2 observers was 12 and $16 \mathrm{~mm}$. At histology a T3 tumour was confirmed with a distance of more than $10 \mathrm{~mm}$.

deposit or suspected lymph node in the mesorectum was located nearer to the mesorectal fascia than the primary tumour, the distance between the tumour deposit or lymph node and mesorectal fascia was considered the resection margin (fig.3). Tumour infiltration into the mesorectal fascia was defined as diffuse stranding from the tumour into this structure with loss of fat planes on contrast enhanced $\mathrm{T} 1 \mathrm{~W}$ images and T2W images (fig.4). When a tumour was staged T4 on MRI the mesorectal resection plane along the mesorectal fascia was by definition involved, and a distance of $0 \mathrm{~mm}$ was recorded.

\section{Surgery}

The standard surgical procedure was a total mesorectal excision, as described by Heald ${ }^{6}$. The rectum with the complete surrounding mesorectal fat is removed by sharp dissection along the mesorectal fascia. Forty-one patients underwent a sphincter-sparing resection of the rectum and 23 patients an abdominoperineal excision. In some patients the procedure was extended to include nearby structures like the posterior vaginal wall or the seminal vesicles when invasion was suspected on MRI and/or during surgery. Nine of the 76 patients underwent more extensive resectional surgery like pelvic exenterations and partial sacral resections. Three of the 76 patients underwent a trans anal full thickness resection of the tumour.

\section{Histology}

During the study period the histological evaluation was standardized according to the TME trial requirements. The circumferential resection plane of the specimen was inked and the specimen was opened anteriorly and fixed in formalin for 24 hours. The specimen was then sectioned transversely at $0.5 \mathrm{~cm}$ intervals. The extent of lateral tumour spread in the mesorectum was assessed macroscopically on each slice and the shortest distance between the tumour or lymph node and the mesorectal 


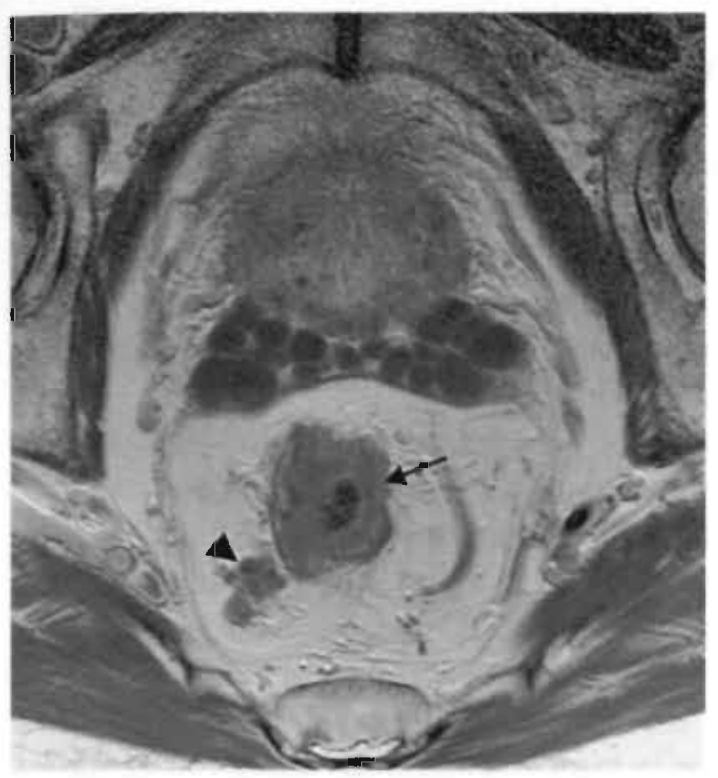

a

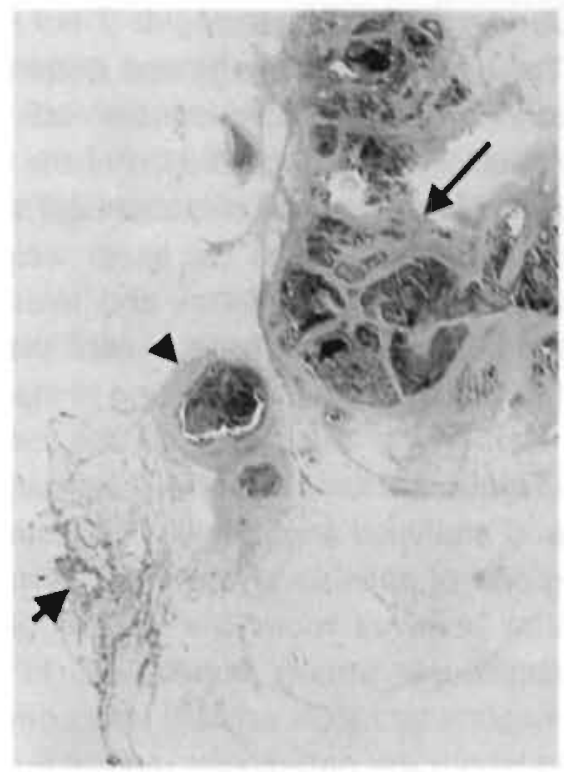

b

Figure 3. T3 rectal cancer with a tumour deposit in the mesorectum in a 60-year-old male patient.

(a). Axial contrast enhanced T1W TSE (TR/TE 612/15 msec) MR image shows the tumour in the rectal wall (black arrow) with minimal invasion in the mesorectum. A tumor deposit is seen in the mesorectum (black arrowhead). The distance should be measured between the mesorectal fascia and the tumour or the mesorectal deposit, whichever is nearest. Observer 1 predicted a distance of $5 \mathrm{~mm}$, while the less experienced observer 2 had ignored the deposit and measured a distance of $22 \mathrm{~mm}$ from the tumour to the mesorectal fascia.

(b). Corresponding histology confirms the extramural extension of the tumour (black arrow) and the mesorectal tumour deposit (black arrowhead), located only $2 \mathrm{~mm}$ from the inked resection plane (black thick arrow).

circumferential resection plane was measured. When at macroscopy the circumferential resection margin was suspected for close or invoived, the distance between the tumour and the circumferential inked resection plane was again measured at microscopy. When the circumferential resection margin exceeded 10 $\mathrm{mm}$ the distance was often not specified and the distance from tumour to the mesorectal fascia categorized as "more than $10 \mathrm{~mm}$ tumour free margin." When adjacent organs were resected, or when a resection was outside the mesorectal fascia, the relation of the tumour to the mesorectal fascia was reconstructed.

When a tumour response to radiotherapy was noted, the area of obvious tumour necrosis and fibrosis was considered as the former tumour extent. For the transanal resections the circumferential resection margin was recorded as more than $10 \mathrm{~mm}$, as these were all $\mathrm{T} 1$ lesions. 


\section{Analysis and statistics}

The histological T stage and distance to the mesorectal fascia were taken as the gold standard against which the MR findings were compared. The sensitivity and specificity for the prediction of the $\mathrm{T}$ stage was not calculated for $\mathrm{T} 1$ because of an insufficient number of patients. The agreement of the MR and histologicai $T$ stage was measured with the linear weighted kappa statistic ${ }^{27}$. This kappa statistic was also used for the intra- and interobserver agreement on the MR T stage of the tumour. All calculations except the intraobserver agreement were performed using the resuits of the first reading of the two observers.

For the evaluation of the circumferential resection margin, patients with an obvious T4 tumour on MRI as judged by the two observers were grouped together and analysed separately. The distance of the tumour to the mesorectal fascia in this group of patients is obviously zero, and a regression curve that includes this group that behaves more like a category than a continuous variable would result in a factitiously strong correlation. In this group of patients the obviously involved mesorectal fascia on MRI was correlated with the final histological outcome. Patients in whom the pathoiogist reports a distance to the circumferential margin of at least 1 $\mathrm{cm}$ without specifying, were evaluated separately. For all other patients both the predicted and histological distances are meaningful continuous variables, and a regression curve with $95 \%$ prediction intervals was constructed for both readings of each observer. The intra and interobserver reliability of the MRI measurements of the predicted resection margin was analysed with a one way ANOVA, and intraclass correlation coefficients were calculated ${ }^{28}$. The interobserver reliability was evaluated using only the results of the first reading of the two observers.

Statistical analysis was performed using the software package SPSS ${ }^{\oplus}$ for windows release 8.0 (SPSS, Chicago, IL, USA).

\section{Results}

All patients tolerated the MRI examination. Three scans showed motion artifacts, but the images, were of sufficient quality to allow a good evaluation.

\section{Tumour Staging}

The MF T staging results of observer 1 and 2 and the $T$ stages at final histology are given in table 1. For observer 1 the MRI stage agreed with the histological stage in 63 of 76 patients $(83 \%)$, with a weighted $\mathrm{k}$ of 0.77 (confidence interval $0.66-0.89$ ). The sensitivity and specificity for the prediction of T2 was $38 \%(5 / 13)$ and $94 \%(59 / 63)$, for T3 $95 \%(38 / 40)$ and $75 \%(27 / 36)$, and for T4 100\% (16/16) and $100 \%(60 / 60)$. For observer 2 the MRI stage agreed with the histological stage in only 51 of 76 patients $(67 \%)$ resulting in a weighted $\mathrm{k}$ of 0.52 (confidence interval $0.37-0.67$ ). The sensitivity and specificity for T2 was $46 \%(6 / 13)$ and $83 \%(52 / 63)$, for T3 $83 \%(33 / 40)$ and $61 \%$ $(22 / 36)$, and for T4. $75 \%(12 / 16)$ and $100 \%(60 / 60)$. 
The intraobserver agreement of observer 1 on the $\mathrm{T}$ stage was good with a $\mathrm{k}$ of 0.80 (confidence interval: $0.69-0.91$ ). The intraobserver agreement of observer 2 on the $T$ stage was only moderate with $a x$ of 0.49 (confidence interval: $0.34-0.65$ ). The interobserver agreement was moderate with a $x$ of 0.53 (confidence interval: $0.38-0.69$ ). The cross table on the basis of which the interobserver agreement was calculated is shown as table 2 .

Table 1a. T staging: MR findings of observer 1 compared with the final histological findings.

\begin{tabular}{cccccc} 
& pT1 & pT2 & pT3 & PT4 & Total \\
\hline MR T1 & 4 & 0 & 0 & 0 & 4 \\
MR T2 & 2 & 5 & 2 & 0 & 9 \\
MR T3 & 1 & 8 & 38 & 0 & 47 \\
MR T4 & 0 & 0 & 0 & 16 & 16 \\
\hline Total & 7 & 13 & 40 & 16 & 76
\end{tabular}

Table 1b. T staging: MR findings of observer 2 compared with the final histological findings.

\begin{tabular}{cccccc} 
& pT1 & PT2 & pT3 & PT4 & Total \\
\hline MR T1 & 0 & 0 & 0 & 0 & 0 \\
MR T2 & 4 & 6 & 7 & 0 & 17 \\
MR T3 & 3 & 7 & 33 & 4 & 47 \\
MR T4 & 0 & 0 & 0 & 12 & 12 \\
\hline Total & 7 & 13 & 40 & 16 & 76
\end{tabular}

Table 2. T staging: MR: findings of observer 1 compared with the MR findings of observer 2.

T1 (observer1) T2 (observer1) T3 (observer1) T4 (observer1) Total

\begin{tabular}{cccccc}
\hline T1 (observer2) & 0 & 0 & 0 & 0 & 0 \\
T2 (observer2) & 3 & 9 & 5 & 0 & 17 \\
T3 (observer2) & 2 & 5 & 35 & 5 & 47 \\
T4 (observer2) & 0 & 0 & 0 & 12 & 12 \\
\hline Total & 5 & 14 & 40 & 17 & 76
\end{tabular}




\section{Circumferential margin}

The mesorectal fascia was visualized on MR in all patients. The measured distances from the tumour to the mesorectal fascia on MRI ranged from 0 to $33 \mathrm{~mm}$ with a mean of $9.5 \mathrm{~mm}$.

In 12 patients there was an obvious T4 tumour on MRI as judged by the two observers. The anticipated distance to the fascia was by definition zero. At histology all 12 patients indeed had a T4 tumour, and by definition an involved mesorectal fascia. The MA image of an obvious T4 tumour is therefore 100\% predictive of an involved mesorectal fascia.

In 29 patients the pathologist reported a tumour free distance to the circumferential resection plane of at least $1 \mathrm{~cm}$ without specifying. In 28 of the 29 patients observer 1 correctly predicted a distance of at least $10 \mathrm{~mm}$. In one patient the predicted distance was $9 \mathrm{~mm}$. Observer 2 correctly predicted a distance of at least $10 \mathrm{~mm}$ in 27 of the 29 patients and of $4 \mathrm{~mm}$ and $9 \mathrm{~mm}$ in the other two patients.

In 35 patients there were meaningful figures that could be compared with a linear regression curve. The curves with the $95 \%$ prediction intervals for both observers are shown in figure 5. In one patient there was a discrepancy between the MR findings and the histological resection margin. This patient had a cancer of the upper rectum that extended anteriorly into the recto sigmoid colon. On MRI the anticipated distance was measured on the rectal component while at histology it was reported to be $5 \mathrm{~mm}$ on the anterior recto sigmoid colon, located intraperitoneally. From the clinical point of view the margin of this part of the tumour is less relevant, and this value was not used to construct the curve, although it is shown in the scatter plot. For observer 1 it can be calculated that a distance to the resection plane of at least $2 \mathrm{~mm}$ can be predicted with a $97.5 \%$ certainty when the measured distance on MRI is at least $5.7 \mathrm{~mm}$ and $5.1 \mathrm{~mm}$ for the first and the second reading, and a histological distance of at least $1 \mathrm{~mm}$ can be predicted with confidence when the measured MR distance is at least $4.8 \mathrm{~mm}$ and $4.1 \mathrm{~mm}$ respectively. For the first reading of observer 2 these figures are $5.2 \mathrm{~mm}$ for a margin of $2 \mathrm{~mm}$ and 4.2 for a margin of $1 \mathrm{~mm}$. The second reading of observer 2 resulted in a much wider confidence interval, because of a single interpretation error, shown in figure 3 and $5 \mathrm{~d}$. Apart from this one patient with an overestimated margin, all patients with a predicted distance of more than $5 \mathrm{~mm}$ had a histological margin of more than $2 \mathrm{~mm}$. In summary a tumour free margin of at least 1 $\mathrm{mm}$ can be predicted with a high degree of certainty when the measured distance on MRI is at least $5 \mathrm{~mm}$, and a tumour free margin of at least $2 \mathrm{~mm}$ when the MR distance is at least $6 \mathrm{~mm}$.

The intra and interobserver reliability of the MRI measurement was analysed with the intraclass correlation coefficient. The coefficient ranges from 0 to 1 , with a value of 0 indicating a completely unreliable measurement, and a value of 1 indicating a $100 \%$ reproducible measurement. The intraclass correlation coefficient of the two MR measurements is 0.99 for observer 1 and 0.91 for observer 2 . The intraclass correlation coefficient for the two different observers is 0.93 . These high intraclass correlation coefficients indicate both a very high intra and interobserver reliability. 


\section{Discussion}

This study evaluated the accuracy of a phased array MRI for preoperative staging of rectal carcinoma and the accuracy for predicting the distance from the tumour to the circumferential resection plane in a total mesorectal excision with the histological findings as the gold standard.

\section{T stage}

In the present study high spatial resolution MRI has an accuracy for predicting the T stage of $67 \%$ and $83 \%$, for two different readers. Although the phased array MR technique presented in this study shows an accuracy that is better than that with body coil MRI ${ }^{14.15}$ and CT ${ }^{29}$, it is far from perfect, and there is considerable intra- and interobserver variability. Most staging failures occurred in differentiating between T2 and minimal T3 lesions. It is difficult on MRI to distinguish spiculation in the perirectal fat caused by fibrosis only (stage pT2) from spiculation caused by fibrosis that contains tumour cells (stage pT3), as illustrated in figures 6 and 1. These findings seem to be in contrast with the results of Brown et al, who reported a remarkable $100 \%$ accuracy and complete agreement between two readers on the T stage of the tumour using a high spatial resolution MR technique ${ }^{24}$. The T stage is an important prognostic factor, and can be used to select patients for adjuvant therapy. However, there is little benefit in the preoperative assessment of the $T$ stage when the preoperative and operative management is not affected. It is in our opinion of far more practical importance to predict the circumferential resection margin of a TME resection specimen, as will be discussed in the following paragraph.

\section{The mesorectal fascia and circumferential resection margin}

Two major improvements in the management of rectal cancer have resulted in a reduction of the local recurrence rates. Postoperative and especially preoperative radiotherapy has shown to reduce the local recurrence rate by about $50 \%$, and has been proposed as the standard for all patients with rectal cancer ${ }^{5}$. Progress has also been made in refining the surgical procedure itself. The generally accepted standard procedure is the total mesorectal excision (TME), in which the rectum is removed by sharp dissection along the mesorectal fascia. This mesorectai fascia, or visceral rectal fascia, completely encloses the mesorectum, a distinct anatomical unit that comprises the rectum, the perirectal fat, the superior haemorrhoidal vessels, nerves and lymphatic vessels ${ }^{6}$. The rectal cancer, the lymph nodes and the perirectal tumour deposits are most often confined to the mesorectum, with the mesorectal fascia as a border for tumour growth. A complete removal of the mesorectum along the mesorectal fascia results in overall local recurrence rates of well below $10 \%$ without the help of radiotherapy ${ }^{6}$. The relative merits of both preoperative radiotherapy and total mesorectal excision in obtaining optimal local control are being tested in a randomized trial comparing TME surgery with and without preoperative radiotherapy ${ }^{30}$. It is anticipated that preoperative radiotherapy adds little to those 
tumours that can be removed with a wide tumour free circumferential resection margin, irrespective of the T stage. Patients with a close or involved resection margin however are at risk for a local recurrence, and preoperative radiotherapy could be restricted to these patients when they can be identified with preoperative imaging ${ }^{8}$. To achieve this it is essential to visualize the anticipated plane of the total mesorectal excision: the mesorectal fascia. Until recently these anatomical relations were not well appreciated by radiologists, as they were hardly visible on CT and conventional MRI.

Our results show that MRI with a phased array coil can accurately predict the distance from the tumour to the mesorectal resection plane. A tumour free margin of at least $1 \mathrm{~mm}$ can be predicted with a high degree of certainty when the measured distance on MRI is at least $5 \mathrm{~mm}$, and a tumour free margin of at least $2 \mathrm{~mm}$ when the MR distance is at least $6 \mathrm{~mm}$. To identify patients at risk for recurrence a cut off value of $5 \mathrm{~mm}$ therefore appears useful. Involved mesorectal fascia and T4 tumours can also be predicted with great accuracy.

A most important point for clinical practice is the high intra and interobserver agreement for the prediction of circumferential resection margin, as opposed to the moderate agreement for the prediction of T stage. In our study observer 1 was highly experienced and specialized in reading pelvic MRI, whereas observer 2 was a general radiologist with a non specialized MRI experience. Therefore the MR prediction of a tumour tree margin is more reliable and less dependent on the observer's experience than the MR prediction of the T stage.

There are some pitfalls in the MR prediction of the circumferential resection margin. Difficulties in image interpretation can lead to errors in the measurements of the lateral margins. This is especially true when mesorectal tumour deposits or enlarged lymph nodes are present (fig. 1 and fig.3). The pathologist measures the

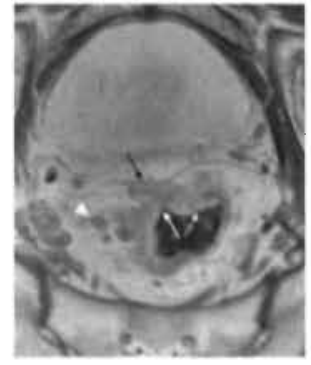

a

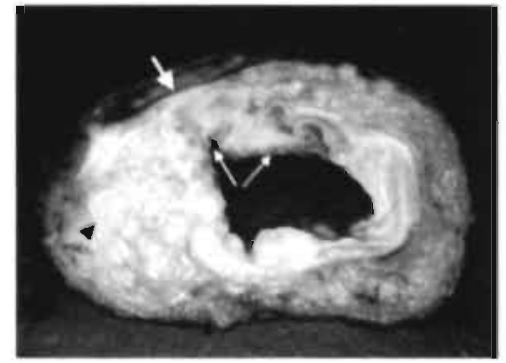

b

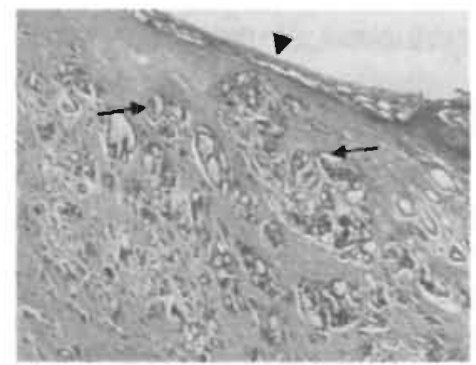

c

Figure 4. T3 rectal cancer with an involved mesorectal margin in a 73. year-old-male patient.

(a). Axial contrast enhanced. T1W TSE (TR/TE 612/15 msec) MR image shows an obvious T3 tumour (white arrows) invading the mesorectal fascia anteriorly(black arrow). The distance therefore was predicted $0 \mathrm{~mm}$. A lymph node (white arrowhead) is seen in the mesorectum.

(b). Corresponding macroscopic section shows the tumour (white arrows) invading the mesorectal fascia (white thick arrow). The distance was $0 \mathrm{~mm}$, as correctly predicted by MRI. The lymph node (black arrowhead) appears to be a metastatic node.

(c). Corresponding histological section shows tumour cells (black arrows) invading the mesorectal resection plane (black arrowhead). 


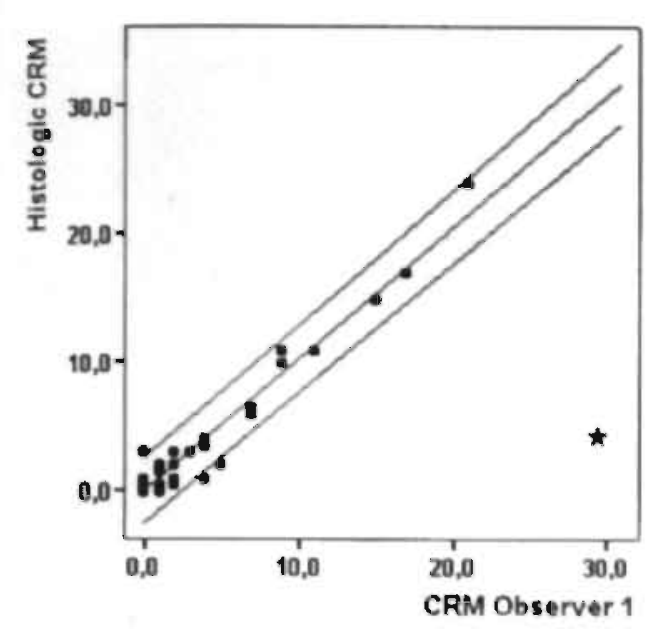

Figure 5a: Linear regression curve with $95 \%$ prediction interval for the circumferential resection margin (CRM in $\mathrm{mm}$ ) of the first res reading of observer 1 vs the histologic CRM rea $(a=-0.15, \beta=1.04)$

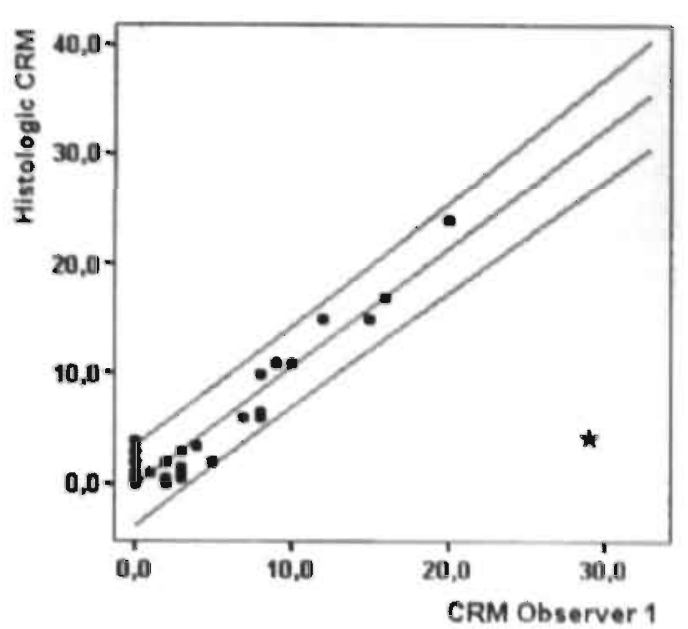

Figure 5b: Linear regression curve with $95 \%$ prediction interval for the circumferential resection margin (CRM in $\mathrm{mm}$ ) of the second reading of observer 1 vs the histologic CRM $(\alpha=-0.18, \beta=1.08)$

* This patient had a rectal tumor extending into the rectosigmoid junction. On MRI the resection margin was measured at rectal level, while at histology the closer resection margin was located at rectosigmoidal level. This case was excluded for the construction of the regression curve.

distance between the inked resection plane and the tumour or a metastatic lymph node or tumour deposit, whichever is nearest. However, it can be difficult on MRI to differentiate enlarged benign reactive lymph nodes from enlarged malignant nodes. In our study these interpretation difficulties resulted in a discrepancy between the predicted distance by different observers (fig. $5 \mathrm{~d}$ and fig.3).

Rectal cancer can provoke a desmoplastic reaction, a host reaction in which fibrous tissue is formed in and around the tumour ${ }^{31-33}$. Radiotherapy can also induce fibrosis, both in normal tissue and in areas of tumour necrosis. MRi cannot reliably distinguish between fibrosis with and without tumour cells $\mathrm{s}^{25}$. In patients with minimal T3 lesions and minimal fibrotic stranding this may lead to incorrect staging (fig. 1 and fig.6), with little consequence however for the prediction of the circumferential resection margin, as the margin in these patients is sufficiently wide. A desmoplastic reaction in patients with bulky T3 and advanced T4 rectal cancer, and fibrosis in patients who had radiotherapy can pose diagnostic problems when predicting whether the mesorectal fascia is involved or whether an organ is actually invaded. Whenever possible the assessment of the mesorecta! plane and organ invasion should be made on an MRI prior to radiotherapy. When there is no baseline pre radiotherapy MRI available, or when the tumour presents with a large desmoplastic 


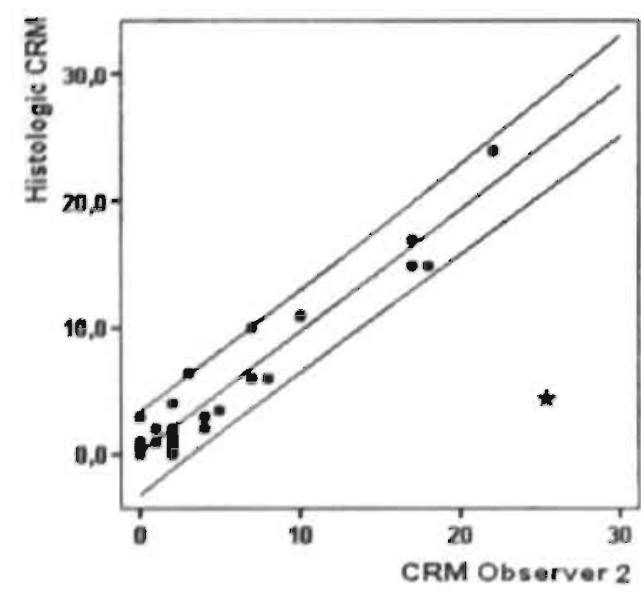

Figure 5c: Linear regression curve with 95\% prediction interval for the circumferential resection margin (CRM in $\mathrm{mm}$ ) of the first reading of observer 2 vs the histologic CRM $(\alpha=0.15, \beta=0.96)$

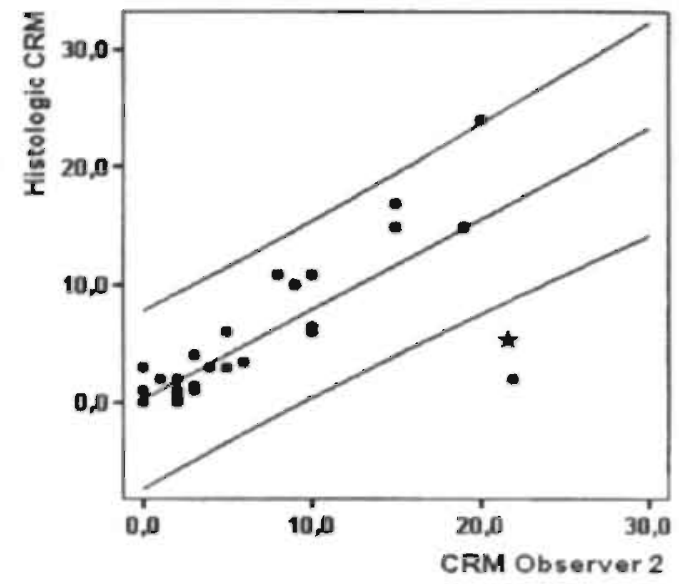

Figure 5d: Linear regression curve with 95\% prediction interval for the circumferential resection margin (CRM in $\mathrm{mm}$ ) of the second reading of observer 2 vs the histologic CRM $(\alpha=-0.27, \beta=0.76)$

The much wider confidence interval of the second reading is the result of a single interpretation error of observer 2: a tumor deposit in the mesorectum close to the mesorectal fascia was ignored and a wide CRM erroneously predicted on MRI.

* This patient had a rectal tumor extending into. the rectosigmoid junction. On MRI the resection margin was measured at rectal level, while at histology the closer resection margin was located at rectosigmoidal level. This case was excluded for the construction of the regression curve.

reaction, it may be prudent to consider the fibrotic area as suspected. It is up to the clinician how to deal with this fibrosis.

\section{MR technique}

The MR technique in our study makes optimal use of the high signal to noise ratio of an external coil, a phased array coil, in order to obtain images with a high spatial resolution. Endorectal MRI can generate images with even higher spatial resolution because of the very high signal to noise ratio nearby the coil. Although this results in a better identification of the rectal wall, the mesorectum, the mesorectal fascia and the surrounding pelvic structures are difficult to evaluate because of the limited field of view. Another drawback of the endorectal MR technique is that insertion of the coil can be difficult or impossible in patients with a stenosing rectal tumour. Failure rates for the insertion of the endorectal coil are as high as $40 \%^{34}$. Because of the 


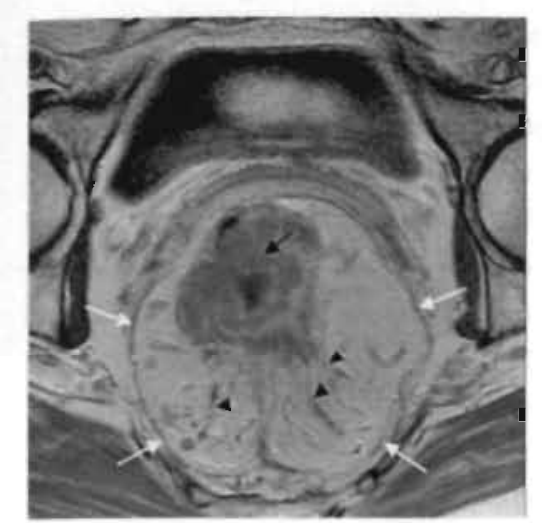

a

Figure 6. Histological T2 rectal cancer in a 67-year-old female patient, overstaged by MRI as a T3 tumor.

(a). Axial contrast enhanced T1W TSE (TR/TE 612/15 msec) MR image shows an enhancing mass in the laterodorsal rectal wall(black arrow). Because of the extramural stranding from the tumour into the perirectal fat (black arrowheads) the tumour was staged as T3. The mesorectal fascia is clearly visualized (white arrows). A tumour free margin of more than $10 \mathrm{~mm}$ was predicted.

(b). Corresponding histology demonstrates that the spiculations are formed by desmoplastic reaction from the tumour. The fibrotic strands (black arrowheads) contain no tumour cells. The tumour (black arrows) does not penetrate the muscular rectal wall (white arrow) and is therefore staged T2. Although MRI overstaged the tumour, it correctly predicted a histological distance from tumour to fascia of more than $10 \mathrm{~mm}$.

combination of a high spatial resolution and a wide field of view, the phased array MR technique used in this study enables a detailed visualization of both the entire mesorectum and the surrounding pelvic structures.

In conclusion phased array MPI shows only a moderate accuracy and reproducibility for the prediction of the $\mathrm{T}$ stage of a rectal tumour. The clinically more important circumferential resection margin, however, can be predicted with a high degree of accuracy and consistency. This allows preoperative identification of patients at risk for a recurrence who will benefit from preoperative radiotherapy and/or more extensive surgery.

\section{References}

1. Sagar PM. Pemberton Jل JH. Surgical management of loçally rẹcurrent rectal cancer. Br J Surg 1996:83(3):293-304.

2. Fielding LP, Stewart-Brown S, Dudley HA. Surgeon-related variables and the clinical trial. Lancet 1978;2(8093):778-9.

3. Quirke P, Durdey P. Dixon MF, Williams NS. Locall recurrence of rectal adenocarcinoma due to inadequate surgical resection. Histopathological study of lateral tumour spread and surgical excision. Lancet 1986;2(8514):996-9. 
4. Quirke P, Dixon MF. The prediction of local recurrence in rectal adenocarcinoma by histopathological examination. Int J Colorectal Dis 1988;3(2):127-31.

5. Improved survival with preoperative radiotherapy in resectable rectal cancer. Swedish Rectal Cancer Trial [see comments]. N Engl J Med 1997;336(14):980-7.

6. Heald RJ, Ryall RD. Recurrence and survival after total mesorectal excision for rectal cancer. Lancet 1986;1(8496):1479-82.

7. MacFarlane JK, Ryall RD, Heald RJ. Mesorectal excision for rectal cancer [see comments]. Lancet 1993;341(8843):457-60.

8. Wiggers $\mathrm{T}$, van de Velde $\mathrm{CH}$. Reduction \&quot;by half\&quot;. The need for standardised surgical technique in studies of radiotherapy for rectal cancer [editorial]. Eur J Surg 1999;165(5):407-9.

9. Rifkin MD, Ehrlich SM, Marks G. Staging of rectal carcinoma: prospective comparison of endorectal US and CT. Radiology 1989:170(2):319-22.

10. Hulsmans FJ, Tio TL, Fockens P, Bosma A, Tytgat GN. Assessment of tumor infiltration depth in rectal cancer with transrectal sonography: caution is necessary [see comments]. Radiology 1994:190(3):715-20.

11. Holdsworth PJ, Johnston D, Chalmers AG, et al. Endoluminal ultrasound and computed tomography in the staging of rectal cancer. Br J Surg 1988;75(10):1019-22.

12. Goldman S, Arvidsson H, Norming U, Lagerstedt U, Magnusson I, Frisell J. Transrectal ultrasound and computed tomography in preoperative staging of lower rectal adenocarcinoma. Gastrointest Radiol 1991; 16(3):259-63.

13. Scialpi M, Andreatta R, Agugiaro S, Zottele F, Niccolini M, Dalla Palma F. Rectal carcinoma: preoperative staging and detection of postoperative local recurrence with transrectal and transvaginal ultrasound. Abdom Imaging, 1993:18(4):381-9.

14. Hodgman CG, MacCarty RL, Wolft BG, et al. Preoperative staging of rectal carcinoma by computed tomography and $0.15 T$ magnetic resonance imaging. Preliminary report. Dis Colon Rectum 1986:29(7):446-50.

15. Butch RJ, Stark DD, Wittenberg J, et al. Staging rectal cancer by MR and CT. AJR Am J Roentgenol 1986:146(6): 1155-60.

16. Hadfield MB, Nicholson AA, MacDonald AW, et al. Preoperative staging of rectal carcinoma by magnetic resonance imaging with a pelvic phased-array coil. Br J Surg 1997;84(4):529-31.

17. Chan TW, Kressel HY, Mitestone B, et al. Rectal carcinoma: staging at MR imaging with endorectal surface coil. Work in progress. Radiology 1991:181(2):461-7.

18. de Lange EE, Fechner RE, Edge SB, Spaulding CA. Preoperative staging of rectal carcinoma with MR imaging: surgical and histopathologic correlation [see comments]. Radiology 1990:176(3):623-8.

19. Imai Y, Kressẹel HY, Saul SH, et al. Colorectal tumors: an in vitro study of high-resolution MR imaging. Radiology 1990;177(3):695-701.

20. Pegios W, Vogi J, Mack MG, et al. MRI diagnosis and staging of rectal carcinoma. Abdom Imaging 1996:21(3):211-8.

21. Schnall MD, Furth EE, Rosato EF, Kressel HY. Rectal tumor stage: correlation of endorectal MR imaging and pathologic findings [see comments]. Fadiology 1994:190(3):709-14.

22. Wallengren NO, Holtas S. Andren-Sandberg A. Preoperative staging of rectal carcinoma using double-contrast MR imaging. Technical aspects, and early clinical experiences. Acta Radiol 1996:37(5):791-8. 
23. Joosten FB, Jansen JB, Joosten HJ, Rosenbusch G. Staging of rectal carcinoma using MR double surface coil, MR endorectal coil, and intrarectal ultrasound: correlation with histopathologic findings. $J$ Comput Assist Tomogr 1995; 19(5):752-8.

24. Brown G. Richards CJ, Newcombe RG, et al. Rectal carcinoma: thin-section MR imaging for staging in 28 patients. Radiology 1999;211(1):215-22.

25. Beets-Tan RG, Beets GL, Borstlap AC, et al. Preoperative Assessment Of Local Tumor Extent in Advanced Rectal Cancer: CT or High Resolution MRI? Abdominal Imaging 2000;25:533-541.

26. Blomqvist L, Rubio C, Holm T, Machado M, Hindmarsh T. Rectal adenocarcinoma: assessment of tumour involvement of the lateral resection margin by MRI of resected specimen. Br $J$ Radiol 1999;72(853):18-23.

27. Cohen J. Weighted kappa: nominal scale agreement with provision for scaled disagreement or partial credit. Psycholl Bull 1968 1968;70:213-230.

28. Shrout PE, Fleiss JL. Intraclass correlations: Uses in assessing rater reliability. Psychological Bulletin 1979;86(2):420 - 428 .

29. Moss AA. Imaging of colorectal carcinoma [see comments]. Radiology 1989;170(2):308-10.

30. Kapiteijn E, Kranenbarg EK, Steup WH, et al. Total mesorectal excision (TME) with or without preoperative radiotherapy in the treatment of primary rectal cancer. Prospective randomised trial with standard operative and histopathological techniques. Dutch ColoRectal Cancer Group. Eur $J$ Surg 1999:165(5):410-20.

31. Krestin GP, Steinbrich W, Friedmann G. Recurrent rectat cancer; diagnosis with MR Imaging versus CT. Radiology 1988;168:307-311.

32. Lange de EE, Fechner RE, Wanebo HJ. Suspected recurrent recto sigmoid carcinoma after abdominoperineal resection: MR Imaging and Histopathologic findings. Radiology 1989;170:323-328.

33. Perna PJ, Bennett WF, Bova JG, Warman P. CT vs MFI in diagnosis of recurrent recto sigmoid carcinoma. J Comput Assist Tomogr 1994;18(2):256-261.

34. Hunerbein M, Pegios W, Vogl TJ, Felix R, Schlag PM. Endorectal MRI for staging rectal carcinoma. Preliminary experience. Br J Cancer 1995;72 (Suppl XXV):11. 
Chapter 6

PREOPERATIVE ASSESSMENT OF LOCAL TUMOR EXTENT IN ADVANCED RECTAL CANCER: CT OR HIGH RESOLUTION MRI?

Beets-Tan RGH, Beets GL, Borstlap ACW, Oei TK, Teune TM, von Meyenfeldt MF, van Engelshoven JMA

Abdominal Imaging 2000; 25: 533-541 


\section{Abstract}

Background: We compared high-resolution magnetic resonance imaging (MRI) with computed tomography (CT) in the assessment of tumor infiltration in surrounding structures for locally advanced primary and recurrent rectal cancer.

Methods: Twenty-six patients with operable, locally advanced rectal cancer (15 recurrent and 11 primary) were evaluated with conventional pelvic CT and 1.5-T high-resolution MRI with a quadrature phased-array coil. The images were scored for invasion of nine neighboring pelvic structures, and the results were compared with surgical and histologic findings.

Results: A total of 234 structures in 26 patients was evaluated for tumor invasion. For MRI the, sensitivity was $97 \%$ and the specificity $98 \%$; for CT, the sensitivity was $70 \%$ and the specificity was $85 \%$. The difference in performance was statistically significant $(p<0.001)$. The failure most frequently made on CT was the false-positive prediction of pelvic floor and piriform muscle invasion (14), whereas MRI showed only four false-positive predictions. MRI correctly predicted all four cases of sacral bone invasion, three of which were missed by CT. MRI was accurate in 20 patients $(80 \%)$ and CT in only five patients (19\%).

Conclusion: High-resolution MRI using a quadrature phased-array coil is highly accurate and superior to CT in predicting tumor infiltration in surrounding structures for locally advanced primary or recurrent rectal cancer and is recommended in the preoperative work-up of these tumors. 


\section{Introduction}

Ten to twenty percent of rectal tumors are locally advanced, with fixation to surrounding pelvic organs. In these cases, the patient's best chance for a local cure is a radical en bloc resection of the tumor and the surrounding invaded structures [1]. Accurate and detailed anatomic information on tumor extent is essential to plan the optimal surgical procedure and to identify those patients who may benefit from neoadjuvant radiotherapy. The same holds true for locally recurrent rectal cancer. A local recurrence after resection of a primary rectal cancer occurs in $20-30 \%$ of patients, and in more than half of these patients, the recurrence is isolated [2]. Survival rates of approximately $25 \%$ can be obtained when a radical excision of the tumor can be performed [2]. Detailed anatomic knowledge of the location of the tumor and invasion of the neighboring structures is essential for optimal treatment planning [3].

Although many studies have described the accuracy of computed tomography (CT) and magnetic resonance imaging (MRI) for predicting the depth of bowel wall and lymph node invasion [4-12], only few have addressed the problems of predicting tumor infiltration in neighboring organs for primary rectal cancer [13,14]. For recurrent rectal cancer, most studies have focused on the detection of suspected tumor masses [15-25] and less on the invasion of adjacent structures [16,26]. To our knowledge, there has been only one report of a comparative study between CT and MRI that has specifically addressed this problem but with only a limited number of patients [26].

The aim of the present study was to compare high-resolution MRI (HR MRI) [27] with CT in the assessment of tumor infiltration in surrounding structures for locally advanced primary and recurrent rectal cancer.

\section{Materials and methods}

Between January 1998 and April 1999, patients with locally advanced primary or recurrent rectal cancer were evaluated for inclusion in the study. A rectal tumor was considered locally advanced when it was fixed to surrounding structures on physical examination or on a pelvic CT scan. Patients were included in the study when they were considered candidates for a curative resection. This decision was made by the surgical team on the basis of the performance status of the patient and on the basis of the physical examination and $C T$ imaging. Patients with distant metastases at staging examination were excluded. During the study period, 26 patients met these criteria and were included. Eleven patients had biopsy-proven primary rectal cancer, and 15 patients had local recurrence of a previously resected rectal cancer. Recurrent rectal cancer was proved by biopsy in 14 of 15 patients and was highly suspected in one patient because of progressive symptoms of pain, a rising CEA level, and a progressive pelvic mass on postoperative follow-up CT. The mean interval between resection of the primary tumor and the diagnosis of the recurrence 
was 2 years (range $=0.5-3.5$ years). The mean age of the patients was 58 years (range $=29-85$ years). All patients underwent an HR MRI and had surgery. Nineteen patients underwent an HR MRI of the pelvis within 2 weeks after the CT scan, followed by immediate surgery in 12 patients and by a full 6-week course of preoperative radiotherapy in seven patients. Two to four weeks after the radiotherapy, these seven patients had a second HR MRI before surgery. Seven patients were referred to our hospital during or after preoperative radiotherapy; in these patients, only a postradiotherapy MRI could be performed, leading to an interval of 8-10 weeks between the original CT and our MRI.

\section{Imaging techniques}

Conventional CT scans were performed according to a pelvic protocol (Siemens Somatom Plus CT, Erlangen, Germany or Philips Tomoscan CX-S 500, Philips Medical Systems, Best $\sim$ The Netherlands). Contiguous axial 8- or 10-mm sections were obtained after oral (Télébrix Gastro, Guerbet, Aulnay-Sous-Bois, France) and intravenous contrast administration (90-120 cc; Omnipaque, Nycomed Ireland LTD, Cork, Ireland; flow rate $=2 \mathrm{ml} / \mathrm{s}$, scan delay $=40-60 \mathrm{~s}$ ). Bone windows were obtained for evaluating bone invasion. MRI was performed at $1.5 \mathrm{~T}$ (Gyroscan, Powertrak 6000 , NT release 6.2.1, $23.0 \mathrm{mT} / \mathrm{m}$, rise time $0.2 \mathrm{~ms}$, slew rate $105 \mathrm{~T} / \mathrm{m} / \mathrm{s}$; Philips Medical Systems). A quadrature phased-array spine coil was used because a torso or pelvic phased-array coil was not available with our MRI system. All subjects were positioned supine, with the pelvis centered on the proximal end of the coil and feet in first position. Sequences used were a pre- and post-gadolinium contrast $(0.2 \mathrm{~mL} / \mathrm{kg}$; Magnevist, Schering, Berlin, Germany)-enhanced T1-weighted, two-dimensional, turbo spin echo (T1W TSE; repetition time/echo time [TR/TE] of $612 / 15 \mathrm{~ms}, 5$ echo train length [ETL], 3-mm slice thickness, 0.3-mm gap, eight signal averages, $383 \times$ 512 matrix, 20-cm field of view [FOV], 0.6- $\mathrm{mm}^{3}$ voxel size, 9.0-min acquisition time) and T2-weighted, two-dimensional, turbo spin echo (T2W TSE; TR/TE of 3427/150 ms, 25 ETL, 3-mm slice thickness, 03-mm gap, eight signal averages, $175 \times 256$ matrix, 20-cm FOV, 2.6- $\mathrm{mm}^{3}$ voxel size, 6.5-min acquisition time). For all patients, T1W precontrast sequences were obtained in the axial plane, and T2W images were obtained in the axial and sagittal planes. For patients with advanced primary rectal cancer, TIW postcontrast images were obtained in the axial, sagittal, and coronal planes; for patients with recurrent rectal cancer, images were obtained in the axial and sagittal planes. The axial plane was always obliquely angled perpendicular to the sacral bone.

Two radiologists, with experience in reading CT images and who were blinded to the MRI results analyzed all CT scans in consensus to determine the local extent of the tumor. CT criteria for tumor recurrence were based on shape, mass effect, and contrast enhancement as described in literature $[15,19,28-30]$. Tumor infiltration into an adjacent organ was defined as diffuse stranding from the tumor to the adjacent structure with loss of fat planes on contrast-enhanced CT images. The relation of the tumor to each of the adjacent structures was classified as involved or not involved. 
The surrounding structures evaluated were the lateral pelvic wall (obturator muscle), the presacral fascia, the sacral bone, the pelvic floor muscles, the piriform muscles, the sciatic nerves, the internal genitals (the prostate gland or seminal vesicles, the vaginal wall or the cervix), the bladder, and the anal sphincter.

Two other radiologists with experience in reading pelvic MRIs similarly analyzed all MRIs in consensus and blinded for the CT results. For the seven patients who had pre- and postradiotherapy HR MRI, both MR scans were read together. Criteria for tumor recurrence were based on shape, mass effect, presence of a high signal relative to muscle on T2W images, and contrast enhancement as described in the literature $[15,24,26,29]$. Tumor infiltration into an adjacent organ was defined as diffuse stranding from the tumor into the adjacent structure with loss of fat planes on contrast-enhanced T1W images and areas of increased signal intensity extending into the adjacent structures on T2W images.

The signal intensities of tumor tissue relative to muscle tissue on gadolinium contrast-enhanced T1W images and T2W TSE images were subjectively recorded for each patient and classified as hypointense, isointense, or hyperintense relative to normal muscle tissue.

\section{Surgery}

The CT and MR findings were discussed with the surgeons before surgery or irradiation. On the basis of all the available information, a detailed operative plan was made, including intraoperative brachytherapy when close or involved resection margins were anticipated. At surgical exploration, three patients were found to have unsuspected, widespread peritoneal or liver metastases, and a resection was not performed. In these patients, the pelvis was surgically prepared for radiotherapy, and the relevant anatomical sites were explored for tumor invasion and biopsied when access was easy and safe. Thirteen patients with recurrent rectal cancer and 10 patients with primary advanced rectal cancer underwent a major resectional procedure, including pelvic exenteration and resection of the sacral bone when required. All the areas that were not included in the resection were verified and biopsied when invasion was suspected.

\section{Histology}

All relevant surrounding organs and structures that were inciuded in the en bioc resection were histologically evaluated for invasion. The margins of the resected specimen were thoroughly evaluated, and when the margin in the direction of a nonresected organ or structure was free of tumor at histology, the structure was considered as noninvaded. When the resection margin was close to a structure and showed tumor involvement, the structure was considered as invaded. The histologic results of the guided biopsies were self-evident. When a tumor response to radiotherapy was noted, the area of obvious tumor necrosis and fibrosis was considered as the former turnor extent. 
Table 1: Magnetic resonance imaging (MRI) and computed tomographic (CT) findings compared with final surgical and histological diagnosis of tumor infiltration in the pelvic structures:

\begin{tabular}{|c|c|c|c|c|c|c|c|c|}
\hline & MRI & & & & CT & & & \\
\hline & True + & True - & False + & False - & True + & True - & False + & False - \\
\hline pelvic sidewall & 7 & 19 & 0 & 0 & 4 & 17 & 2 & 3 \\
\hline pelvic floor & 15 & 8 & 3 & 0 & 13 & 4 & 7 & 2 \\
\hline presacral fascia & 14 & 11 & 0 & 1 & 11 & 10 & 1 & 4 \\
\hline sacral bone & 4 & 22 & 0 & 0 & 1 & 20 & 2 & 3 \\
\hline piriform muscle & 6 & 19 & 1 & 0 & 5 & 13 & 7 & 1 \\
\hline internal genitals & 11 & 15 & 0 & 0 & 7 & 12 & 3 & 4 \\
\hline bladder & 1 & 24 & 0 & 1 & 1 & 23 & 1 & 1 \\
\hline sciatic nerve & 1 & 25 & 0 & 0 & 1 & 25 & 0 & 0 \\
\hline anal sphincter & 2 & 24 & 0 & 0 & 1 & 21 & 3 & 1 \\
\hline total & 61 & 167 & 4 & 2 & 44 & 145 & 26 & 19 \\
\hline
\end{tabular}

\section{Analysis and statistics}

The sensitivity, specificity, positive predictive value (PPV), and negative predictive value (NPV) were calculated for both CT and MRI in predicting infiltration of the surrounding pelvic structures by using the combination of histologic and surgical findings as the gold standard. These figures were again calculated by using only the histologic findings as the gold standard to evaluate the hypothesis that the surgical findings were not as correct as the histologic findings. To exclude the possibility of a confounding effect of comparing the preradiotherapy CT images with the postradiotherapy MR images, the figures were again caiculated on the basis of the data of the 19 patients who had CT and MRI performed at the same time.

The sensitivity and specificity for HR MRI and CT were compared with the McNemar test, using the software package SPSS for Windows release 8.0 (SPSS, Chicago, IL, USA). A p value of less than 0.05 was considered significant.

\section{Results}

The correlation of the MR and CT findings with the surgical and histologic findings of tumor infiltration in the surrounding pelvic structures is presented in table 1. A total of 234 structures was evaluated for tumor invasion in 26 patients. Two hundred ten of these 234 structures $(90 \%)$ were correlated with histology; the remaining 24 were correlated with the surgical findings $(10 \%)$. CT produced 26 false-positive findings, 
with the most common failure being a false prediction of muscle invasion (pelvic floor: seven, piriform muscle: seven). MRI was more successful than CT in predicting muscle infiltration, with only three false-positive cases of pelvic floor infiltration and one false-positive case of piriform muscle invasion. Only two false-negative findings were recorded with MRI, whereas 19 false-negative findings were recorded with CT.

Table 2: Paired $2 \times 2$ table of magnetic resonance imaging (MRI) and computed tomographic (CT) findings for all invaded and noninvaded structures

CT - $\quad$ CT + total

$\begin{array}{lrrr}\text { Invaded structures } & & & \\ \text { MRI - } & 2 & 0 & 2 \\ \text { MRI+ } & 17 & 44 & 61 \\ \text { total } & 19 & 44 & 63 \\ \text { Noninvaded structures } & & & \\ \text { MRI - } & 144 & 23 & 167 \\ \text { MRI+ } & 1 & 3 & 4 \\ \text { total } & 145 & 26 & 171\end{array}$

Note.-The difference in performance between CT and MRI is statistically significant: $p<0.001$.

The sensitivity of HR MRI for the prediction of invasion was $97 \%$, specificity was $98 \%$, PPV was $94 \%$, and NPV was $99 \%$. CT had a sensitivity of $70 \%$, specificity of $85 \%$, PPV of $63 \%$, and NPV of $88 \%$. The difference in performance between MRI and CT for predicting tumor invasion was statistically significant $(\rho<0.001)$. The $2 \times 2$ tables on the basis of which this was calculated are shown in table 2. MRI never missed an invasion that was detected by CT. For the false-positive prediction, MRI performed better than CT 23 times, whereas CT performed better than MRI only once.

Table 3: Magnetic resonance signal intensities for mucinous, nonmucinous, and irradiated tumors relative to muscle tissue

\begin{tabular}{llll}
\hline$n$ & Histology & T2W TSE & Contrast enhanced T1W TSE \\
\hline 7 & Mucinous adenoca & Strongly hyperintense & Heterogeneous hyperintense \\
5 & Non-mucinous adenoca & Hyperintense & Homogeneous hyperintense \\
14 & Irradiated adenoca & Iso- to hypointense & Homogeneous hyperintense \\
\hline
\end{tabular}


The sensitivities and specificities of CT and HR MRI did not change significantly when only histologic proof was used as the gold standard, and there was no difference when the seven patients with only a postradiation MRI were excluded from statistical analysis.

The MRI findings were accurate in 20 of 26 patients $(80 \%)$, whereas the CT was accurate in only five of 26 patients (19\%).

The MR signal intensity of tumor tissue relative to normal muscle tissue and the histologic correlation are shown in table 3 . In five patients with recurrent rectal cancer and two patients with primary advanced rectal cancer, histology demonstrated an adenocarcinoma of the mucinous type. All tumors with a substantial mucinous component showed a very strong hyperintense signal intensity on T2W TSE and a characteristic heterogenous enhancement pattern on contrast-enhanced T1W MR images.

\section{Discussion}

Patients with a locally advanced primary or recurrent rectal cancer benefit from accurate information on the local extent of the tumor [3,31]. With the exact knowledge of where the tumor comes close to or actually invades the surrounding structures, a detailed operative plan can be made for an en bloc resection with wide margins around the tumor. This maximizes the chances for a complete resection and thus the chances for survival $[1,2]$. Some patients may be selected for neoadjuvant chemo- or radiotherapy to obtain tumor shrinkage and wider resection margins. When close or involved resection margins are anticipated preoperatively, one should consider the use of intraoperative radiotherapy, which requires planning from the radiotherapy department.

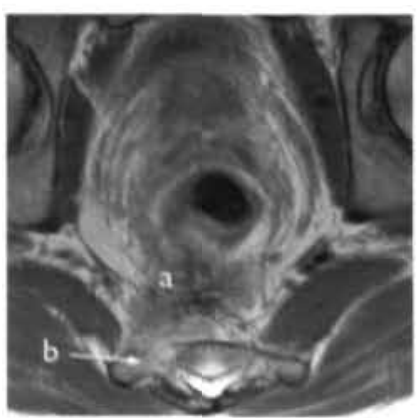

a

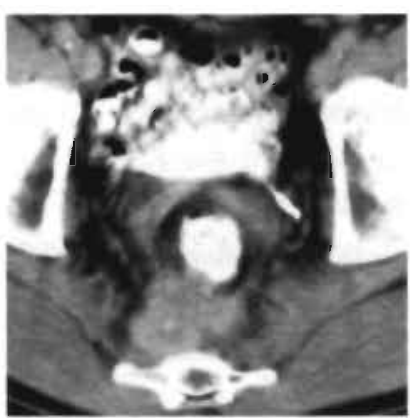

b

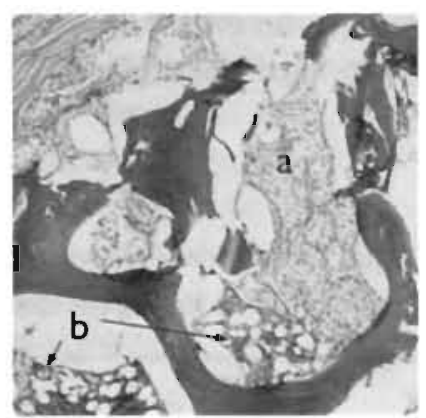

c

Figure 1. A 48-year-old male with recurrent rectal cancer in the presacral region. A. Axial contrast-enhanced T1W TSE MRI shows the fumor (a) invading the bone marrow (b). B. Axial CT at the level of the tumor fails to show bone invasion. The axial CT section may appear to be at a different level because of the slightly different angulation of the MR axial section (perpendicular to the sacral bone). C. Histology confirms the tumor (a) invading the bone marrow (b). The trabecular bone is intact. 

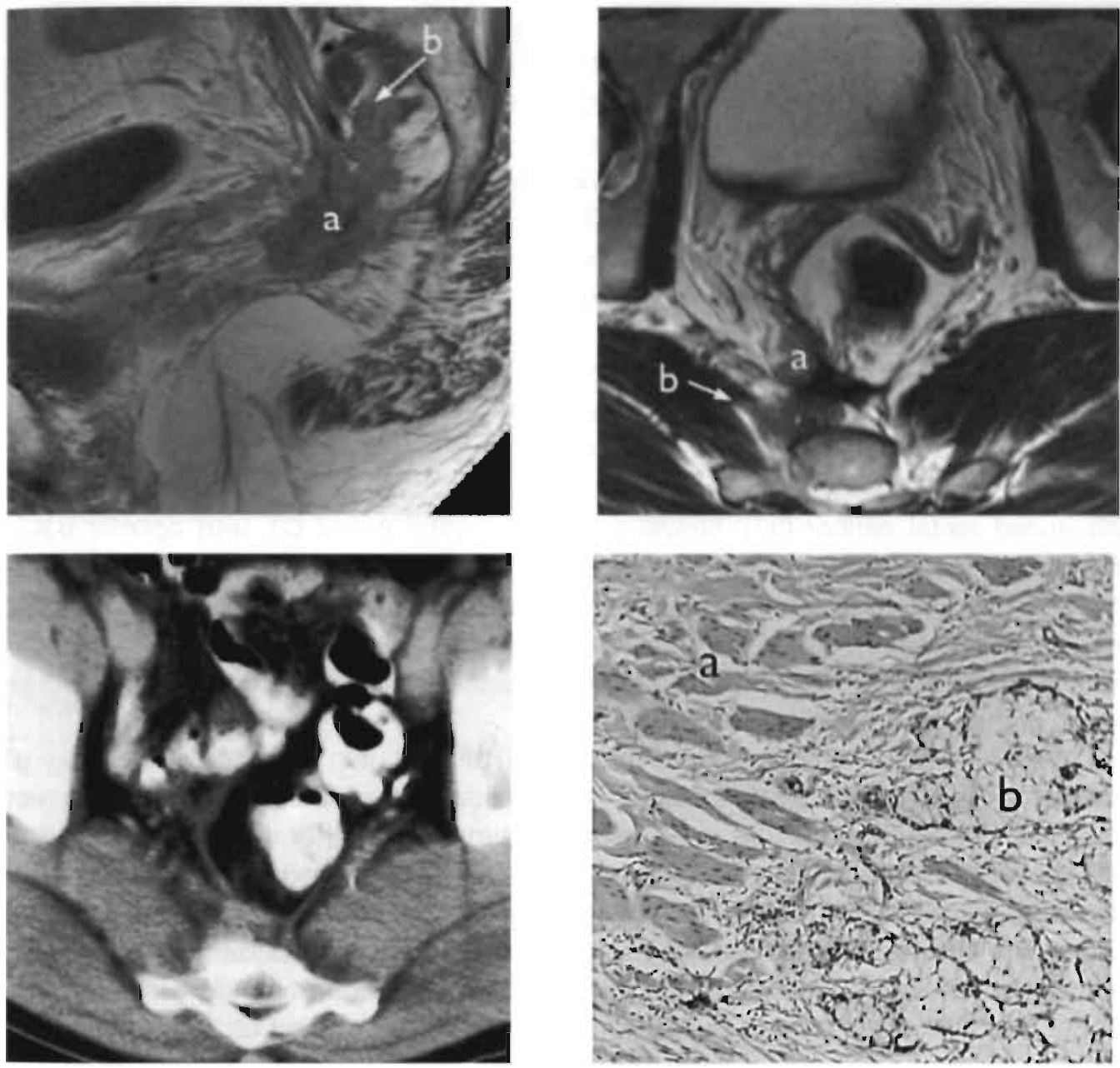

a

\section{b}

d

Figure 2. A 55-year-old male with recurrent rectal cancer in the presacral region. A. Sagittai contrast-enhanced T1W TSE MRI accurately shows the fumor (a) invading the right pirilorm muscle (b). B. Axial T2W TSE MRI also clearly visualizes the tumor (a) invading the presacral space and the right piriforin muscle (b). (The axial plane was angled perpendicular to the sacral bone.) C. CT shows the tumor mass but fails to show piriform muscle invasion. $D$.

Corresponding histologic section through the right piriform muscle shows tumor (b) infiltrating the muscle fibers (a).

Our study shows that HR MRI using a quadrature phased-array coil is highly accurate and superior to conventional pelvic CT in predicting the local tumor extent for advanced primary and recurrent rectal cancer. HR MRI had a sensitivity of $97 \%$ and a specificity of $98 \%$, whereas CT had a sensitivity of $70 \%$ and al specificity of $85 \%$. 
The sensitivities and specificities of CT in our series are in agreement with data from other investigators $[12,31,32]$. CT is unable to differentiate fibrosis, normal tissue, and tumor recurrence $[15,20,21,29,31,33-36]$.

In the present study, this resulted in a low specificity for the prediction of muscle invasion, mainly due to false-positive invasion of the pelvic floor and piriform muscle, a finding also seen by Clark et al. [31]. The low sensitivity of CT in our study was due mainly to missed invasion of the pelvic sidewall, the presacral fascia, and the sacral bone (Fig. 1). This confirms the difficulties in detecting a subtle sacral bone invasion described by others $[15,28]$.

The slice thickness of the conventional pelvic CT protocol in our study was 8 or $10 \mathrm{~mm}$. CT scanning with thinner slices could theoretically produce more detailed images. However, Skriver et al. did not find any difference in outcome between thinand thick-slice CT techniques in a small study with nine patients with locally advanced rectal cancer [37]. Newer-generation spiral pelvic CT with optimal bolus timing and reconstructions in multiple planes may perform much better than conventional pelvic CT, but it has not been fully investigated in advanced rectal cancer $[38,39]$. Although spiral CT techniques may improve imaging results as compared with conventional CT, the inherent lack of soft tissue contrast remains a disadvantage when compared with MRI.

Many reports have described the value of $\mathrm{MRI}$ for preoperative staging of colorectal cancer $[4,6-8,12,16,26,40]$. However, most of these studies have not focused on the invasion of surrounding organs, but rather have assessed the prediction of the depth of bowel wall invasion and lymph node invasion and have included only a limited number of patients with locally advanced rectal cancer. The body coil MRI technique that was used in most studies has demonstrated little advantage over CT because of the inherent low resolution obtained with the body coil. Most MRI studies on recurrent rectal cancer have focused on the detection of suspected tumor masses [15-25]. Only a few investigators have addressed the important problem of predicting organ invasion in advanced rectal cancer with MRI $[13,16,26]$. De Lange et al. concluded from a study with 11 patients that MRI with a body coil was reasonably useful for the evaluation of tumor extent [16]. Blomqvist et al. evaluated an MR! technique with a pelvic phased-array coil in patients with recurrent rectal cancer and found a better prediction for organ invasion with MRI (six of nine) than with CT (three of nine) [26]. In these two studies, sensitivities and specificities were not presented, but MRI seemed to perform better than CT. Popovich et al. evaluated the accuracy of a body coil MRI technique in 22 patients with a variety of pelvic tumors requiring a pelvic exenteration [13]. They reported a sensitivity of $100 \%$ and a specificity of $76 \%$ for predicting involvement of the pelvic side wall muscles. Although the high sensitivity corresponds with our figures, the specificity is substantially lower. This is attributed to the false-positive interpretations of pelvic wall invasion in patients who had undergone radiotherapy. In our study, the sensitivity and specificity remained equally high whether or not patients with an MRI after radiotherapy were included. 


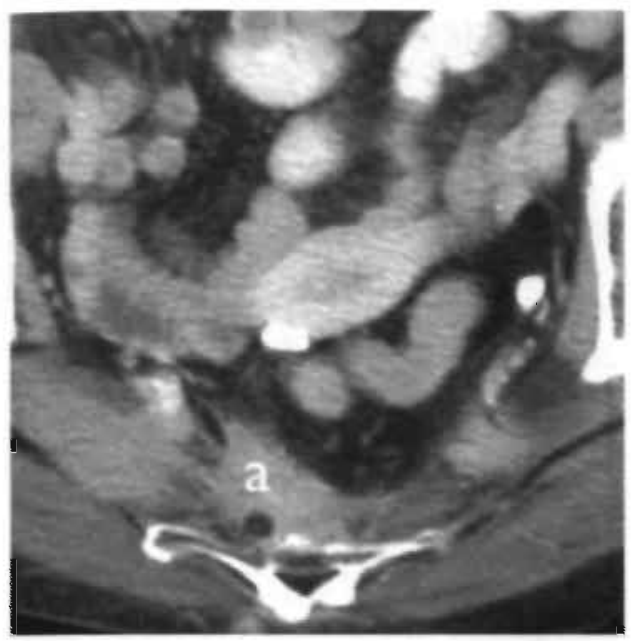

a

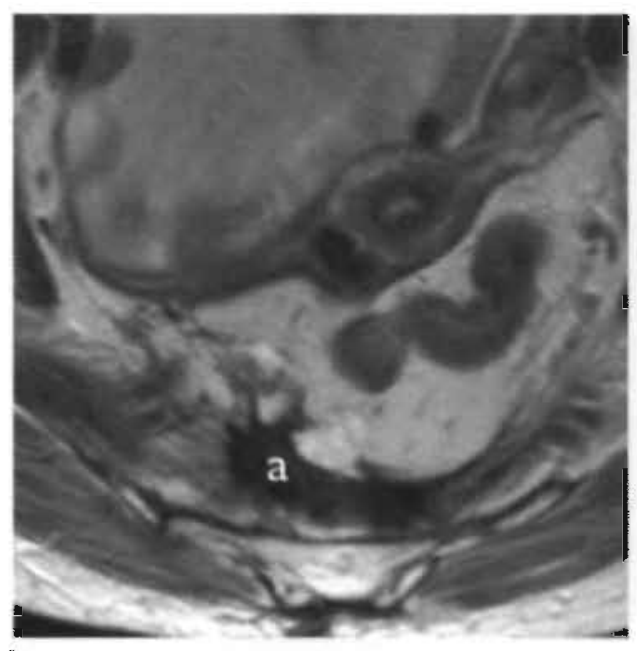

b

Figure 3. An 81-year-old female with recurrent rectal cancer in the perineal region. A. CT section above the recurrence shows an enhancing mass in the presacral region (a), which could be either tumor or fibrosis. B. Corresponding axial T2W TSE MRI shows a homogeneous hypointense signal intensity of the mass (a), suggesting fibrosis only, which was confirmed at histology.

The excellent pertormance of MAI in advanced rectal cancer in the present study can be largely attributed to the use of a quadrature phased-array coil. The multiple coil arrangement in a phased-array coil increases the signal-to-noise ratio and provides images with smaller voxel sizes and a higher resolution than with a body or surface coil $[27,41]$. In our study, a quadrature phased-array spine coil was used. This was more a necessity than a choice because at the time of the study a torso or pelvic phased-array coil was not available for our Philips MR machine. In this phasedarray spine coil, the coil components are arranged in quadrature in contrast to the linear arrangement of a torso or pelvic phased-array coil. This quadrature arrangement further improves the signal-to-noise ratio, and even smaller voxel sizes can be obtained. The use of ultra small voxel sizes $\left(0.6 \mathrm{~mm}^{3}\right)$ in our T1W sequence resulted in very detailed images of the pelvic structures and contributed to the high sensitivity and specificity results.

Another factor that contributes to the superiority of MRI over CT in assessing organ invasion is the inherent high soft tissue contrast resolution [15]. The differentiation between normal tissue. scar tissue, and tumor is easier with MRI because of the difference in signal intensities (Fig. 2). Tumor tissue has a relatively high water content and thus a high signal intensity on T2W images in contrast to the low water content and low signal intensity of scar tissue (Fig. 3) and the intermediate water content and signal intensity of normal muscle tissue $[15,42]$. The differentiation between tumor tissue and muscle is further improved by the more pronounced enhancement of tumor on T1W images after administration of gadolinium (Fig. 2) [24]. 


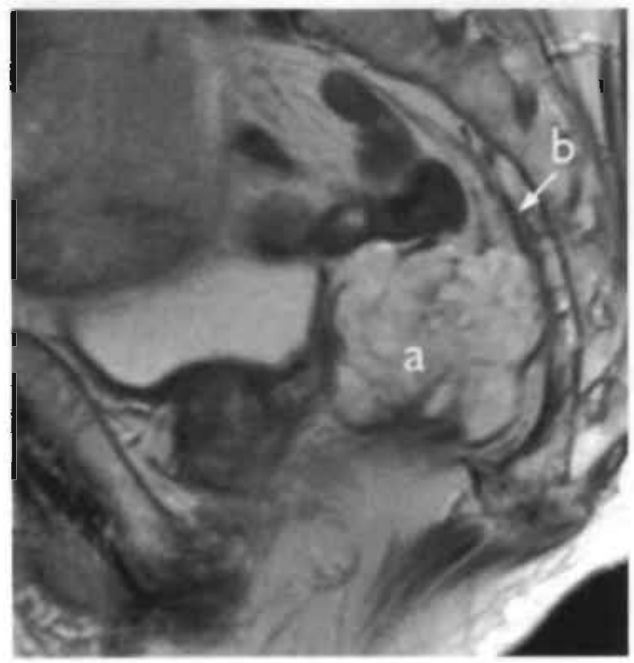

a

Figure 4. An 83-year-old male with mucinproducing recurrent rectal cancer in the presacral region. A. Sagittal T2W TSE MRI shows a strong hyperintense welldefined tumor mass (a) in the presacral region, adherent to the presacral fascia (b). B. On the corresponding sagittal contrast-enhanced T1W TSE MRI, the tumor is seen with a. characteristic heterogeneous enhancement pattern. caused by numerous nonenhancing lakes of mucin (c) surrounded by enhancing tumor cells (d).

Our findings show a characteristic MR pattern for mucinous tumors. The strong hyperintense signal intensity on T2W images reflects the high water content of mucin and mucin-producing tumor cells. The characteristic heterogenous enhancement pattern on TIW images after gadolinium contrast administration is explained by the numerous lakes of mucin found within the tumor (Fig. 4). These MP characteristics have also been described by Hussain et al. [43]. The lower water content in nonmucinous tumors and even more so in irradiated tumors is reflected in decreasing signal intensities on T2W TSE (Table 3).

There are some pitfalls in MRI of rectal cancer. Masses that are hypointense on T2W images generally represent fibrosis but, in some cases, can contain tumor. This can occur in tumors that have been irradiated. When the tumor responds to the radiotherapy, it is partly or completely replaced by fibrosis, but these fibrotic areas can still contain viable tumor cells. MRI cannot reliably distinguish between fibrosis with and fibrosis without tumor $[16,44,45]$. To ensure that no viable tumor is left behind at surgery, the complete area of the original tumor needs to be resected, including the parts of the tumor that have been replaced by fibrosis. Because patients with locally advanced rectal cancer are now frequently treated with a full course of radiotherapy before surgery, the assessment of tumor invasion should be made on a baseline MRI before radiotherapy. Some of the difficulties with radiation fibrosis are shown in Figures 5-7.

The same problem of differentiation between tumor and fibrosis can occur in patients without prior radiotherapy. Some malignant tumors provoke a desmoplastic 
reaction, a host reaction in which fibrous tissue is formed in and around the tumor $[15,16,18]$. As with radiotherapy fibrosis, it is difficult to predict on MRI the presence or absence of tumor cells interspersed between the fibrotic tissue. When a

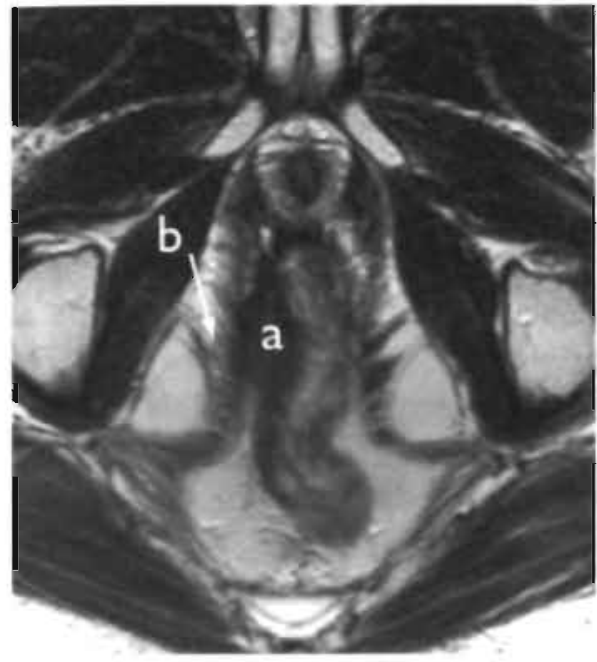

a

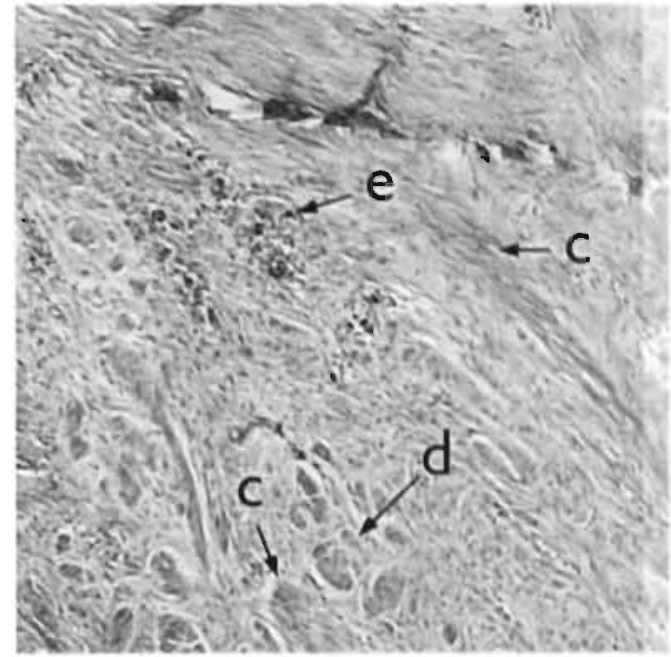

b

Figure 5. A 67-year-old male with rectal cancer involving the pelvic floor, after a full dose of preoperative radiotherapy. A. Axial postirradiation T2W TSE MRI shows a hypointense thickening of the right lateroventral rectal wall (a) extending into the right pelvic floor (b), suggesting fibrosis. B. Corresponding histology shows fibrosis (c) between the muscle fibers (d). No tumor cells were visualized. Apparently, the tumor has responded well to radiotherapy and has been completely replaced by fibrosis. (e) inflammatory response.

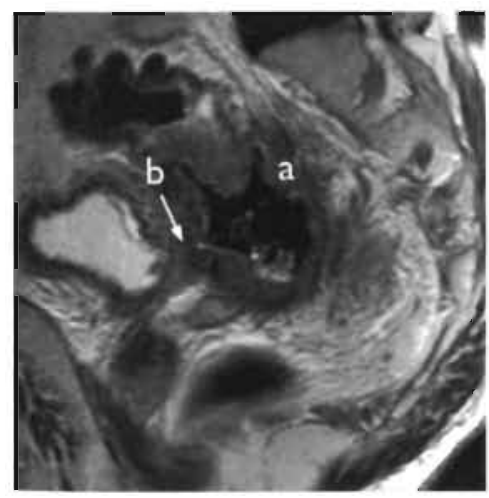

a

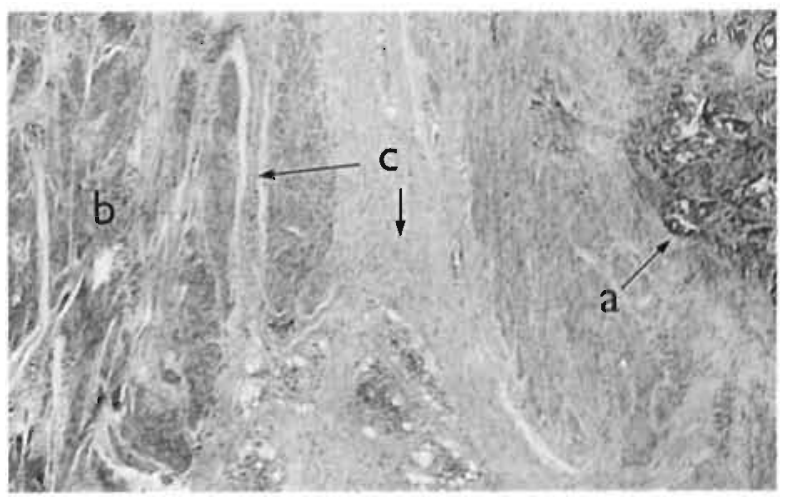

b

Figure 6. A 62-year-old male with primary rectal cancer involving the bladder, after a full dose of radiotherapy. A. Sagittal T2W TSE MRI shows a hypointense thickening of the rectal wall (a) invading the dlorsal bladder wall (b), suggesting fibrosis. B. At histology there is still viable tumor in the rectal wall (a), surrounded by extensive fibrosis (c), that is invading the muscular bladder wall (b). This fibrosis may be tumor that has responded to radiotherapy. MRI was not able to distinguish between fibrosis and the tumor. 
desmoplastic reaction is suspected, it should be resected with the tumor, even if this. involves resection of surrounding structures.

Another pitfall can occur in the early postoperative phase. In the first year after surgery, the scar tissue can still be in the inflammatory phase and can show MR characteristics suggestive of tumor tissue. Therefore, one should be cautious during this period in diagnosing a pelvic mass that is hyperintense on T2W and homogeneously enhancing on T1W as a recurrence [24].

Endorectal MRI provides detailed high-resolution images of the prostate, the anal sphincter, and the rectal wall [25]. Therefore, endorectal MRI would seem useful for the assessment of the local extent of advanced rectal cancer, but the limited FOV due to a significant signal drop-off at a short distance from the coil [46-49] is a disadvantage in this clinical setting. Other practical problems are that the technique is not applicable in patients who have had an abdominoperineal resection of the rectum and it can be painful in patients with a stenosing tumor $[25,50]$.

In conclusion, HR MRI with a phased-array spine coil is highly accurate and superior to CT in predicting tumor infiltration in surrounding structures for locally advanced primary and recurrent rectal cancer and is recommended in the

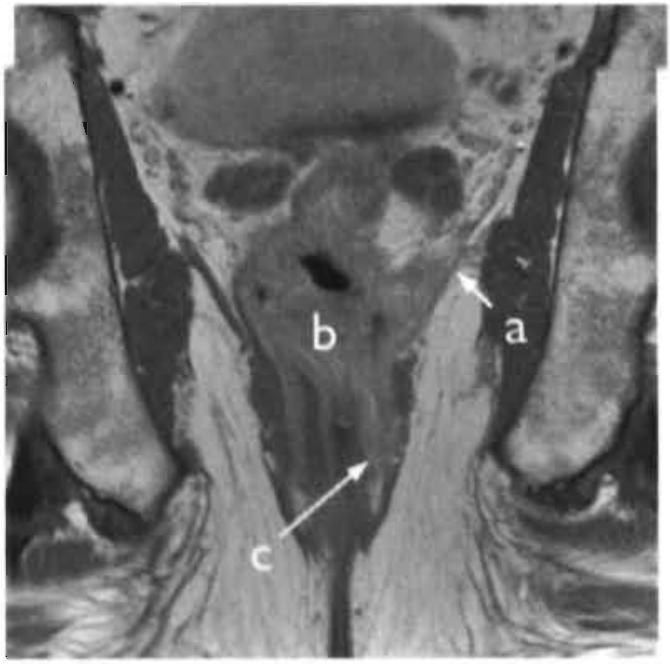

Figure 7a. - 65-year-old man with distal rectal cancer involving the pelvic floor. Coronal contrast enhanced T1W TSE MR image shows enhancement of the left pelvic floor muscles (a), suggesting tumor extension from the distal rectal cancer (b), confirmed at histology. Also note how the tumor is invading the left anal sphincter muscles (c).

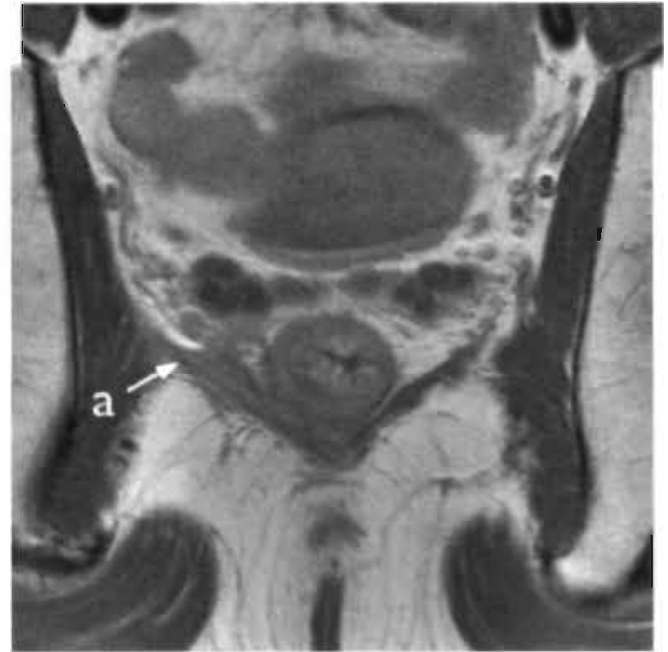

Figure 7b. -67-year-old man with rectal cancer involving the pelvic floor, after irradiation.

Coronal contrast enhanced T1W TSE MRI shows unilateral enhancement of the pelvic floor muscles (a) similar to Fig 7. However, only fibrosis without tumor cells was seen at histology. This fibrosis must have been tumor that has responded to radiotherapy. A symmetrical bilateral pelvic floor enhancement would be more suggestive for fibrotic changes in normal tissue secondary to irradiation 
preoperative work-up of patients with these tumors. The assessment of tumor invasion should be made on MRI before preoperative radiotherapy because it remains difficult to accurately distinguish tumor from postradiation fibrosis.

\section{References}

1 Poeze M, Houbiers JGA, van de Velde $\mathrm{CJH}$, Wobbes T, von Meyenfeldt MF. Radical resection of locally advanced colorectal cancer. Br J Surg 1995;82:1386-1390

2. Sagar PM, Pemberton JH. Surgical management of locally recurrent rectal cancer. Br J Surg 1996;83:293-304

3. Krestin GP. Is magnetic resonance imaging the method of choice in the diagnosis of recurrent rectal cancer? Abdominal Imaging 1997;22:343-345

4. Hadfield MB, Nicholson AA, MacDonald AW, et al. Preoperative staging of rectal carcinoma by magnetic resonance imaging with a pelvic phased-array coil. Br J Surg 1997;84:529-531

5. Thoeni RF. Colorectal cancer. Radiologic staging. Radiol Clin North Am 1997:35:457-485

6. Heriot AG, Grundy A, Kumar D. Preoperative staging of rectal carcinoma. Br J Surg 1999;886:17-28

7. Hodgman CG, MacCarthy RL, Wolff BG, et al. Preopertive staging of rectal carcinoma by computed tomography and $0.15 \mathrm{~T}$ magnetic resonance imaging. Preliminary report. Dis Colon Rectum 1986:29:446-450

8. Okizuka $\mathrm{H}$, Sugimura $\mathrm{K}$, Ishida $\mathrm{T}$. Preoperative local staging of rectal carcinoma with MR imaging and a rectal balloon. JMRI 1993;3:329-335

9. Goldman S, Arvidsson H, Norming U, Lagerstedt U, Magnusson I, Frisell J. Transrectal ultrasound and Computed tomography in preoperative staging of lower rectal adenocarcinoma. Gastrointest Radiol 1991;16:259-263

10. Balthazar EJ, Megibow AJ, Hulnick D. Naidich DP. Carcinoma of the colon: detection and preoperative staging by CT. AJR 1988;150:301-306

11. Meyenberger $C$, Huch Boni AA, Bertschinger P, Zala GF, Klotz HP, Krestin GP, Endoscopic ultrasound and endorectal Magnetic resonance imaging: a prospective, comparative study for preoperative staging and follow up of rectal cancer. Endoscopy 1995;27:469-479

12. Butch RJ, Stark DD, Wittenberg J, ef al. Staging rectal cancer by MR and CT. AJR 1986:146:1155-1160

13. Popovich MJ, Hricak $H$, Sugimura $K$, Stem JL. The role of MR imaging in determining surgical eligibiility for pelvic exenteration. AJR 1992;160:525-531

14. Cova M, Frezza F, Pozzi-mucelli RS, et al. Contribution of CT and MRI to the preoperative staging of rectal carcinoma. Correlation with histopathologic findings. La Radiologica Medica 1994;87:82-89

15. Krestin GP. Steinbrich W. Friedmann G. Recurrent rectal cancer: diagnosis, with MR Imaging versus CT. Radiology 1988;168:307-311

16. Lange de EE. Fechner RE, Wanebo HJ. Suspected recurrent rectosigmoid carcinoma after abdominoperineal resection: MR Imaging and Histopathologic findings. Radiology 1989;170:323-328

17. Romano G, Esercizio L, Santangelo M, Vallone G, Santangelo ML. Impact of CT versus intrarectal $\mathrm{U} / \mathrm{S}$ on the diagnosis, resectability, and prognosis of locally recurrent rectal cancer. Dis Colon Rectum $1993 ; 36: 261-265$ 
18. Pema PJ, Bennett WF, Bova JG, Warman P. CT vs MRI in diagnosis of recurrent rectosigmoid carcinoma. J Comput Assist Tomogr 1994;18:256-261

19. Mendez RJ, Rodriguez R, Kovacevich T, Martinez S, Moreno G, Cerdan J. CT in local recurrence of rectal carcinoma. J Comput Assist Tomogr 1993;17:741-744

20. Moss A, Thoeni RF, Schnyder P, Margulis AR. Value of computed tomography in the detection and staging of recurrent rectal carcinomas. J Comput Assist Tomogr 1981:5:870-874

21. Grabbe E, Winkler R. Local recurrence after sphincter saving resection for rectal and rectosigmoid carcinoma. Radiology 1985; 155:305-310

22. Muller-Schimpfle M, Brix G, Layer G, et al. Recurrent rectal cancer: Diagnosis with dynamic MR imaging. Radiology 1993:189:881-889

23. Krestin GP, Steinbrich W, Friedmann G. Diagnosis of recurrent rectal cancer: Comparison of CT and MR. ROFO Fortschr Geb Rontgenstr Nuklearmed 1988;148:28-33

24. Markus J, Morissey B, deGara C, Tarulli G. MRI of recurrent rectosigmoid carcinoma. Abdominal Imaging 1997:22:338-342

25. Huch Boni AA, Meyenberger C, Pok Lundquist J. Trinkler F, Lutolf U, Krestin GP. Value of endorectal coil versus body coil MAI for diagnosis of recurrent pelvic malignancies. Abdominal Imaging $1996 ; 21: 345-352$

26. Blomquist L, Holm T, Goranson H, Jacobsson H, Ohlsen H, Larsson SA. MR imaging, CT and CEA scintigraphy in the diagnosis of local recurrence of rectal carcinoma. Acta Radiologica 1996;37:779-784

27. Beets-Tan RGH, Beets GL, Gerritsen van der Hoop A, et al. High-resolution magnetic resonance imaging of the anorectal region without an endocoil. Abdominal Imaging 1999;24:576-581

28. Husband JE, Hodson NJ. Parsons CA. The use of Computed Tomography in recurrent rectal cancer. Radiology 1980; 134:677-682

29. Lee JKT, Stanley RJ, Sagel SS, Levitt RG, McClennan BL. CT appearance of the pelvis after abdominoperineal resection for rectal carcinoma. Radiology 1981;141:737-741

30. Adalsteinsson B, Glimelius B, Graftman S, Hemmingsson A, Pahlman A. Computed tomography in staging of rectal carcinoma. Acta Radiologica Diagnosis 1985;26:45-55.

31. Clark J, Bankoff M, Carter B, Smith TJ. The use of computerized tomography scan in the staging and follow-up study of carcinoma of the rectum. Surg, Gynecol \& Obstell 1984:159:335-342

32. Lassau $\mathbf{N}$, Leclere $\mathrm{J}$, Elias $\mathrm{D}$, Lasser $\mathrm{P}$. Role of imaging in abdominopelvic follow-up after resection of colorectal cancer. J Chir (Paris) 1997; 134:51-58

33. McCarthy SM, Barnes D. Deveney K, Moss AA, Goldberg HI. Detection of recurrent rectosigmoid carcinoma: Prospective evaluation of CT and clinical factors. AJR 1985;144:577-579

34. Watanabe M, Sugimura K, Kuroda S, Okizuka H, Ishida T. CT assessment of postirradiation changes in the rectum and perirectal region. Clin Imaging 1995;19:182-187

35. Joosten FBM, Verbeek ALM, Jansen JBMJ. Rosenbusch G. Wertigkeit der CT fur die diagnostik des rektumkarzinomrezidivs. Radiologe 1994:34:144-152

36. Shank B, Dershaw DD, Caravelli J, Barth J, Enker W. A prospective study of the accuracy of preoperative computed tomographic staging of patients, with biopsy-proven rectal carcinoma. Dis Colon Rectum 1990;33:285-290

37. Skriver EB, Nielsen MB. Qvitzau S, Christiansen J. Comparison of precontrast, postcontrast, and delayed CT scanning for the staging of rectal carcinoma. Gastrointest Radiol 1992:17:267-270 
38. Okizuka $\mathrm{H}$, Sugimura $\mathrm{K}$, Shinozaki $\mathrm{N}$, Watanabe $\mathrm{K}$. Colorectal carcinoma: evaluation with ultrafast CT. Clinical Imaging 1995; 19:247-251

39. Hundt W, Braunschweig R, Reiser M. Evaluation of spiral CT in staging of colon and rectum carcinoma. Eur Radiol 1999;9:78-84

40. Blomqvist L, Holm T, Rubio C, Hindmarsch T. Rectal tumours- MR Imaging with endorectal and/or Phased-array coils, and histopathological staging on giant sections. Acta Radiologica $1997: 38: 437-444$

41. Smith RC, Feinhold C, MacCauley TR, et al. Multicoil High-Pesolution Fast Spin-Echo MR Imaging of the fernale pelvis. Radiology 1992;184:671-673

42. Glazer HS, Lee JKT, Levitt RG, et al. Radiation fibrosis: differentiation from recurrent tumor by MR imaging. Radiology 1985;156:721-726

43. Hussain SM, Outwater EK, Siegelman ES. Mucinous versus Nonmucinous Rectal Carcinomas: Differentiation with MR Imaging. Radiology 1999;213:79-85

44. Kahn $\mathrm{H}$, Alexander A, Rakinic J, Nagle D, Fry R. Preoperative staging of irradiated rectal cancers using digital rectal examination, computed tomography, endorectal ultrasound, and magnetic resonance imaging does not accurately predict TO, NO pathology. Dis Colon Rectum 1997;40:140-144

45. Lange de EE, Fechner RE, Edge SB, Spaulding CA. Preoperative staging of rectal carcinoma with MR Imaging: surgical and histopathological correlation. Radiology 1990;176:623-628

46. Chan TW, Kressel HY, Milestone B, et al. Rectal carcinoma: staging at MA imaging with endorectal surface coil. Radiology 1991;181:461-467

47. Schnall MD, Furth EE, Rosato EF, Kressel HY. Rectal tumor stage: correlation of endorectal MR imaging and pathologic findings. Radiology 1994;190:709-714

48. Choen S, Burnett S, Bartram Cl, Nicholls RJ. Comparison between anal endosonography and digital examination in the evaluation of anal fistulae. Br J Surg 1991;78:445-447

49. Pavlicek W. Geisinger M, Castle L, et al. The effects of nuclear magnetic resonance on patients with cardiac pacemakers. Fasdiology 1983;147:149-153

50. Hussain SM, Outwater EK. MR imaging of anorectal region: intraluminal, extraluminal, que sera? Abdominal Imaging 1999;24:582-584 
Chapter 7

SUMMARY, CONCLUSIONS AND RECOMMENDATIONS 


\section{Summary}

The aim of this thesis is to evaluate whether high spatial resolution images of the entire anorectal region can be obtained with a noninvasive MR technique using a quadrature phased array coil and to assess whether the application of high resolution phased array MRI is of clinical benefit in the management of patients with anorectal diseases.

The pilot study in chapter 2 tests the feasibility of a noninvasive MR technique with quadrature phased array coil in obtaining detailed images of the entire anorectal region.

The visualization of the pelvic structures and the anal sphincter muscles was independently scored by three observers on the scans of 22 healthy volunteers. The results show that detailed imaging of both the pelvic structures and the anal sphincter muscles is feasible with a high spatial resolution MR technique using a quadrature phased array spine coil. The pilot study in 12 patients with various anorectal diseases shows exact correlation between MR findings and surgery or histology and suggests useful applications of phased array MRI in the management of patients with anorectal diseases.

The study in chapter 3 compares phased array MRI with endoanal ultrasound (EUS) and endoanal MRI for the measurement of anal sphincter muscles in 60 normal volunteers. The study investigates the inherent discriminatory power and reproducibility of each imaging method by evaluating the intra- and interobserver reliability. The results of the three methods were compared with a correlation analysis and regression curves. With a multivariate analysis the influence of age, height, gender, parity and obstetric trauma on the sphincter dimensions was assessed for every modality.

The results show that with EUS only the internal anal sphincter thickness can be reliably measured, whereas with $\mathrm{MRI}$ reliable measurements can be made of all the sphincter components. Phased array MRI appears as reliable as endoanal MRI in measuring sphincter dimensions. Overall there was little correlation between the techniques, except for the two MR techniques, which showed a strong correlation for total sphincter and perineal body thickness. The multivariate analysis shows that with increasing age the internal sphincter becomes thicker but this relation was only found for the measurements with EUS and endoanal MRI. Gender differences were only found for the measurements with phased array MRI, a positive correlation between parity and total sphincter thickness only for endoanal MRI and a positive correlation between the number of obstetric trauma and perineal body thickness only for phased array MRI.

The divergent findings between the imaging techniques suggest that values of anal sphincter muscle thickness performed with different techniques are not interchangeable, and every imaging technique has its own set of normal values. 
When sphincter measurements are going to be used for clinical decision making or for further research the imaging techniques should be standardized as much as possible.

Chapter 4 presents a study that evaluates the accuracy and the additional clinical value of a high resolution phased array MRI in the preoperative work up of patients with primary and complex anal fistulas. Fifty-six consecutive patients were preoperatively evaluated with phased array MRI. The MR scans were evaluated independently by three observers. The information of the MRI was withheld from the surgeon until the end of the operation. The MR findings were then verified, and the surgical treatment was extended when required.

Phased array MRI shows a sensitivity and specificity of $100 \%$ and $86 \%$ for the detection of primary tracks, $96 \%$ and $97 \%$ for abscesses, $100 \%$ and $100 \%$ for horseshoe fistulas, and $96 \%$ and $90 \%$ for internal openings. High areas under the receiver operating curves confirm high accuracies for the prediction of fistula tracks and extensions for all three observers. The inter- and intraobserver agreement was very high with the best agreement achieved for the detection of horseshoes and abscesses. Overall MRI showed important additional information in 12/56 patients (21\%). In patients with Crohn's disease the benefit was $40 \%(6 / 15)$, in patients with recurrent fistulas $24 \%(4 / 17)$ and in patients with primary fistulas $8 \%(2 / 24)$. The difference in benefit from MRI between the group of the primary simple fistulas versus complex fistulas was statistically significant $(p<0.05)$, as was the difference in benefit between the group with Crohn's fistulas versus non Crohn's fistulas $(p<0.05)$.

This study convincingly shows that a phased array MRI is highly accurate for the detection of fistulas and secondary extensions and that it helps surgeons to identify all secondary extensions of a complex fistula. High resolution phased array MRI is therefore recommended in the preoperative work up of these patients.

The study in chapter $\mathbf{5}$ evaluates the accuracy of high resolution MRI with a phased array coil for preoperative staging of rectal cancer and the accuracy for predicting the distance from the fumour to the circumferential resection plane in a total mesorectal excision (TME). Two observers independently scored the tumour for $\mathrm{T}$ stage and measured the distance to the mesorectal fascia on MR scans of 76 patients with primary rectal cancer. The MR findings were compared with the final histology.

The MR T stage agreed with the histological stage in 63 of 76 patients $(83 \%)$ with a weighted $k$ of 0.77 for observer 1 , and in 51 of 76 patients $(67 \%)$ with a weighted $\mathrm{k}$ of 0.52 for observer 2 . The intraobserver agreement on the $T$ stage was good $(x 0.80)$ for observer 1 but moderate $(\kappa 0.49)$ for observer 2 . The interobserver agreement was only moderate $(\kappa 0.53)$.

In 12 patients with an obvious T4 tumour a margin of $0 \mathrm{~mm}$ to the mesorectal fascia was correctly predicted. Of the 29 patients in whom the pathologist reported a distance of at least $1 \mathrm{~cm}$ without specifying, observer 1 predicted a distance of at least $10 \mathrm{~mm}$ in 28 of the 29 patients, and observer two in 27 out of 29 patients. For 
the remaining 35 patients a regression curve with $95 \%$ prediction intervals was constructed, and a histological distance of at least $1 \mathrm{~mm}$ can be predicted with high confidence when the measured distance on MRI is at least $5 \mathrm{~mm}$. Both the intra- and interobserver reliability of the measurements were very high.

High resolution MRI with a phased array coil shows a moderate accuracy and reproducibility for predicting the $T$ stage of a rectal tumour. The clinically more important circumferential resection margin however can be predicted with high accuracy and consistency. This allows preoperative identification of patients at risk for a recurrence who will benefit from preoperative radiotherapy and/or more extensive surgery.

The study in chapter 6 compares high resolution phased array MRI with CT in the assessment of tumor infiltration in surrounding structures in 11 patients with a locally advanced primary and 15 patients with a recurrent rectal cancer. The images were scored for invasion of nine neighboring pelvic structures by three radiologists. The results were compared with surgical and histological findings.

HR MRI showed a sensitivity of $97 \%$ and a specificity of $98 \%$, while CT had a sensitivity of $70 \%$ and a specificity of $85 \%$. The difference in performance between MRI and CT for predicting tumor invasion was statistically significant $(p<0.001)$. MRI was without doubt more successful than $\mathrm{CT}$ in predicting pelvic floor, piriform muscle invasion and subtle bone invasion.

High resolution phased array MRI is therefore recommended in the preoperative work up of patients with advanced primary and recurrent rectal cancer. 


\section{Conclusions}

The first aim of this thesis was to evaluate whether high spatial resolution images of the entire anorectal region can be obtained with a noninvasive MR technique using a quadrature phased array coil.

In general, MR images can be improved by enhancing contrast resolution and/or by increasing spatial resolution. Spatial resolution is defined by the ability to distinguish between closely spaced objects. With the MR technique in the present study we aimed to improve the spatial resolution by the optimal use of a phased array coil. The multiple coil arrangement in a phased array coil increases the signal to noise ratio and allows us to obtain images with smaller voxel sizes and higher spatial resolution than with a body coil. The specific coil in our study was a quadrature phased array spine coil. A quadrature phased array coil exploits the signal-to-noise-ratioadvantages of multiple small surface coils and of the quadrature arrangement of these coils. Theoretically voxel sizes can be generated that are almost as small as with endoluminal MRI, but with a larger field of view, resulting in detailed images of the entire anorectal region.

Our studies show that high spatial resolution images of the entire anorectal region can be obtained with a noninvasive MR technique using a quadrature phased array coil. The studies with normal volunteers show that the individual structures of the anal sphincter complex can be visualized with as much detail as with endoanal MRI. The studies in anal fistulas and rectal cancer convincingly demonstrate the importance of the large field of view that gives excellent information on secondary fistula extensions, abscesses above the pelvic floor, and tumor ingrowth into the structures around the rectum.

The second aim of the thesis was to assess whether the application of high resolution phased array MRI is of clinical benefit in the management of patients with anorectal diseases.

High resolution phased array MRI is very accurate in detecting perianal fistulas, and for the detection of secondary extensions and abscesses it is even more accurate than a surgical exploration. This additional information can help surgeons to achieve complete drainage of secondary extensions and abscess collections that would otherwise have been missed. Eventually, this may lead to fewer recurrences. The benefit was most obvious in patients with complex fistulas associated with Crohn's disease and recurrent fistulas, and a phased array MRI is recommended in the preoperative work up of these patients.

High resolution MRI with a phased array coil has a moderate accuracy for predicting the $T$ stage in rectal cancer. How relevant is it to distinguish between stage $T 1, T 2$ 
and T3 preoperatively? Although it may be important for some patients with small superficial tumors that can be treated with a transanal resection, the majority of patients have a T2 or T3 tumor, both of which require a complete rectal excision. There is therefore little benefit in differentiating T2 from T3 preoperatively. Of more clinical importance than the exact stage is the circumferential resection margin of the rectal excision specimen. When there is a close or involved resection margin the local recurrence rate increases dramatically. This study shows that high resolution phased array MRI can predict the circumferential resection margin with high accuracy and consistency, enabling a preoperative identification of patients at risk for a local recurrence. In these patients the recurrence rate can be decreased by approximately $50 \%$ with preoperative radiotherapy. Conversely preoperative radiotherapy can safely be omitted in patients who are not shown to be at risk for a local recurrence on the MRI.

For patients with a locally advanced primary or recurrent rectal tumor the chances for survival increase when a radical excision can be performed. Accurate and detailed preoperative information on the extent of the tumor is therefore essential to plan the optimal surgical approach. Our study shows that high resolution phased array MRI is far more accurate than conventional CT in predicting the local extent of the tumor, and MRI therefore has a definite role in the preoperative work up of patients with advanced primary and recurrent rectal cancer.

\section{Recommendations}

The radiologist who is asked to provide the clinician with anatomical information of the ancrectal region has to consider different diagnostic imaging techniques: endoluminal ultrasound, computed tomography, and magnetic resonance imaging with an endoluminal or a phased array coil. At present no single method clearly standis out as superior for all anorectal conditions. There are relatively few comparative studies and each technique is still evolving because of the ongoing advances in technology and software. At present the radiologist's choice will be influenced by the type of clinical problem, the availability of the imaging modalities and the local expertise.

For patients with fecal incontinence, endoanal ultrasound (EUS) remains the imaging modality of choice. It is a widely available and inexpensive imaging method to select patients with sphincter lesions who may benefit from surgical repair. The main disadvantages are the operator dependency, and the limited soft tissue contrast resolution that makes accurate evaluation of the external sphincter complex more difficult. Because of the higher soft tissue contrast resolution, endoanal MRI is theoretically superior for the evaluation of the anal sphincter complex, and our studies as well as studies from others confirm that endoanal MRI is more accurate than EUS in the visualization of the external sphincter. Our study suggests that the noninvasive 
phased array MRI may be as good as the endoanal MRI. The exact place of EUS, endoanal MRI and phased array MRI in the work up of patients with fecal incontinence remains to be established in prospective comparative studies.

For patients with anal fistulas it is clear that the majority of simple fistulas do not require any imaging at all. In patients with complex and recurrent fistulas clinical benefit is derived mainly from the detection of secondary extensions and abscesses. Because of the wide field of view and the high spatial resolution, phased array MRI is the definite imaging method of choice.

Some patients with villous adenomas and superficial rectal cancer can be treated with a transanal local resection as opposed to a transabdominal resection of the complete rectum. EUS can provide an accurate assessment of the ingrowth in the superficial layers of the rectal wall. Because of the high signal intensity near the coil, endoluminal MRI may prove to be at least as accurate as EUS, while phased array MRI will probably be less accurate. The exact place of EUS and both MRI methods in the management of villous adenomas and superficial rectal cancer remains to be evaluated.

Because of the high spatial resolution and wide field of view, phased array MRI is in my opinion the method of choice in rectal cancer imaging both for preoperative selection of patients at increased risk for a local recurrence who will benefit from preoperative radiotherapy and for preoperative assessment of the local extent of advanced and recurrent rectal cancer.

CT generally is not the preferred imaging modality for anorectal diseases. However, when MRI is not available, CT is a reasonable alternative to evaluate the pelvic area for abscesses and for tumor extent of rectal cancer. As with other imaging techniques, CT technology is still evolving, illustrated by the recent introduction of helical CT scans, and further improvements are expected. Although CT has the advantages of a lower cost, a wider availability, and a shorter acquisition time, the main drawback in comparison with MRl remains the lower soft tissue contrast resolution. It remains to be determined whether or not state of the art spiral CT scan can compete with MRI.

MR technology is progressing at a fast pace, and research is directed at improving spatial resolution, improving contrast resolution, and shortening acquisition time. Our work has focused on improving spatial resolution by making optimal use of a phased array coil. Another area of research involves the use of contrast agents and dynamic MR. New developments in the software and hardware of MR machines and the design of new external surface or body coils will undoubtedly lead to images with a higher resolution. Given the present status of MRI and the expected improvements in 
the near future, we believe that MRI will become the imaging method of choice for most anorectal conditions. 
SAMENVATTING, CONCLUSIES EN AANBEVELINGEN 
Chapter 7 


\section{Samenvatting}

Het doel van dit proefschrift is te onderzoeken of hoge resolutie afbeeldingen van het gehele anorectale gebied verkregen kunnen worden met een niet-invasieve MR techniek gebruikmakend van een quadratuur phased array coil en te bepalen of de toepassing hiervan klinische waarde heeft bij patiënten met anorectale aandoeningen.

In de pilot studie in hoofdstuk 2 wordt onderzocht of een gedetailleerde afbeelding van het gehele anorectale gebied verkregen kan worden met een noninvasieve MR techniek met een quadratuur phased array coil. Drie observers scoorden onafhankelijk van elkaar de visualisatie van de bekken structuren en anus kringspieren op scans van 22 gezonde vrijwilligers. De resultaten laten zien dat gedetailleerde afbeelding van zowel de bekken structuren als de anus kringspieren zeer goed mogelijk is. De pilot studie in 12 patiënten met verschillende anorectale aandoeningen toont een exacte correlatie tussen de MR bevindingen en chirurgische en/of histologische bevindingen. Phased array MRI zou hierdoor waardevol kunnen zijn bij het beleid van patiënten met anorectale aandoeningen.

De studie in hoofdstuk 3 vergelijkt phased array MRI met endoanale echografie (EUS) en endoanale MRI voor het meten van anus kringspieren in 60 gezonde vrijwilligers. De studie onderzoekt de intra- en interobsenver variabiliteit als maat voor het intrinsieke onderscheidingsvermogen en de reproduceerbaarheid van de verschillende afbeeldingstechnieken. De resultaten van de drie methoden werden vergeleken met een correlatie analyse en regressie curven. Met een multivariate analyse werd de invloed van leeftijd, lengte, geslacht, pariteit en het aantal obstetrische trauma's op de kringspier dimensies bepaald.

De resultaten tonen aan dat met de EUS alleen de dikte van de interne anale sphincter betrouwbaar gemeten kan worden, terwijl met MRI betrouwbare metingen verricht kunnen worden van alle kringspieren. Phased array MRI blijkt even betrouwbaar te zijn als endoanale MRI. Over het algemeen is er weinig correlatie tussen de technieken, met uitzondering van de twee MR technieken, die een sterke correlatie vertonen voor de totale dikte van de anussfincter en perineal body. De multivariate analyse laat zien dat met het toenemen van de leeftijd, de interne sfincter dikker wordt, doch deze relatie werd alleen geconstateerd voor de metingen met EUS en endoanal MRI. Verschillen tussen beide geslachten werden alleen gevonden voor metingen met phased array MRl; een positieve correlatie tussen pariteit en totale sfincter dikte bij endoanale MRI en een positieve correlatie tussen het aantal obstetrische trauma's en perineale body dikte bij phased array MRI.

De uiteenlopende resultaten met de verschillende afbeeldings technieken suggereren dat de gemeten waarden afhankelijk zijn van de gebruikte methode. Elke afbeeldingsmethode heeft zijn eigen serie van normaal waarden. Alvorens sfincter 
metingen gebruikt kunnen worden in de klinische praktijk, dienen de afbeeldings technieken zoveel mogelijk gestandaardiseerd te worden.

Hoofdstuk 4 beschrijtt een studie waarin de nauwkeurigheid en de klinische meerwaarde van een hoge resolutie phased array MRI bepaald wordt bij de preoperatieve work up van patiënten met primaire en complexe anale fistels. Bij zesenvijftig opeenvolgende patiënten werden de MR scans preoperatief beoordeeld door 3 observers onafhankelijk van elkaar. De MR bevindingen werden pas aan het einde van de chirurgische exploratie aan de chirurg bekend gemaakt. Op dat moment werden de MR bevindingen gecorreleerd met de chirurgische bevindingen en zo nodig werd de ingreep uitgebreid.

Phased array MRl heeft voor het detecteren van primaire fistels een sensitiviteit en specificiteit van respectievelijk $100 \%$ en $86 \%$, voor het detecteren van abcessen $96 \%$ en $97 \%$ resp., voor hoefijzer verbindingen $100 \%$ en $100 \%$ resp. en voor interne openingen $96 \%$ en $90 \%$ resp. De grote oppervlakten onder de receiver operating curves voor de drie observers benadrukken de grote nauwkeurigheid waarmee MRI fistels en secundaire extensies kan opsporen. De inter- en intraobserver agreement. was zeer hoog, met de beste overeenkomst voor het opsporen van hoefiigzerverbindingen en abcessen. In de gehele groep van 56 patiënten leverde MRI klinische meerwaarde op in 12 patiënten. Bij patiënten met de ziekte van Crohn had MPI meerwaarde in $6 / 15(40 \%)$, bij patiënten met recidief fistels in $4 / 17(24 \%)$ en bij patiënten met primaire fistels in 2/24 (8\%). Het verschil in meerwaarde van MRI tussen de groep van primaire simpele fistels versus complexe fistels was statistisch significant $(p<0.05)$, evenals het verschil in meerwaarde tussen de groep met Crohnse fistels versus niet Crohnse fistels $(p<0.05)$.

Deze studie toont aan dat phased array MRI zeer nauwkeurig is voor het detecteren van fistels en hun secundaire uitlopers. Een preoperatieve MRI helpt de chirurg bij de identificatie van alle secundaire extensies van een complexe fistel. Hoge resolutie phased array MRI wordt daarom aanbevolen bij de preoperatieve work up van deze patiënten.

De studie in hoofdstuk 5 onderzoekt de nauwkeurigheid van de hoge resolutie MRI voor de preoperatieve stadiering van rectum tumoren en voor het voorspellen van de tumor vrije marge na een totale mesorectale excisie (TME). Twee observers bepaalden onafhankelijk van elkaar het $T$ stadium en de afstand van de tumor tot de mesorectale fascie bij 76 patiënten met primaire rectum tumor. De MR bevindingen werden vergeleken met de histologische bevindingen.

Het T stadium zoals voorspeld met de MRI kwam overeen met het histologisch stadium in 63 van de 76 patiënten $(83 \%)$ met een gewogen $\mathrm{k}$ van 0.77 voor observer 1 , en in 51 van de 76 patiënten(67\%) met een gewogen $\mathrm{k}$ van 0.52 voor observer 2 . De intraobserver agreement van de T stadia was goed $(\mathrm{k} 0.80)$ voor observer 1 maar matig ( $\mathrm{k} 0.49$ ) voor observer 2 . De interobserver agreement was matig $(\mathrm{k} 0.53)$. 
Bij 12 patiēnten met een evidente T4 tumor werd een marge van $0 \mathrm{~mm}$ correct voorspeld. Van de 29 patiënten waarbij de patholoog zonder specificatie een afstand aangaf van minstens $1 \mathrm{~cm}$, voorspelde observer 1 een afstand van minstens $10 \mathrm{~mm}$ bij 28 van de 29 patiënten en observer 2 bij 27 van de 29 patiënten. Van de data van de resterende 35 patiënten werd een regressie curve gereconstrueerd met een $95 \%$ predictie interval. Een histologische marge van ten minste $1 \mathrm{~mm}$ kon met grote zekerheid worden voorspeld wanneer de afstand op MRI ten minste $5 \mathrm{~mm}$ was. Zowel de intra- als de interobserver betrouwbaarheid van de metingen was zeer hoog.

Hoge resolutie MRI met een phased array coil toont een matige accuraatheid en reproduceerbaarheid voor het voorspellen van het $T$ stadium van een rectum tumor. De klinisch veel belangrijkere circumferentiële resectie marge kan echiter met grote nauwkeurigheid en consistentie worden voorspeld. Dit laat een preoperatieve identificatie toe van patiënten die een verhoogd risico hebben voor een lokaal recidief en die baat hebben bij een preoperatieve radiotherapie en/of uitgebreidere resectie.

De studie in hoofdstuk 6 vergelijkt hoge resolutie phased array MRI met CT voor de evaluatie van tumor infiltratie in de omringende structuren bij 11 patiënten met een lokaal uitgebreide primaire en 15 patiënten met een recidief rectum tumor. De scans werden gescoord voor invasie in 9 omringende bekken structuren door drie radiologen. De resultaten werden vergeleken met de chirurgische en histologische bevindingen.

HR MRI had een sensitiviteit van $97 \%$ en een specificiteit van $98 \%$, terwijl CT een sensitiviteit had van $70 \%$ en een specificiteit van $85 \%$. Het verschil tussen MRI en CT voor het voorspellen van tumor invasie was statistisch significant $(p<0.001)$. MRI was zonder twijfel meer succesvol dan CT voor het voorspellen van invasie in de bekkenbodem, de musculus piriformis en het bot.

Hoge resolutie phased array MRI wordt daarom aanbevolen bij de preoperatieve work up van patiënten met uitgebreide primaire en recidief rectum tumor. 


\section{Conclusies}

Het eerste doel van dit proefschrift was te onderzoeken of het gehele anorectale gebied met een hoge resolutie afgebeeld kon worden met een niet-invasieve MR techniek door middel van een quadratuur phased array coil.

MR afbeeldingen kunnen worden verbeterd door optimalisatie van de contrast resolutie en/of de spatiele resolutie. Spatiele resolutie houdt in het vermogen om structuren te kunnen onderscheiden die dicht bij elkaar gelegen zijn. Met de MRI techniek in deze studie beoogden wij de spatiele resolutie te verbeteren door het optimaal gebruik van een phased array coil. Door de combinatie van multipele oppervlakte spoelen in een phased array coil wordt een hogere signaal ruis verhouding bereikt en kunnen beelden worden gecreëerd met een kleinere voxel volume en dus een hogere spatiele resolutie dan hetgeen mogelijk is: met een body coil of oppervlakte spoel.

Wij maakten gebruik van een quadratuur phased array spine coil. Met deze coil is men in staat nog kleinere voxel volumes te creëren door de multicoil quadratuur opstelling waarmee een hogere signaal ruis verhouding kan worden bereikt dan met een standaard phased array coil. Dit kan resulteren in zeer gedetailleerde afbeeldingen, vergelijkbaar met de beelden verkregen met endoanale MRI, maar, in tegenstelling tot endoluminele MRI, met een grotere field of view.

Onze studie heeft aangetoond dat hoge resolutie afbeeldingen van het anorectum verkregen kan worden met een niet-invasieve MR techniek met een quadratuur phased array coil. De studies met gezonde vrijwilligers laten zien dat de individuele structuren van de anus sfincter in detail afgebeeld kunnen worden. De studies over anale fistels en rectum tumoren bewijzen dat een grote field of view belangrijk kan zijn om informatie te verschaffen over secundaire uitlopers van fistels, supralevatore abces collecties en tumor ingroei in de perirectale structuren.

Het tweede doel van dit proefschrift was te onderzoeken of de toepassing van hoge resolutie phased array MRI klinische waarde heeft bij patiënten met anorectale aandoeningen.

Hoge resolutie phased array MRI is zeer nauwkeurig voor het detecteren van perianale fistels. Voor het opsporen van secundaire uitlopers en abcessen is MRI zelfs accurater dan chirurgische exploratie. De informatie van de MRI kan de chirurg helpen om een abces collectie, welke anders gemist zou kunnen worden, adequaat te draineren. Dit zou kunnen leiden tot een lager recidief percentage. De meerwaarde was het grootst bij patiënten met complexe fistels geassocieerd met de ziekte van Crohn en recidief fistels. Phased array MRI wordt daarom aanbevolen bij de preoperatieve work up van deze patiënten. 
Hoge resolutie MRI met een phased array coil is slechts matig betrouwbaar voor het voorspellen van het T stadium van rectum tumoren. De vraag echter is hoe belangrijk het wel is om preoperatief te kunnen differentieren tussen de stadia T1, T2 of T3. Alhoewel kleine oppervlakkige tumoren behandeld kunnen worden met een lokale transanale resectie,wordt het merendeel van de tumoren (stadium T2 of T3) behandeld met een complete rectum resectie. Het preoperatief kunnen differentieren tussen een T2 of T3 tumor heeft dus weinig klinische consequenties. Het voorspellen van de circumferentiele resectie marge zou beduidend meer klinische waarde kunnen hebben.

De kans op een lokaal recidief stijgt aanmerkelijk indien de resectie marge niet tumor vrij of erg krap is. Deze studie heeft aangetoond dat hoge resolutie phased array MRI de circumferentiele resectiemarge zeer nauwkeurig en toch goed kan voorspellen. Hierdoor kunnen preoperatief die patiënten die een verhoogde kans hebben op een recidief worden geïdentificeerd. Bij deze patiënten zou met een preoperatieve bestraling de recidief kans met de helft kunnen worden gereduceerd. Patiënten die op basis van de MRI geen verhoogd risico hebben op een lokaal recidief hoeven dan niet preoperatief bestraald te worden.

De prognose van patiënten met een lokaal uitgebreide primaire of recidief rectum tumor verbetert wanneer een radicale excisie uitgevoerd kan worden. Voor een optimale chirurgische planning is daarom accurate en gedetailleerde informatie over de uitbreiding van de tumor noodzakelijk. Onze studie laat zien dat hoge resolutie phased array MRI veel nauwkeuriger is dan conventionele CT voor het voorspellen van de locale uitbreiding van de tumor. Bij de preoperatieve work up van patiënten met gevorderde primaire en recidief rectum tumor is MRI dan ook erg waardevol.

\section{Aanbevelingen}

De radioloog die door een clinicus wordt geconsulteerd om het anorectaal gebied anatomisch af te beelden heeft de keuze uit vier soorten afbeeldings methoden: endoluminele echografie, computer tomografie en MRI met een endoluminele of phased array coil. Momenteel bestaat er geen afbeeldings techniek die als enige alle anorectale aandoeningen op een bevredigende wijze afbeeldt. Er bestaan slechts een beperkt aantal vergelijkende studies tussen de verschillende technieken en ieder techniek ondergaat nog steeds een enorme ontwikkeling. De keuze van de radioloog zal beïnvloed worden door de klinische probleemstelling, de beschikbaarheid van de afbeeldingsmodaliteit en de aanwezige expertise.

Voor patiënten met fecale incontinentie blijft endoanale echografie de modaliteit van eerste keuze. Het is een goedkope en algemeen beschikbare methode om patiënten te selecteren die in aanmerking komen voor een chirurgisch herstel van een sfincterdefect. 
De nadelen zijn de onderzoekersafhankelijkheid van de methode en de beperkte weke delen contrast resolutie waardoor een nauwkeurige evaluatie van de externe sfincter bemoeilijkt wordt. Endoanale MRI is theoretisch nauwkeuriger voor de evaluatie van de anus sfincter vanwege de superieure weke delen contrast resolutie. Deze studie en studies van andere auteurs hebben aangetoond dat endoanale MRI inderclaad veel nauwkeuriger is in het afbeelden van de externe sfincter dan EUS. Onze studie suggereert dat de niet-invasieve phased array MRI even nauwkeurig kan zijn als de endoanale MRI. Prospectieve vergelijkende studies zijn echter noodzakelijk om de exacte rol van EUS, endoanale MRI en phased array MRI te bepalen bij de work up van patiënten met fecale incontinentie.

Het is duidelijk dat bij de meerderheid van patiënten met anale fistels geen preoperatieve afbeelding nodig is, en dit geldt met name voor de patiënten met primaire simpele fistels. De klinische meerwaarde van een preoperatieve afbeelding vinden wij vooral voor het detecteren van secundaire uitlopers en abcessen bij patiënten met complexe en recidief fistels. Phased array MRI is hiervoor de modaliteit van eerste keuze vanwege de grote field of view.

Sommige patiënten met villeuze adenomen en oppervlakkige rectum tumoren kunnen behandeld worden met een transanale locale resectie zonder dat het gehele rectum verwijderd hoeft te worden. EUS is in staat de invasie in de oppervlakkige lagen van het rectum nauwkeurig aan te tonen. De juiste rol van EUS en beide MRI technieken voor villeuze adenomen en oppervlakkige rectum tumoren dient echter nader geëvalueerd te worden.

Vanwege de hoge spatiele resolutie en de grote field of view is phased array MRI naar mijn mening de afbeeldingsmethode van eerste keuze voor de preoperatieve selectie van patiënten met rectum tumor die een verhoogd risico hebben op een lokaal recidief en baat hebben bij een preoperatieve bestraling. Phased array MRl is ook de afbeeldingsmethode van eerste keuze voor de preoperatieve evaluatie van locale tumor uitbreiding bij patiënten met lokaal uitgebreide primaire rectum tumor of patiënten met recidief rectum tumor die in aanmerking komen voor een operatie.

$\mathrm{CT}$ is in het algemeen niet de voorkeurs modaliteit voor het afbeelden van anorectale pathologie. CT is echter een geschikte alternatief voor de evaluatie van bekken abcessen en lokale uitbreiding van primaire rectum tumoren indien een MRI niet beschikbaar is. Zoals alle andere afbeeldingstechnieken is de CT techniek nog steeds in ontwikkeling, getuige de recente introductie van snelle spiraal CT technieken. Een nadeel van CT is dat de weke delen contrast resolutie lager blijft dan MRI, alhoewel er ook duidelijk voordelen zijn van de CT: lagere kosten, algemene beschikbaarheid en kortere scantijden. De vraag blijft of state of the art CT technieken kunnen competeren met MRI. 
De MR technieken evolueren snel, en er wordt met name gewerkt aan het verbeteren van de spatiele resolutie en de contrast resolutie en het verkorten van de acquisitie tijden. Onze studie heeft zich gericht op het verbeteren van de spatiele resolutie door middel van het optimaal gebruiken van een phased array coil. Een ander gebied van research is de toepassing van contrast MRI en dynamische MRI. Nieuwe ontwikkelingen in de hardware en soft ware van MR machines en nieuwe verbeterde externe surface of body coils zullen ongetwijfeld leiden tot beelden met een nog hogere resolutie. In het licht van de huidige status van MRI en de te verwachten verbeteringen in de nabij toekomst, zal MRI op korte tijd zonder meer de afbeeldings methode van voorkeur worden voor de meeste anorectale aandoeningen. 


\section{DANKWOORD}




\section{Dankwoord}

Mijn promotor Prof. Dr. J.M.A. van Engelshoven, radioloog en hoofd van de afdeling radiologie in het Academisch Ziekenhuis Maastricht.

Beste Jos, jij gaf mij een hernieuwde kans in de radiologie, waar ik je nog altijd zeer dankbaar voor ben. Ik heb je leren kennen als een zeer gewaardeerde opleider en collega. De laatste jaren mocht ik onder jouw leiding aan dit promotieonderzoek werken. Naast een gestructureerde begeleiding gaf je mij veel vrịheid om het onderzoek uit te voeren. Ondanks je drukke werkzaamheden was er altijd tijd om de resultaten te bespreken, maar ook "om mijn hart te luchten". Jij hebt mij gesteund in voor- en tegenspoed. Mijn respect voor jou, als collega en als mens, is niet in woorden uit te drukken. Beste Jos, ik dank je voor het in mị gestelde vertrouwen.

Mijn tweede promotor Prof. Dr. C.G.M.I. Baeten, hoogleraar colorectale chirurgie, Academisch Ziekenhuis Maastricht. Beste Cor, jouw enthousiasme heeft mij gestimuleerd tot het uitvoeren van dit onderzoek. Op een koude december avond, tijdens een stafdiner, wist jij mij te overtuigen dat het van groot belangl was om een goede diagnostische afbeeldingstechniek te vinden voor anorectale aandoeningen. Jij hebt mijn nieuwsgierigheid geprikkeld en dit boekje is het uiteindelijke resultaat. Ik wil je dan ook hartelijk danken voor je begeleiding, je stimulans en je enthousiasme.

De leden van de beoordelingscommissie, Prof. Dr. J.L.H. Evers, Prof. Dr. J.W. Arends, Prof. Dr. J.S. Laméris, Prof. Dr. M.F. von Meyenfeldt en Prof. Dr. Th. Wiggers wil ik heel hartelijk dankzeggen voor de moeite die zij genomen hebben om dit proefschrift te beoordelen.

Speciale clank aan Prof. Dr. P.F.G.M. van Waes, hoogleraar radiologie van het Universitair Medisch Centrum Utrecht. Het begin van mijn carrière heeft $u$ meegemaakt en mij sindsdien altijd ondersteund, ook bij het nemen van moeilijke beroepskeuzen in mijn leven. Toen ik de radiologie verliet heeft $u$ voorspeld dat ik toch eens radioloog zou worden. Het betekent heel veel voor mij dat $u$ er nu bij kunt zijn. Groot is mijn dank voor wat u voor mij heeft betekend.

Fons Kessels, epidemioloog. Beste Fons, ik wil je hartelijk danken voor je begeleiding in de statistiek. Je wist altijd perfect een manier te vinden om iedere statistische uitdaging op een pragmatische manier boeiend te maken. Ik ging en ga nog steeds met veel plezier naar je toe.

Arthur Gerritsen van der Hoop, chirurg. Beste Arthur, wij hebben in de eerste jaren samen heel wat gebrainstormd al dan niet onder het genot van een "chinees banket". Jouw enthousiasme werkte aanstekelijk. Ik miste deze gezellige discussies toen je naar het Universitair Medisch Centrum Leiden vertrok. Ik dank je voor je medewerking en inzet in mijin onderzoek en wens je een succesvolle carrière toe in Leiden.

Geert Morren, chirurg. Beste Geert, samen met Kadri en Etienne hebben wij heel wat weekenden doorgebracht bij de MRI en veel vrijwilligers zien passeren. Ook jou wil ik hartelijk danken voor je medewerking en inzet in mijn onderzoek. Ik wens je veel succes toe bij het afronden van jouw proefschrift. 
Kadri el Naggar, assistent-onderzoeker in de chirurgie. Ik herinner hem als een bijzonder mens, fijngevoelig en prettig in de omgang. Een collega met wie je graag wilde samenwerken en voor wie niets te veel was..... een veelbelovend jonge onderzoeker. Lieve Kadri, je hebt ons zo plotseling verlaten! Je blijft in onze herinnering.

Hester van Boven en Thea Teune, mijn collega's pathologen, wil ik bedanken voor hun hulp en medewerking bij het snijden en beoordelen van iedere rectumpreparaat. Jullie hebben mij ingewijd in de wereld van de histologie. Het blijft boeiend om de MRI te correleren met de histologie.

Alle laboranten van de MRI unit van het academisch ziekenhuis Maastricht dank ik heel hartelijk voor hun inzet bij mịn onderzoek en voor het vervaardigen van de talloze scans van patiënten.

Henk Schoenmaekers, unit hoofd laborant van de MRI. Beste Henk, je wist in tijden van 'scan-tijd-nood' altijd een oplossing te vinden om een patiënt "even tussendoor" te scannen. De patiënten en ik zijn je hiervoor dankbaar. Henk, ook heel veel dank voor de leerzame lessen over de MRl.

Etienne Lemaire, MR-research laborant. Beste Etienne, zonder jouw hulp was deze thesis niet zo snel afgerond. Vanaf het begin was je zeer toegewijd bij mijn onderzoek betrokken en samen hebben wij vele uren geëxperimenteerd met sequenties. Je hebt mij veel praktisch werk uit handen genomen en nooit was iets te veel voor je. Ik waardeer je, en dank je voor je toewijding en inzet en hoop op een nog lange samenwerking.

Ine Kengen, mijn secretariële ondersteuning. Beste Ine, ik bewonder je kundigheid in de grafische vormgeving en in het werken met ingewikkelde computer programma's. Ik denk dat je net zo blij bent als ik dat het proetschrift gedrukt is. Beste Ine, heel erg bedankt voor je geduld, alle adviezen en al de uren die je aan de lay out hebt besteed.

De medewerkers van de AudioVisuele dienst wil ik hartelijk danken voor hun hulp en adviezen bij het verzorgen van mijn illustraties.

Het administratief personeel van de afdeling radiologie dank ik voor hun hulp bij de planning van de talloze MRI scans van patiënten.

Alle patiënten en vrijwilligers dank ik voor hun medewerking aan dit onderzoek.

Mijn beide ouders. Mams en paps, $u$ beiden hebben mij altijd met liefde ondersteund, mij raad gegeven en mij ook vrijheid gegeven bij het maken van mijn keuzes. Lieve pappie, ik mis $u$ nog steeds, ik wou dat $u$ heel even weer bij me kon zijn... Lieve mams en paps, dank u wel.

Geerard, mijn echtgenoot en levensvriend, mijn copromotor. Onvoorwaardelijk is jouw liefde en steun. Ik heb een andere kant van jou mogen leren kennen namelijk als wetenschappelijke begeleider. Mijn respect voor jou is des te groter. Samen sluiten we een bijzondere periode met ons tweeën aff, met z'n drieën gaan we verder. Lieve Geerard, ik hou van jou. 
Chapter 7 


\section{CURRICULUM VITAE}

\section{Regina Gien Hoa Beets-Tan}

Born

Place of Birth

Married to

1974-1980

1980-1983

1982-1988

1988 - 1989

$1990-1991$

$1991-1995$

1995 - sept 1999

Since sept 1999

Jan 1998 - June 2000 26th oct. 1961

Makassar, Indonesia

G.L. Beets

GYMNASIUM $\beta$, Rotterdamsch Lyceum

PHARMACY, University of Leiden

* Candidaats Degree

MEDICINE , Erasmus University of Rotterdam

- Cum Laude Medical Degree

- Award for being the first student graduated in the new Dutch medical curriculum.

Residency' in General Medicine \& Oncology

Royal Devon and Exeter Hospital, Exeter, UK

Residency in Radiology

Chairman: Prof. Dr. P.F.G.M. van Waes

University Hospital Utrecht

Residency in Radiotherapy

Chairman: Prof. Dr. E. Van der Schueren

University Hospital Leuven

Residency in Radiology

Chairman: Prof. Dr. J.M.A. van Engelshoven

University Hospital Maastricht

Staff member of the radiology department

Chairman: Prof. Dr. J.M.A. van Engelshoven

University Hospital Maastricht

Clinical Research resulting in this thesis 
Financial support for the publication of this thesis was generously provided by: Schering, Kodak, Philips, Nycomed, Coloplast.

Acuson, Aloka, Astra Zeneca, ATL, Guerbet, Jomed, Medi NL BV, Medtronic, Terumo. 

E-mail: rbe@rdia.azm.nl 